\title{
BIOLOGICAL CONSEQUENCES OF ENVIRONMENTAL
} CHANGES RELATED TO COASTAL UPWELLING: A SIMULATION STUDY

STEVEN OLSON HOWE

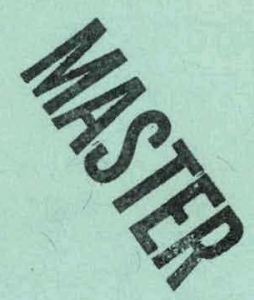

May 1979

OCEANOGRAPHIC SCIENCES DIVISION DEPARTMENT OF ENERGY AND ENVIRONMENT

BROOKHAVEN NATIONAL LABORATORY ASSOCIATED UNIVERSITIES, INC.

UNDER CONTRACT NO. EY-76-C-02-0016 WITH THE

UNITED STATES DEPARTMENT OF ENERGY 


\section{DISCLAIMER}

This report was prepared as an account of work sponsored by an agency of the United States Government. Neither the United States Government nor any agency Thereof, nor any of their employees, makes any warranty, express or implied, or assumes any legal liability or responsibility for the accuracy, completeness, or usefulness of any information, apparatus, product, or process disclosed, or represents that its use would not infringe privately owned rights. Reference herein to any specific commercial product, process, or service by trade name, trademark, manufacturer, or otherwise does not necessarily constitute or imply its endorsement, recommendation, or favoring by the United States Government or any agency thereof. The views and opinions of authors expressed herein do not necessarily state or reflect those of the United States Government or any agency thereof. 


\section{DISCLAIMER}

Portions of this document may be illegible in electronic image products. Images are produced from the best available original document. 


\section{BIOLOGICAL CONSEQUENCES OF ENVIRONMENTAL CHANGES RELATED TO COASTAL UPWELLING: \\ A SIMULATION STUDY}

Steven OLSON HOWE

May 1979

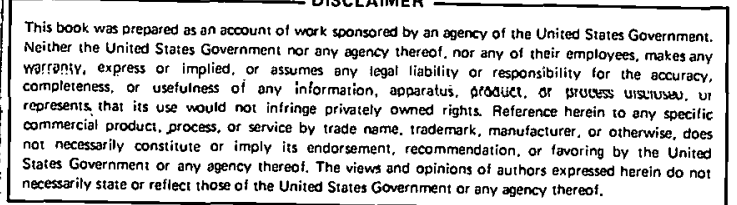

\section{OCEANOGRAPHIC SCIENCES DIVISION DEPARTMENT OF ENERGY AND ENVIRONMENT}

BROOKHAVEN NATIONAL LABORATORY

UPTON, NEW YORK 11973. 


\section{NOT I C E}

This report was prepared as an account of work sponsored by the United States Government. Neither the United Elules uur the Uniter States Departmcnt of Energy (DOE), nor any of their employees, nor any of their contractors, subcontractors, or their employees, makes any warranty, express or implied, or assumes any legal liability or rooponsilility fur the accuracy, completeness or usefulness of any information, apparatus, product or prosess discloeed, or repitsrruis that lto usc would nut infringe prlvately owned rights.

Printed in the United States of America Available from

National Technical Information Service

U.S. Department of Commerce 5285 Port Royal Road Springfield, VA 22161

Price: Printed Copy Microfiche $\$ 3.00$ 


\section{Abstract}

Two simulation models of marine ecosystem dynamics are formulated and applied tc field data. The first is a time-dependent model of phytoplankton growth in nutrient-enriched batch cultures where spa- . tial gradients of dependent variables and the effects of higher tropic level processes are not included. Rates of photosynthesis, nutrient uptake, chlorophyll synthesis and cell division for a single phytoplankton functional group are simulated as functions of photosynthetically active solar radiation, dissolved nutrient concentrations and cell quotas of carbon, nitrogen and silica. Comparisons of simulated results with published field data show that the model can represent the effects of light and nutrient limitation important in the control of primary production in a coastal upwelling region.

The second model combines the phytoplankton growth model with a time dependent, two-dimensional model of coastal upwelling off northwest Africa. Herbivores are represented by one type of fish and two size classes of zooplankton. Results from simulation experiments show a flux of nutrient-rich water into the euphotic zone supporting high rates of primary production seaward of a turbid nearshore region. High ammonium concentrations, observed in the nearshore region, are shown to be sensitive to local physical circulation processes and phytoplankton uptake rates. Simulated rates of primary production may exceed the observed rates and the losses attributed to physiological mortality and ingestion by herbivores. An underestimate of the significance of grazing related to the vertical distribution and ingestion rates of the zooplankton is identified as the factor responsible for the difference between observed and simulated results. 


\section{ACKNOWLEDGMENTS}

I would like to express my appreciation to Dr. John J. Walsh for his support and advice throughout this study. I am grateful to Dr. Peter Hamilton for contributing results from his upwelling circulation model and to Creighton D. Wirick and Drs. James J. O'Brien and Terry E. Whitledge for many helpful तtscussions. I wuuld also like to thank Drs. Brure Froct and Làly Coachman for reviewing thio work alld for their helpful comments.

I am grateful for the patience and support of all the members of my family throughout this study.

Financial support was provided by the Office of the International Decade of Ocean Exploration under National Science Foundation grant 0CE76-82830-A01 to Dr. J. J. Wa1sh. Preparation of this manuscript was done under the auspices of the U. S. Department of Energy under contract Nn. EY-76-C-02-0016. 
List of Figures . . . . . . . . . . . . . . . . v11

List of Tables. . . . . . . . . . . . . . . . . xi

CHAPTER 1

INTRODUCTION

1.1 Introduction . . . . . . . . . . . . .

CHAPTER 2

THE PHYTOPLANKTON GROWTH MODEL

2.1 Formulation. . . . . . . . . . ...

2.2 Rationale....................

a. Photosynthesis

b. Solar Radiation

c. Nutrient Uptake and Growth

d. Respiration

e. Chlorophyl1 Synthesis

2.3 Application. . . . . . . . . . . . . .

2.4 Results. . . . . . . . .......... 25

2.5 Discussion ................. 32

CHAPTER 3

THE NORTHWEST AFRICAN UPWELLING ECOSYSTEM MODEL

3.1 Formulation. . . . . . . . . . . . . 46

a. Physical Circulation 38

b. Biological Interactions 46

3.2 Rationale... . . . . . . . . . . . . 48

a. Incident Solar Radiation and 48

Submarine Light Attenuation

b. Phytoplankton $\quad 49$

c. Zooplankton . 53

d. Fish $\quad 62$

e. Benthos 65

3.3 Results. . . . . . . . . . . . . . . 66

a. A Case with Weak Vertical Mixing 67 and No Advection

b. A Case with Advection and Weak 73

Vertical Mixing

c. A Case with Advection and strong 76

3.4 Discussion . . . . . . . . . . . . . . . 80

3.5 Summary and Conclusions. . . . . . . . . . 93 
TABLE OF CONTENTS

Page

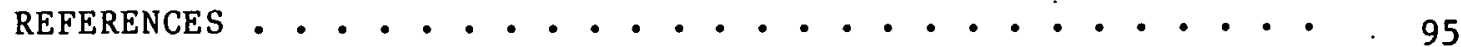

\section{APPENDICES}

I. BIOCEAN, A FORTRAN Program for Simulation in Biological Oceanography. . . . . . . . . . . 104

A. The Numerical Integration Scheme - 105

B. The Finite Difference Scheme 107

II. Boundary and Initial Conditions . . . . . . . . . 113

III. Computer Methnds for Booulto Post-Flucessing. . . . . . 115

IV. Definition of Symbols . . . . . . . . . . . . . 11/

V. Equations of the Physical Circulation Submodel. . . . . 122 


\section{LIST OF FIGURES}

Figure

Page

1 A comparison of measured $(\rightarrow$ (Reed and Halper, 1974) and computed (-) clear-day solar radiation of wavelengths less than $2800 \mathrm{~nm}$ at $45^{\circ} 15.8^{\prime} \mathrm{N}, 124^{\circ} 7.8^{\prime} \mathrm{W}$, $120 \mathrm{Km}$ off the Oregon coast on 11 , July 1973 .

2 Simulated photosynthetically active radiation (wavelengths less than $720 \mathrm{~nm}$ ) as a function of time at $32^{\circ} \mathrm{N}$ on $11 \mathrm{July}$.

3 Observed ( 0 ) and simulated ( - ) silicate concentrations in the treatment without an added nitrogen source. In all of the following comparisons of observed and simulated concentrations, time zero is 0600 hours and the darkened areas on the abscissa are night-time periods.

4 Observed ( $O$ ) and simulated (-) concentrations of chlorophyll a in the treatment without an added nitrogen source.

5 Observed ( $\bullet$ ) and simulated $(-)$ cell numbers in the treatment without an added nitrogen source

6 The simulated variation in the carbon to chlorophyll ratio (by weight) in the treatment without an added nitrogen source.

7 A comparison of the observed ammonium concentration (O) and the graph of the function, $S_{3}=.33$ exp $[.017 t]$, used to specify the ammonium concentration during the course of the treatment with nitrate added as the nitrogen source. Time zero is at $0600 \mathrm{hrs}$ local time and darkened areas on the abscissa are night time periods.

8 Observed ( $)$ and simulated $(-$ nitrate concentrations in the treatment with nitrate added as a nitrogen source.

9 Observed ( $O$ ) and simulated (-) silicate concentrations in the treatment with nitrate added as a nitrogen source.

10 Observed ( $($ ) and simulated $(-)$ cell numbers in the treatment with nitrate added as a nitrogen source.

Please note that the symbols defined here do not necessarily have the same definitions in the state equations of the ecosystem model. Symbols used in the ecosystem state equations are defined in Appendix IV. 
Figure

Page

11 Observed $(\bullet)$ and simulated $\longleftrightarrow$ chlorophy 11 a concentrations in the treatment with nitrate added as a nitrogen source.

12 Observed ( $\bullet$ ) and simulated $\longleftrightarrow$ particulate carbon concentrations in the treatment with nitrate added as. a nitrogen source. The circled observation at 84 hours may be erroneously high (Banse, 1974).

13 Observed ( $\bullet$ ) and simulated $\longleftrightarrow$ particulate nitrogen concentrations in the treatment with nitrate added as a nitrogen source.

14 Observed ( $)$ and simulated $\longrightarrow$ values of the carbon to chloroplyll racio (hy weight) in the lreatment with nitrate added as a nitrogen source.

15 The simulated growth rate $\left(h r^{-1}\right)$ during the course of the treatment with nitrate added as a nitrogen source. The mean observed growth rate was $0.039 \mathrm{hr}^{-1}$.

16 A comparison of measured and simulated nitrogen assimilation rates as a function of time.

17 The half-saturation constant for growth $\mathrm{k}_{\mathrm{y}}$ ae a fune tion of the ratio of maximum uptake and cell division rates: $K_{g}$ is expressed as a fraction of the half-saturation constant for uptake.

18. Location of the JOINT-I study. The circles and triangles indicate the position of moored current meter arrays and meteorological towers. The squares indicate the locations on the $21{ }^{\circ} 40^{\prime} \mathrm{N}$ transect where productivity and hydrographic stations were repeatedly occupied. From Barher (1977).

19 The grid system of the system model. The grid spacing varies from $5 \mathrm{~km}$ in the horizontal by $5 \mathrm{~m}$ in the vertical nearohore tu $20 \mathrm{~km}$ by $2 U \mathrm{~m}$ in the offshore area below $60 \mathrm{~m}$.

20 Resultant current velocity vectors plotted from horizontal and vertical currents in the circulation submodel after 2 days simulation time.

21 Resultant current velocicy vectors plotted from horizontal and vertical currents in the circulation submodel after 5 days simulation time. 
LIST OF FIGURES (Cont'd.)

Figure

22 Resultant current velocity vectors plotted from hori$z$ ontal and vertical currents calculated in the circulation submodel after 10 days simulation time.

23 Cross-shelf flow during active upwelling in the JoINTI study area.

24 The initial nitrate distribution. Above $30 \mathrm{~m}$ the concentration is $1.48 \mu \mathrm{g}$ at $1^{-1}$ and below $30 \mathrm{~m}, 2.84 \mu \mathrm{g}$ at $1^{-1}$. Contour interval is $2 \mu \mathrm{g}$ at $1^{-1}$.

25 The nitrate distribution after 5 days in the case without upwelling, $\mathrm{K}_{\mathrm{z}}=1 \mathrm{~cm}^{2} \mathrm{~s}^{-1}$. Contour interval is $2 \mu \mathrm{g}$ at $1^{-1}$.

26 The nitrate distribution after 10 days in the case without upwelling, $\mathrm{K}_{\mathrm{z}}=1 \mathrm{~cm}^{2} \mathrm{~s}^{-1}$. Contour interval is $2 \mu \mathrm{g}$ at $1^{-1}$.

27 The ammonium distribution after 5 days in the case without upwelling, $\mathrm{K}_{z}=1 \mathrm{~cm}^{2} \mathrm{~s}^{-1}$. Contour interval is $1 \mu \mathrm{g}$ at $1^{-1}$.

28 The ammonium distribution after 10 days in the case without upwelling, $\mathrm{K}_{\mathrm{z}}=1 \mathrm{~cm}^{2} \mathrm{~s}^{-1}$. Contour interval is $1 \mu \mathrm{g}$ at $1^{-1}$.

29 The chlorophyll a distribution after 5 days in the case without upwelling, $\mathrm{K}_{z}=1 \mathrm{~cm}^{2} \mathrm{~s}^{-1}$. Contour interval is $3 \mu \mathrm{g}$ at $1^{-1}$.

30 The chlorophyll a distribution after 10 days in the case without upwelling, $\mathrm{K}_{z}=1 \mathrm{~cm}^{2} \mathrm{~s}^{-1}$. Contour interval is $3 \mu \mathrm{g}$ at $1^{-1}$.

31 The nitrate distribution after 5 days in the case with upwelling, $\mathrm{K}_{z}=1 \mathrm{~cm}^{2} \mathrm{~s}^{-1}$. Concentrations exceeding $10 \mu \mathrm{g}$ at $1^{-1}$ appear near the intersection of the shelf with the bottom boundary. Contour interval is $2 \mu \mathrm{g}$ at $1^{-1}$.

32 The nitrate distribution after 10 days of upwelling with $\mathrm{K}_{\mathrm{z}}=1 \mathrm{~cm}^{2} \mathrm{~s}^{-1}$ : Contour interval is $2 \mu \mathrm{g}$ at $1^{-1}$.

33 The chlorophyll distribution after 5 days of upwelling $\mathrm{K}_{\mathrm{z}}=1 \mathrm{~cm} \mathrm{~s}^{-1}$. Contour interval is $3 \mu \mathrm{g}$ at $1^{-1}$. 
Figure

Page

34 The chlorophyl1 a distribution after 10 days of upwelling with $\mathrm{K}_{\mathrm{z}}=1 \mathrm{~cm}^{2} \mathrm{~s}^{-1}$. Contour interval is $3 \mu \mathrm{g} 1^{-1}$.

35. The nitrate distribution after 5 days of upwelling with $\mathrm{K}_{\mathrm{z}}=40 \mathrm{~cm}^{2} \mathrm{~s}^{-1}$. Contour interval is $2 \mu \mathrm{g}$ at $1^{-1}$.

36 The nitrate distribution after 10 days of upwelling with $\mathrm{K}_{\mathrm{z}}=40 \mathrm{~cm}^{2} \mathrm{~s}^{-1}$. Contour interval is $2 \mu \mathrm{g}$ at $\mathrm{1}^{-1}$.

37 The chlorophyll a distribution after 5 dayo of upwelling with $\mathrm{k}_{2}=40 \mathrm{~cm}_{2} \mathrm{~s}^{-1}$. Contour interval is $3 \mathrm{\mu g} \mathrm{1}^{-1}$.

38 The chlorophyll a distribution afler 10 days of upweling with $\mathrm{K}_{2}=\mathrm{cm}^{2} \mathrm{~s}^{-1}$. Contour interval is $3 \mu \mathrm{g} 1^{-1}$. 1974, during JOINT-I.

40 'Ihe distribution of chlorophyll at $21 \% 40^{\prime} \mathrm{N}$ on $23-24$ March, 1974, during JOINT-I.

41 Observed and simulated onshore-offshore distributions of nitrate concentrations. Measured concentrations are averages over the euphotic zone for the JOINT-I cruise period, March-May, 1974 (From Huntsman and Barbcr, 1977.) Simulated concentrations are mean euphotic zone concentrations after 10 days simulation time. The depth of the euphotic zone in the simulation cases is defined for each column as the depth of the bottom boundary of the deepest segment where daily phytoplankton carbon fixation exceeds respiration.

42 Observed and simulated onshore offshore distributions chlorophyl1 a concentrations. Measured concentrations are averages over the euphotic zone for the JOINTI cruise period, March-May, 1974 (From Huntsman and Barber, 1977). Simulated concentrations are averages for the euphotic zone as defined for Figure 41 .

43 A schematic diagrain sluwing the convention used in the model to define the relative and absolute locations of state variables ( $S$ ), eddy coefficients $(K)$ and horizontal (u) and vertical (w) current velocities. A segment whose center is at $i, k$ has a dimension $x_{i}$ on the horizontal $i$ axis and $a$ dimensiun $z_{k}$ on the vertical $k$ axis. Current velocities and eddy coefficients are defined on the faces between the centers of the rectalinear spatial segments. 
Table

Page

1 Initial values of variables in the simulations

22

of the two nutrient treatments of phytoplankton

batch cultures.

2 The vertical distribution of the partial extinction

50 coefficient attributable to substances other than seawater and chlorophyll. Values $l$ isted are averages calculated from JOINT-I chlorophy 11 and submarine light measurements made along the transect at $210^{\circ} 40^{\prime} \mathrm{N}$.

3a Organic weights of zooplankton collected during JOINT-I over the continental shelf. Weights 1 isted are corrected for contamination by phytoplankton. Phytoplankton contamination in each tow is expressed as a ratio of estimated phytoplankton and zooplankton organic matter weights.

$3 b$ Organic weights of zooplankton collected seaward of the shelf-break. Weights listed are corrected for contamination by phytoplankton. Phytoplankton contamination in each tow is expressed as a ratio of estimated phytoplankton and zooplankton organic matter weights $x 100$.

4 Initial values for a short term simulation of the mean JOINT-I conditions.

5 Offshore and lower boundary conditions of nutrients and chlorophyll a, based on JOINT-I observations.

6 Estimates of offshore and lower boundary phytoplankton concentrations and cell numbers. 


\section{CHAPTER 1}

\section{INTRODUCTION}

Over most of its surface the ocean is a dilute and impoverished biological broth. Vertical density stratification limits the upward flux of nutrients necessary to support autotrophic growth at the surface where light is abundant. Upwelling, however, brings large quantities of nutrient-rich water to the surface and its effects on biological productivity are dramatic. Whereas primary production may average only $0.14 \mathrm{~g} \mathrm{C} \cdot \mathrm{m}^{-2} \cdot \mathrm{d}^{-1}$ in the open ocean, it may occasionaly

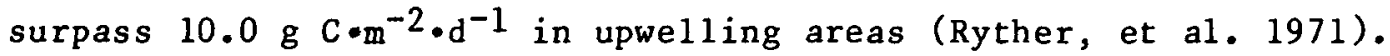
Furthermore, it has been estimated that about half of the total annual world's fish catch is taken in upwelling regions which occupy a fraction of one percent of the ocean's surface (Ryther 1969).

Systematic investigations of a few of the anomalous regions of the oceans where upwelling occurs began early in this century (Cushing, 1971). More recent studies have shown that similar physical features and biological communities are common to all of the major upwelling systems (Walsh 1972). A comparison of ecosystem yields suggests that differences in meteorology, bottom topography and water mass characteristics may, however, have important consequences for particular systems (Walsh, 1976a).

Simulation models offer an approach towards assessment of the interactions of these types of environmental characteristics and an understanding of the extent to which they influence the productivity of upwelling ecosystems. In this study, two simulation models are formulated at different levels of ecosystem complexity. The first is 
a model of phytoplankton growth in the absence of the effects of circulation and higher trophic level processes. Rates of photosynthesis, nutrient uptake, chlorophyll synthesis and cell division for a phytoplankton population are simulated as functions of photosynthetically active solar radiation, dissolved nutrient concentrations and cell quotas of carbon, nitrogen and silica. This model will be referred to as the phytoplankton growth model and is first applied to a field study off California of phytoplankton growth in nutrient-enriched batch cultures where spatial gradients of dependent variables can be igriored. The second model uses the first as a submodel and also includes the effects of physical circulation, nutrient regeneration from the bottom, and grazing and excretion of herbivorous fish and zooplankton in a study of biological responses to upwelling off northwest Africa.

The coastal upwelling region off northwest Africa has recently been studied during a number of expeditions as part of CINECA (Cooperative Investigations of the North East Central Atlantic). One of these expeditions, JOINT-I, took place during the months of February to May, 1974, and was the first major expedition of the Coastal Upwelling Ecosystems Analysis (CUEA) Program. Barber (1977) has introduced the organization of JOINT-I and reviewed its scientific objectives. One of the objectives was to develop a oeriog of simulation models that would provide the basis for a predictive understanding of the response of upwelling ecosystems to natural variation, man-induced perturbation, or different management strategies. The models used in this simulation study represent a contribution to that series and have been formulated in an attempt to account for some of the phytoplankton 
responses to lime dependent coastal upwelling and changes in the associated nutrient fields.

Some elements of the ecosystem model are considered to be its structural characteristics and have been defined to resemble features of the northwest African upwelling system. Structural characteristics, based on CUEA field observations, include approximations for the shelf topography, boundary conditions, nonchlorophyll components of the submarine light extinction and the biomass of herbivorous fish and zooplankton. Time varying estimates of solar radiation and upwelling circulation, although calculated in theoretical submodels, are also included as structural characteristics of the environment.

Experiments performed with the ecosystem model were designed to investigate the biological responses to the physical process of upwelling. The experiments or simulated cases are related by a common set of boundary conditions and functional relationships among the biological components. The differences among cases are due to the absence or occurrence of simulated upwelling, and differences in the intensity of vertical mixing. Comparisons of JOINT-I observations with results from these simulation experiments show how some biological characteristics of the northwest African upwelling ecosystem may occur as consequences of the interaction of structures and functions represented in the model. The siunlation experiments also identify other characteristics which are less well understood. Recongitun of these characteristics and their significance in the simulation experiments offers a strategy towards improving future models and, hopefully, their predictive capabilities. 
CHAPTER 2

THE PHYTOPLANKTON GROWTH MODEL

\subsection{Formulation}

An equation describing the distribution of a generalized nonconservative, $S$, in the sea is

$$
\frac{\partial S}{\partial t}=\Delta \cdot K \Delta S-\Delta \cdot v S+R
$$

where

$$
\begin{aligned}
& t \quad=\text { time } \\
& \Delta \cdot K \Delta S \quad=\text { the effects of lusbulent mixing; } \\
& \Delta \cdot v S \quad=\text { the effects of advection, and } \\
& \mathrm{R} \quad=\text { nonconservative effects. } \mathrm{R} \text { includes the effects of } \\
& \quad \text { biological and chemical interactions affecting } \mathrm{S} .
\end{aligned}
$$

When spatial gradients of the nonconservative variable can be ignored, the equation [2.1] may be written more simply as

$$
\frac{d S}{d L}-R \text {. }
$$

In this model of phytoplankton growth, a set of such equations describes the time dependent responses of variables for cell numbers and particulate silica, nitrogen, carbon and chlorophyll representing a single phytoplankton population. Although several distinct phytoplankton populations could be represented in the model by increasing the number of equations, only one population will be considered in this study. Equations [2.3-2.10] are the eight basic state equations and [2.11-2.24] define the algebraic relationships among the state variables. Michaelis-Menton type functions [2.18-2.21] describe uptake of 
nitrate, ammonium and silicate, and a modified form [2.23] of steele's (1962) equation describes net photosynthetic fixation of carbon as a .. function of light intensity. Concentrations of ammonium are assumed to reduce the maximal uptake rate of nitrate [2.20] and ammonium and nitrate uptake are combined to represent total nitrogen uptake [2.22]. Chlorophyll synthesis is related to the nitrogen quota status of the cells [2.24] and cell division rate is described as a general form of the function proposed by Droop (1973) [2.15-2.17] to relate growth rate to the cell quota of a limiting nutrient. The effects of temperature and losses due to grazing, sinking or physiological mortality are not included.

In the equations below, numerically subscripted uppercase letters represent state (dependent or dynamic) variables or state variabledependent specific rates. Numerical subsripts refer to a compound or element according to the following convention:

Numerica 1

Subscript Symbol, $\mathrm{n}$

1

.2

3

4

5

6
Compound or Element

Silica

Nitrate Nitrogen

Ammonium Nitrogen

Total Nitrogen

Carbon

Ch 1oropliy 11 
Although they may appear in only one function, model parameters expressed as lower case letters are also subscripted for clarity according to the convention above. In a few cases the literature convention for alphabetically subscripting some unambiguous forcing functions and constants has been retained. All symbols are defined in Appendix 4 and in the rationale for the derivation of each function following the list of equations. The BIOCEAN simulation system, described in Appendix $I$, was used to integrate the model equations. dP $\frac{\mathrm{dP}}{\mathrm{dt}}=\mathrm{P}_{\mathrm{n}} \mathrm{V}_{\mathrm{n}} \quad$ for $\mathrm{n}=1,4,5,6$

$\frac{\mathrm{dS}_{1}}{\mathrm{dt}}=-\mathrm{v}_{1} \mathrm{P}_{1}+\alpha_{1}$

$\frac{\mathrm{dS}_{2}}{\mathrm{dt}}=-\hat{\mathrm{V}}_{2} \mathrm{P}_{4}+\alpha_{2}$

$\frac{\mathrm{dS}_{3}}{\mathrm{dt}}=-\mathrm{v}_{3} \mathrm{P}_{4}+\alpha_{3}$

$\frac{\mathrm{dN}}{\mathrm{dt}}=\mathrm{GN}$

$C_{n}=\frac{P_{n}}{N} \quad$ for $n=1,4,5,6$

$[2.11-2.14]$ 


$$
\begin{aligned}
& \begin{aligned}
G & =0 \quad \text {, if } c_{n} \leq d_{n} \\
& =\text { minimum of }\left[g\left(c_{n}-d_{n}\right) / C_{n}\right] \text {, otherwise }
\end{aligned} \text { for } n=1,4,5 \\
& v_{1}=v_{1}\left(s_{1} /\left(k_{1}+s_{1}\right)\right) \text { if } c_{1}<c_{1} \text { and } v_{1}<G \\
& \doteq 0 \text {. } \quad \text { otherwise } \\
& v_{2}=v_{2}^{\prime}\left(s_{2} /\left(k_{2}+s_{2}\right)\right) \quad \text { if } c_{4}<c_{4} \text { and } v_{4}<G \\
& =0 \quad \text {, otherwise } \\
& v_{2}^{\prime}=v_{2}-a_{3} s_{3} \\
& v_{3}=v_{3}\left(s_{3} /\left(k_{3}+s_{3}\right)\right) \quad \text { if } c_{4}<c_{4} \text { and } v_{4}<G \\
& \text { - } 0 \text {, otherwise } \\
& v_{4}=v_{2}+v_{3} \\
& V_{5}=\left(Q_{\max } \cdot I_{\max } \cdot K_{c} \cdot P_{6}\right) \cdot \\
& \left.\left(\exp \left[-I_{z} / I_{\max }\right]-\exp \left[-I_{0} / I_{\max }\right]\right) /\left(K_{T} \cdot z\right)\right)-R_{5}, \\
& \text { if } C_{5}<c_{5} \text { and } V_{5}<G \\
& =0 \quad \text {, otherwise } \\
& \mathrm{P}_{6} \mathrm{~V}_{6}=\mathrm{P}_{6}\left(\mathrm{~g}\left(\mathrm{C}_{4}-\mathrm{d}_{4}\right) /\left(\mathrm{C}_{4}\right) \text { if } \mathrm{G} \text { is minimum for } \mathrm{n}=1\right. \text { or } \\
& \mathbf{n}=5 \text { in equations }[2.14-2.16] \\
& =\mathrm{e}_{6} \mathrm{~V}_{4} \mathrm{P}_{4} \quad \text { if } \mathrm{G} \text { is mini um for } \mathrm{n}=4 \text { in } \\
& \text { equations [2.14-2.16] } \\
& =0 \quad \text { if } \mathrm{c}_{6} \geq \mathrm{c}_{6} \text { and } \mathrm{v}_{6} \geq \mathrm{C}
\end{aligned}
$$




\subsection{Rationale}

2.2a Photosynthesis. The function for photosynthetic fixation of carbon [2.23] is based on the following form of steele's (1962) equation expressing photosynthesis rate as a function of light intensity

$$
P=P_{\max }\left(I_{0} / I_{\max }\right)\left(\exp \left[1-\left(I_{0} / I_{\max }\right)\right]\right) \text {. }
$$

For a layer of finite optical thickness, $z$, with a constant total extinction coefficient, $K_{t}$, Steele's equation may be analytically integrated (Vollenweider 1965) to give:

$F(x)=I_{\max }\left(\operatorname{cxp}\left[1-\left(I_{\bar{z}} / I_{\max }\right)\right]-\operatorname{cxp}\left[1-\left(I_{0} / I_{\operatorname{tad}}\right)\right]\right) / K_{i}[2.26]$ where

$P(z)=$ rate of photosynthesis per unit surface area of the layer of thickness, $z$, meters;

$\mathrm{K}_{\mathrm{t}} \quad=$ average total spectral extinction coefficient $\left(\mathrm{m}^{-1}\right)$. for sea water and all light attenuating components. $K_{t}$ may be regarded as the sum of several partial extinction coefficients (Lorenzen 1972), $\mathrm{K}_{\mathrm{t}}-\mathrm{K}_{\mathrm{w}}+\mathrm{K}_{\mathrm{c}} \mathrm{P}_{6}+\mathrm{K}_{\mathrm{d}} \mathrm{X}$;

$\mathrm{K}_{\mathrm{w}} \quad=$ average spectral extinction coefficient for seawater $=0.04 \mathrm{~m}^{-1}($ Lorenzen 1972);

$\mathrm{K}_{\mathrm{c}}$ = average spectral exliativa coefficient pes unit phytoplankton concentration, where phytoplankton concentration is expressed as $\mathrm{P}_{6}$, the concentration of chlorophyll a, and $\mathrm{K}_{\mathrm{c}}=0.016 \mathrm{~m}^{2} \cdot \mathrm{mg} \cdot \mathrm{Chl} \mathrm{a}^{-1}$ (Bannistér 1974);

$K_{d} \quad=$ average spectral extinction coefficient for all other materials of concentration $X$ in the water column; 
$I_{\max }=$ the light intensity at which the maximum photosynthesis rate occurs; $I_{\max }$ may vary with phytoplankton class, species; and physiological state; however $I_{\max }$ is assumed constant in this model and equal to 2.07 einst $\mathrm{m}^{-2} \mathrm{hr}^{-1}$ (approximately $10.81 \mathrm{y} \mathrm{hr}^{-1}$ or $2715 \mathrm{ft}-\mathrm{c}$ ) (Parsons and Takahashi 1973);

$I_{0}=$ light intensity at the surface of a depth interval (einsteins $\cdot \mathrm{m}^{-2} \cdot \mathrm{hr}^{-1}$ );

$I_{z}=1$ ight intensity at the bottom of a depth interval; $I_{z}$ is calculated as $I_{z}=I_{0} \exp \left[-K_{t} z\right]$

The integrated mean photosynthetic carbon production rate for a layer of thickness $z$ is given as:

$$
\overline{P(z)}=P(z) / z
$$

These and other similarly integrated production equations may be useful for steady state calculations, but are unsatisfactory for dynamic populations. $\quad P_{\max }$, the light saturated or maximal rate of photosynthesis with dimensions of carbon mass fixed per volume and time is not adequately expressed as a single constant, because it is not an explicit function of phytoplankton concentration. For Steele's equation, Bannister (1974) shows that $\mathrm{P}_{\max }$ may be defined in more fundamental terms as

$$
P_{\max }=Q_{\text {Illax }} I_{\max } K_{c} P_{6} \exp [-1]
$$


where

$$
\begin{aligned}
Q_{\max }= & \text { the maximum quantum yield; quantum yield is the } \\
& \text { ratio of the rate of photosynthesis and the rate } \\
& \text { at which light is absorbed by the phytoplankton; } \\
& \text { quantum yield becomes maximum at low light inten- } \\
& \text { sities and is assumed to be a constant of } 60 \mathrm{~m} \text { moles } \\
& \text { carbon einstein }
\end{aligned}
$$

The other parameters are defined following [2.26]. Sulstitution of [2.29] for $P_{\max }$ in [2.26] and [2.28] gives the expression used in the model to calculate the integrated-mean gross photosynthetic carbon fixation for a layer of thickness $z$ :

$$
\left.P(Z)=\left(Q_{\max } I_{\max } K_{c} P_{6}\right)\left(\exp \left[-I_{z} / I_{\max }\right]-\exp \left[-I_{o} / \max \right]\right) / K_{t^{z}}\right)
$$

This function expressès the mean rale of pioduction ao a rate of photosynthesis integrated over the light available through a depth interval, divided by the thickness of the interval.

2.b Solar radiation. Incident solar radiation values required for the evaluation of the photosynthesis function are calculated in a submodel adapted from the SOLRAD program of McCullough and Porter (1971). Direct, clear sky radiation fluxes for 111 spectral intervals within the wavelength range of 290 to $4000 \mathrm{~nm}$ can be computed with SOLRAD for any time period or geographic position when visibility and precipitable water content of the atmosphere are specified. Total incident radiation is the sum of direct and diffuse radiation and empirical approximations are used in this study to calculate the diffuse component of total radiation. 
Diffuse radiation, $D$, is approximated to within $0.013 \mathrm{ly} \mathrm{min}^{-1}$ by

$$
D=0.54\left(s_{0}-s_{s}\right) \sin h
$$

where $h$ is the angle of the sun above the horizon, $s_{0}$ is the sub-ozone intensity of direct radiation and $s_{s}$ is the intensity of direct radiation at the sea surface after attenuation due to atmospheric scattering (Sivkov 1971).

Some of the direct and diffuse radiation reflected at the surface is returned by the atmosphere due to secondary scattering. Sea surface albedo, $A$, is calculated as

$$
A=0.04 /(\sin h+0.04)
$$

following Portman and Ryznar (1971). The effects of secondary scattering on increasing the total incoming flux are included in a factor, $F$ (Sivkov 1971) where

$$
\mathbf{F}=1 /(1-0.2 \cdot \mathrm{A})
$$

Incident radiation, $I$, is obtained by adding direct and diffuse radiation components integrated over the desired wvelength range and allowing for the effects of secondary scattering

$$
I=\left(D+s_{s}{ }^{\prime}\right) \cdot F
$$

where $s_{s}^{\prime}$ is direct radiation at the sea surface after attenuation due to atmospheric scattering and water vapor absorption. Calculations of incident radiation are limited to the sensitivity range of the measuring instrument when comparisons with observations are made. Values of To used in the model arc based on a calculation of I for the photosynthetically active spectral interval because the parameters in the function for photosynthesis are expressed in terms of radiation in this wavelength range. The amount of incident phytosynthetically active 
radiation is then reduced to simulate in situ conditions by the surface albedo factor, A, or by a screening factor equivalent to a specified experimental treatment for the surface of an artificial enclosure. 2.2c Nutrient Uptake and Growth. Caperon (1967) and Dugdale (1967). found the Michaelis-Menton equation, originally applied by Monod (1942) to describe the nutrient-limited growth of bacterial populations, could also express the rate of nutrient uptake by algae as a function of nutrient concentration. The equation has subsequently been widely applied in laboratory (Eppley, et al. 1.969; Eppley and Renger 1974; Eppley and I'homas 1969; Cärpenter and Guillard 1971), field (MacIssac and Dugdale 1969; Goering, et a1. 1973) and modelling studies (O'Brien and Wroblewski 1973; Lehman, et al. 1975; Bierman, et al. 1973). Variability of kinetic parameters has been documented (Ëppley, et al. 1969; Falkowski 1975) and Eppley, et al. (1969) have discussed the significance of differences in uptake efficiencies and their potential effect on the outcome of species competition for nutrients.

Several significant charactcriotice of phytoplankton growth subject to environmental changes are, however, not adequately accounted for by simple Michaelis-Menton kinetics. Growth rate has been observed to be related to the cellular content or quota of a limiting nutrient and not necessarily to its external concentration (Fuhs 1969; Droop 1974). Except in a stéady stace environment, iuslaulautuus giviti rate is a function of the integrated nutrient experience or past history of the population (Caperon 1969; Williams 1971) rather than current environmental conditions. Anuther prublem with the simple Michaelis-Mcnton 
relationship is that nutrient uptake and growth are fundamentally functionally different processes and are not adequately described by the same kinetic expression. Maximum uptake rates may exceed the maximum cell division rate by a factor of 2 to 20 (Droop 1968; Eppley and Thomas 1969; Syrett 1962; Healey 1973) and cell division may occur using internally stored nutrient in the absence of external nutrient supply (Williams 1971).

In the formulation of this model, uptake and growth are thus treated as individual, but related processes. Uptake processes increase cell quotas and the particulate biomass of the population. The status of the cell quotas reflects the past nutrient history of the cells and varies as a function of absolute and relative concentrations of nutrients in the environment. Growth, however, is considered to be cell division. Cell division produces more cells with no change in biomass and consequently reduces cell quotas.

The cell division rate, $G$, is determined according to the following expression as the minimum of a general function proposed by Droop (1973) to relate growth rate and cell quota

$$
G=g\left(C_{n}-d_{n}\right) / C_{n}
$$

where

$$
\begin{aligned}
& G=\text { cell division rate }\left(h r^{-1}\right) \text {; } \\
& g=\text { maximum cell division rate; } g=0.08 \mathrm{hr}^{-1} \text { is assumed } \\
& \text { characteristic of upwelling arcas (Eppley 1972); } \\
& C_{n}=\text { cell qunta nf nutrient } n \text { (pg atome coll-1); } \\
& \mathrm{d}_{\mathrm{n}}=\text { minimum cell quota of nutrient } \mathrm{n} \text {. When } \mathrm{C}_{\mathrm{n}}<\mathrm{d}_{\mathrm{n}} \text {, cell } \\
& \text { division rate is zero. For all quotas, } d_{n} \text { is defined }
\end{aligned}
$$


conservatively (Caperon and Meyer 1972, p. 625) to be $d_{n}=0.25 \cdot c_{n}$, where $c_{n}$, is a maximum quota which is not exceeded by continued uptake. Maximum carbon quota $\left(c_{5}\right)$ must be specified during initialization and essentially defines the maximum phytoplankton cell size. Maximum ... nitrogen quota $\left(c_{4}\right)$ is defined as $c_{4}=0.25 \cdot c_{5}$ and allows a minimum $\mathrm{C} / \mathrm{N}$ ratio by atoms of 4 (Banse 1974). Maximum silica quota $\left(c_{1}\right)$ is defined on the basis of the mean rhemical composition of diatoms grown in continuous culcure at high dilution rates (Greater than $0.6 \mathrm{hr}^{-1}$, (Harrison, et a1. 1976)) to be $c_{1}=0.35 \cdot c_{4}$.

A Michaelis-Menton function

$$
v_{n}=v_{n}\left(\dot{s}_{n} /\left(k_{n}+s_{n}\right)\right) \text {, }
$$

where

$v_{n}=$ specific nutrient uptake rate $\left(h r^{-1}\right)$;

$v_{n}=$ maximum specific nutrient uptake rate $\left(v_{n}=0.12 \mathrm{hr}^{-1}\right.$, a rate twice the maximum attainable growth rate, is as sumed );

$k_{n}=$ half-saturation constant for uptake $\left(k_{n}=1.0 \mu g\right.$ at $1^{-1}$ io acsumed (Eppley, et a1. 1969; MacIsaac and Dugdale 1969);

$S_{n}=$ concentration of nutrient $n\left(\mu g\right.$ at $\left.1^{-1}\right)$,

is used to determine the nutrient uptake rate when the cell quota of a particular nutrient is less than maximuum. No simulated uptake occurs if the cell quota exceeds the maximum quota and the uptake ratc cxcccdo the cell division rate. 
Nitrate uptake, $v_{2}$, and ammonium uptake, $v_{3}$, are considered separately because of the differences in the relative importance of : these sources of nitrogen within oligotrophic and eutrophic systems (Dugdale and Goering 1967). When nitrate and ammonium are both present in the environment, ammonium is usually taken up preferentially and nitrate uptake is partially or completely inhibited until the ammonium is exhausted (Syrett and Morris 1963; Caperon and Meyer 1972). Field measurements from the Peru Current (MacIsaac and Dugdale 1969), the subtropical Pacific (Goering, et a1. 1970), the California Current (McCarthy 1972), the Saronikos Gulf (MacIsaac and Dugdale 1972) and the Chesapeake Bay (McCarthy, et al. 1977) support the observation that ammonium is the preferred inorganic nitrogen source.

Ammonium may cause partial inhibition at oceanic concentrations (Eppley, et al. 1969) and effectively. lower the maximal uptake rate of nitrate. The effect can be approximated by

$$
v_{2}^{\prime}=v_{2}-a_{3} s_{3}
$$

where

$$
\begin{aligned}
\mathrm{v}_{2}{ }^{\prime}= & \text { maximum specific uptake rate of nitrate }\left(\mathrm{hr}^{-1}\right) \text { in } \\
& \text { the presence of an ammonium concentration, } \mathrm{s}_{3} ; \\
\mathrm{v}_{2}= & \text { maximum specific uptake rate of nitrate }\left(\mathrm{hr}^{-1}\right) \text { in } \\
& \text { the absence of ammonium; } \\
\mathrm{a}_{3}= & \text { a coefficient with a value of } \sim .01 \text { (Dugdale and } \\
& \text { Macisaac } 1971 \text {; Conway } 1977) .
\end{aligned}
$$

These uptake functions all increase cell quotas and biomass whenever a given quota is less than maximum. Net photosynthesis (gross photosynthesis minus respiration), although not described by a 
Michaelis-Menton function, is similarly treated as the uptake process increasing the cell quota and population biomass of carbon. When a cell quota maximum has been reached and the current uptake rate exceeds the cell division rate, uptake is stopped until one or both of these conditions change. This method of relating environmental conditions, internal nutrient status and cell division rate avoids the use of end-product inhibition expressions for uptake and allows growth to be determined by one factor in shortest supply instead of a multiplicative interaction of several submaximal fractional uptake expressions.

\section{2d Respiration. Respiration tends to diminish cell quotas of} carbon. In the model, respiration rate is considered to be a function of growth rate, as expressed below in the linear relationship (Bannister 1974), based on the data of Myers and Graham (1971)

$$
\mathrm{R}_{5}=\mathrm{f}_{5}+\mathrm{b}_{5} \mathrm{G}
$$

where

$$
\begin{aligned}
\mathrm{R}_{5}= & \text { carbon respiration rate }\left(\mathrm{hr}^{-1}\right) ; \\
\mathrm{f}_{5}= & \text { basal respiration rate }(\mathrm{f}=0.00 .3 \mathrm{hr}-1) \text { when gruwth } \\
& \text { rate }\left(\mathrm{G}\left(\mathrm{hr}^{-1}\right)\right) \text { is zero; } \\
\mathrm{b}_{5}= & \text { a constant, } 0.11 .
\end{aligned}
$$

The range of calculated carbon-specific respiration rates appears reasonable in relationship to the size of the organisus and to the simulated rate of photosynthesis. The simulated respiration rate varies between $0.003 \mathrm{hr}^{-1}$ and $0.010 \mathrm{hr}^{-1}$ as the growth rate varies between minimum and maximum attainable values of 0.00 and $0.06 \mathrm{hr}^{-1}$. Banse's (1976) review suggests ratco of approximately $0.01 \mathrm{hr}^{-1}$ con l. be expected on the basis of the size of the phytoplankton (if, as in 
this application the maximum carbon quota $c_{5}$ is $36.6 \mathrm{pg}$ at $\mathrm{C}$ ce $11^{-1}$ and $\mathrm{d}_{5}$, the minimum carbon quota is $9.2 \mathrm{pg}$ at $\mathrm{C}$ cell-1). Observed respiration rates are often reported as 5 to 10 percent of the light-saturated rate of photosynthesis (Ryther 1956; Steeman-Nielsen and Jorgensen 1968) and [2.37] gives a possible range in respiration rates of 4 to 15 percent of the simulated maximum rate of photosynthesis.

2.2e Chlorophy11 Synthesis. Chlorophy11 a concentration is commonly used as a representation of phytoplankton standing stock, but relatively little is published concerning the functional relationship of environinental conditions and the chlorophyll synthesis rate of marine phytoplankton at the time scale of this model. It is known, however, that chlorophyll a synthesis is very closely associated with nitrogen metabolism (Strickland 1965) and that synthesis of chlorophy 11 is limited in the absence of dissolved nitrogen. Accordingly, simulated chlorophy 11 synthes is rate, $V_{6}$, is considered in the model to be a function of the nitrogen quota when nitrogen is not limiting cell division,

$v_{6}=g\left(c_{4}-d_{4}\right) / c_{4}$.

For the alternative condition, when nitrogen is limiting cell division, the synthesis of chlorophyll is considered to be dependent on the uptake of nitrogen. The dependence is based on the amount of nitrogen required for the synthesis of chlorophyll molecules and on a nitrogen/chlorophyll composition ratio observed for nitrogen-1imited phytoplankton. Chlorophyl1 a weighs $89.3 \mathrm{~g}$ mole $\mathrm{e}^{-1}$ (Shuman and Lúrenzen 1975) and with four nitrogen atoms per molecule, chlorophyll a is $6.27 \%$ nitrogen by weight. Under conditions of nitrogen limitation, when the 
cell nitrogen to chlorophyll ratio may equal 16/1 (Strickland 1965), chlorophyl1 contains $0.39 \%(0.0627 / 16=0.0039)$ of the cell nitrogen. If this condition is to be maintained, $0.39 \%$ of net nitrogen uptake must go to chlorophyll synthesis. In other words, for each mole of nitrogen assimilated, chlorophyll increases by $0.875 \mathrm{~g}$.

To summarize, the equations used to define the rate of chlorophyll synthes is are:

$$
\begin{aligned}
& P_{6} V_{6}=P_{6}\left(g\left(C_{4}-d_{4}\right) / C_{4}\right) \text { if cell nitrogen is not limiting } \\
& \text { cell division; } \\
& =\mathrm{e}_{6} \mathrm{~V}_{4} \mathrm{P}_{4} \text { if cell, nitrogen ie limiting rell }[2.24] \\
& \text { division rate; } \\
& =0 \quad \text { if } \mathrm{C}_{6} \approx \mathrm{c}_{6} \text { and } \mathrm{v}_{6} \geq G
\end{aligned}
$$

where

$\mathrm{P}_{6}$ is chlorophyli ( $\left.\mu \mathrm{g} \cdot 1^{-1}\right)$;

$V_{6}$ is the sperific rate of increases of chlorophyil $\left(\mathrm{hr}^{-1}\right)$. The product $\mathrm{P}_{6} \mathrm{~V}_{6}$ is the mass increase in chlorophyll per time ( $\mu g$ chlorophyll.1-1.hr-1). Similarly, $\mathrm{P}_{4}$ and $v_{4}$ are particulate nitrogen $\left(\mu g\right.$ at $1^{-1}$ ) and the specific uptake rate of nitrogen $\left(\mathrm{hr}^{-1}\right)$ respectively; $e_{6}=0.875$ chlorophyll (g atom total nitrogen uptake) $)^{-1}$; $\mathrm{e}_{6}$ is the factor relating nitrogen uptake and chlorophyll synthesis when nitrogen is limiting cell division.

Chlorophyll synthesis is stopped if the chlorophyll per cell $\left(\mathrm{C}_{6}\right)$ exceeds the maximum quota and the chlorophyll synthesis rate exceeds the cell division rate, G. The maximum chlorophyll quoca is defined according to the assumption that the minimum nitrogen to chlorophyll 
ratio (by weight) is 5 (Strickland 1965) and the minimum carbon to chlorophyll ratio (by weight) is 36 .

\subsection{Application}

One of the ultimate purposes of this simulation study is to relate changes in the physiological characteristics of phytoplankton populations to changes in a realistically complex environment. The growth model is first applied, however, to a field experiment designed to eliminate some in situ sources of natural variability. Eppley, Carlucci, et al. (1971), from 2-15 July, 1970, carried out an intensive study of the growth, physiology and chemical composition of phytoplankton, maintained in 200 liter batch cultures at sea to remove the organisms from the effects of advection and turbulence within the California upwelling ecosystem. A fairly complete set of nutrient, biomass and phytoplankton rate measurements was obtained as the cultures responded to suddenly elevated nutrient concentrations. Nutrient-depleted surface seawater was filtered through $183 \mu$ mesh to remove the larger zooplankton. It was then supplied with trace metals, vitamins, phosphate, silicate and one of three sources of nitrogen; nitrate, ammonium, or urea. In one treatment the batch culture received all nutrient additions except the nitrogen source. Temperature was maintained between $20^{\circ}$ and $25^{\circ} \mathrm{C}$ and solar insolation was reduced to about $20 \%$ of natural intensity with a neutral density filter.

Measurements of incident solar radiation are not reported for the experiment, but the timing and intensity of the incident radiation measured off Oregon with an Eppley pyranometer (sensitive to wavelengths 
less than $2800 \mathrm{~nm}$ ) on $11 \mathrm{Ju} 1 \mathrm{y}, 1973$ (Reed and Halpern 1974) is approximated within $5 \%$ (Figure 1) by the solar radiation submodel, assuming 25 km visibility and $3 \mathrm{~cm}$ precipitable water (Portman and Ryznar 1971). In substantial agreement with previous observations (Strickland 1958), simulated values of photosynthetically active radiation vary between $48 \%$ and $50 \%$ of the total incident flux; depending on the altitude of the sun. At $32^{\circ} \mathrm{N}$ (the approximate latitude of San Diego) on $11 \mathrm{Ju} 1 \mathrm{y}$ (the approximate time of the batch experiments) the simulated photosynthetically active radiation (Figure 2) is 361 ly $\mathrm{d}^{=1}$ or approximatoly 59.4 einsteins $\mathrm{m}^{-2} \mathrm{~d}^{-1}$, if the ayerage energy of an einstain of visible solar light is $52 \mathrm{Kcal}$ (Bannister 1974). Values used in the model at each iteration are reduced from surface incident values by $80 \%$ to represent light conditions inside the partially shaded experimental containers. The mean light path through the batch culture container, depth $z$ in [2.23] and [2.30], is assumed to be 1 meter, and the attenuation of light inside the container due to causes other than water and phytoplankton biomaos $\left(k_{\mathrm{d}} \mathrm{X}\right.$ in [2.2\%] is assumed to be aegligible.

The phytoplankton growth model was run to consider two different treatments of the batch cultures. In the first treatment, the culture received trace metals, vitamins, but no inorganic nitrogen source. In the second treatment, the culture received similar additions, but niträte was added ds the suntce of inorganie nitrogen. Initial values of each state variable are 1 isted in Tabie 1 and are based on data reported by Eppley, Carlucci, et al. (1971) and Univ. Calif. Inst. Mar. Resour. (1972). The maximum carbon quota, $c_{5}$, is arbitrarily assumed to be twice the initial carbon quota. Initial quotas which were not 


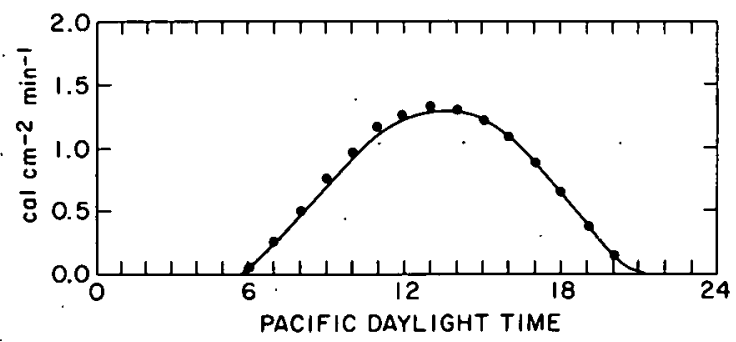

Figure 1. A comparison of measured (-) (Reed and Halper, 1974) and computed ( $\bullet$ ) clear-day solar radiation of wavelengths less than $2800 \mathrm{~nm}$ at $45^{\circ} 15.8^{\prime} \mathrm{N}, 124^{\circ} 7.8^{\prime} \mathrm{W}, 120 \mathrm{Km}$ off the Oregon coast on 11 , July 1973 .

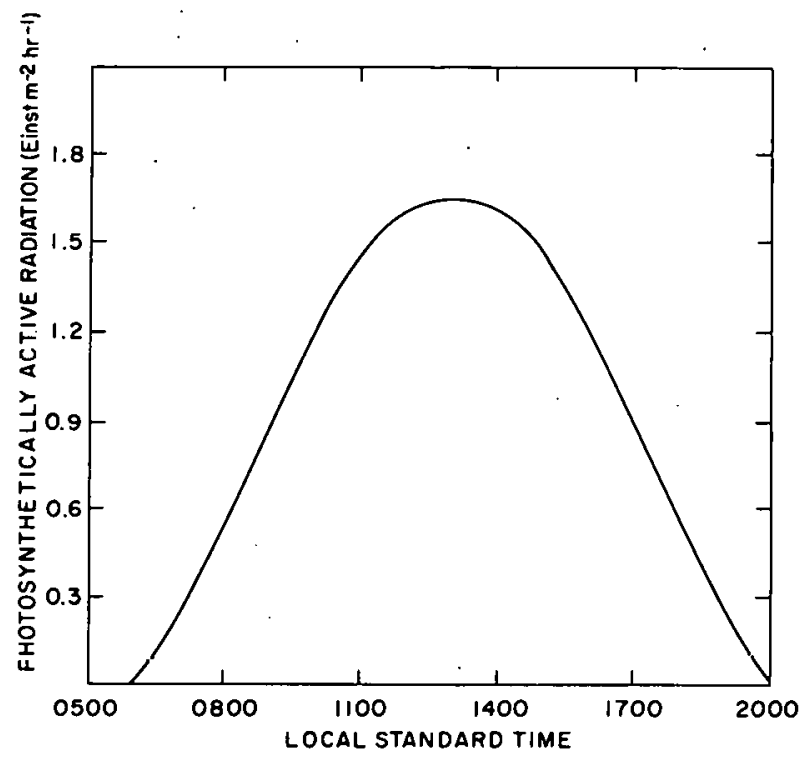

Figure 2. Simulated photosynthetically active radiation (wave-lengths less than $720 \mathrm{~nm}$ ) as a function of time at $32^{\circ} \mathrm{N}$ on $11 \mathrm{July}$. 
Table 1. Initial values of variables used in the simulations of the two nutrient treatments. Initial particulate cabon, $P_{5}$, is defined as the product of the carbon per cell (18.3 pg at $\mathrm{C}$ cell-1, from Table 3 . of Eppley, Carlucci, et al. (1971)) and the initial cell numbers, $N$.

Treatment 1

All nutrients added except
nitrogen

Variable

$\begin{array}{ll}\mathrm{P}_{1} & 0.09 \mu \mathrm{Hg} \text { at } 1^{-1} \\ \mathrm{P}_{4} & 0.26 " \\ \mathrm{P}_{5} & 6.41 " \\ \mathrm{~F}_{6} & 0.73 \mu \mathrm{g} 1^{-1} \\ \mathrm{~S}_{1} & 22.8 \mu \mathrm{g} \text { at } 1^{-1} \\ \mathrm{~S}_{2} & 0.0 \mathrm{\prime \prime} \\ \mathrm{S}_{3} & 0.33 " \mathrm{~N} \\ \mathrm{~N} & 0.35 \times 10^{6} \text { cells } 1^{-1}\end{array}$

Treatment 2

All nutrients added, nicrace as the nitrogen source

$0.09 \mu \mathrm{g}$ at $1^{-1}$

$0.26 " 1$

6.4111

$0,73 \quad 1.8 \quad 1^{-1}$

$50.0 \mu \mathrm{g}$ at $1^{-1}$

$5.0 \quad 11$

$0.33 \quad 1$

$0.35 \times 10^{6}$ cells $1^{-1}$ 
measured at the beginning of the experiment are set to minimum values to represent the effects of pretreatment low-nutrient conditions.

The two treatments differ with respect to the initial values of nutrients, $s_{1}, s_{2}, s_{3}$ (silicate, nitrate and ammonium, respectively) added at the start of the experiment and the additions of nutrients, made during the course of the experiment. No further additions were made to treatment 1 , but an ammonium concentration of approximately $0.33 \mu \mathrm{g}$ at $1^{-1}$ persisted during the period of observation. In the second treatment with nitrate added, the ammonium concentration increased with time. The persistant ammonium concentrations in each treatment could be attributed to nitrate reduction in the dark or to excretion by those microzooplankton not removed by the pretreatment filtering. Zooplankton processes or other possible sources of ammonium are not represented in the equations of this model and the observed ammonium concentrations are therefore treated as a given condition of the experiment. The regression equation (Aird 1972)

$$
s_{3}=0.33 \exp [0.17 \mathrm{t}]
$$

is used to specify the ammonium concentration, $s_{3}$, as a function of time, $t$, in hours since the beginning of the experiment (Figure 7 ). This condition unfortunately precludes a mass balance, but it reproduces the nutrient environment for this model of phytoplankton growth and it avoids the introduction of variables and functions for which no data exist.

Concentrations of nitrate and oilicate are illceased in the simulation according to the schedule used in the actual experiment. The nitrate concentration was increased by $20 \mu \mathrm{g}$ at $1^{-1}$ after 28 hours. and 

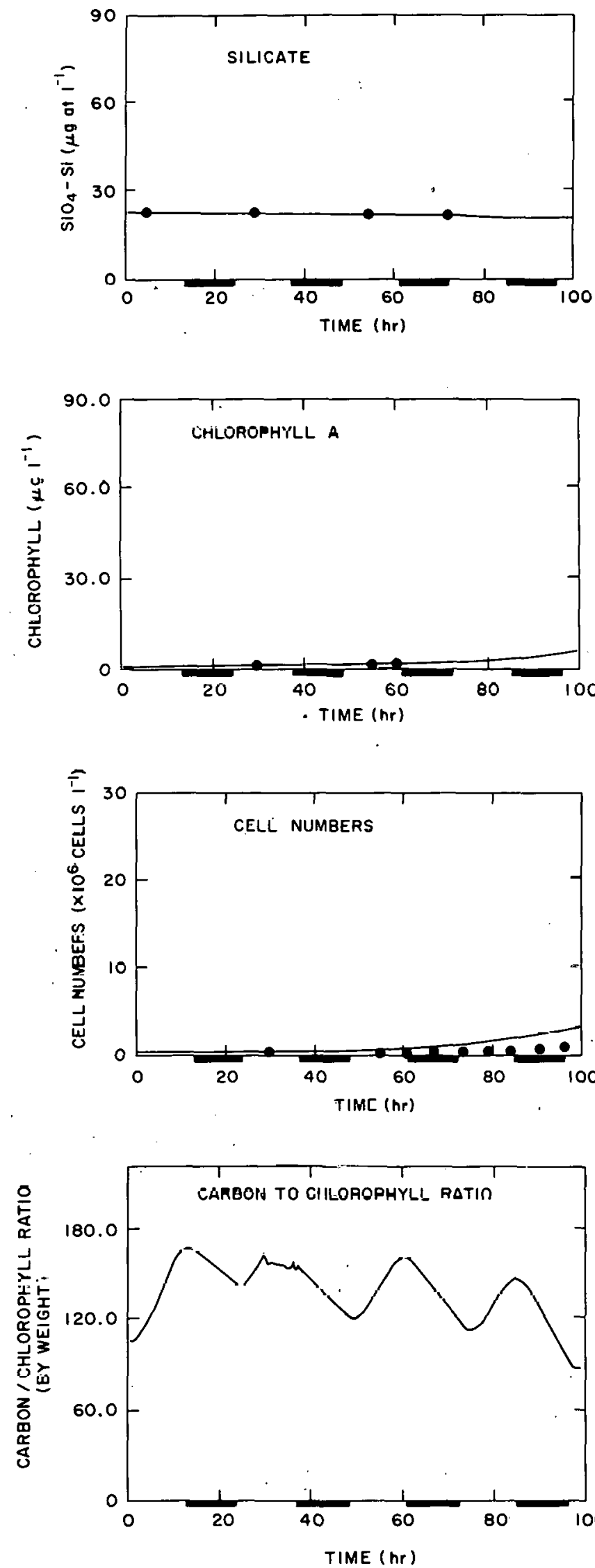

Figure 3. Observed ( $\bullet$ ) and simulated (-) silicate concentrations in the treatment without an added nitrogen source. In all of the following comparisons of observed and simulated concentrations, time zero is 0600 hours and the darkened areas on the abscissa are night-time periods.
Figure 4. Observed (O) and simulated (-)concentrations of chloruphyl1 a in the treatment without an added nitrogen source.

Figure 5. Observed ( $)$ and simulated ( $\rightarrow$ cest numbers in the treatment without an added nitrogen source.

Figure 6. The simulated variation in the carbon to chlorophyl1 ratio (by weight) in the treatment without an added nitrogen source. 
$50 \mu \varepsilon$ at $1^{-1}$ after 77 hours. Also after 77 hours, the concentration of silicate was increased by $67 \mu \mathrm{g}$ at $1^{-1}$.

\subsection{Results}

A comparison of the observations and calculated results for the treatment lacking an added nitrogen source is made in Figure 3 to 5 . Relatively few measurements were made on the culture with no nitrogen added. The nitrate concentration remained essentially undetectable and addition of all the other nutrients had little or no effect on growth, suggesting nitrogen was the factor limiting population growth in this experiment.

It is difficult to understand how an ammonium concentration of approximately $0.33 \mu \mathrm{g}$ at $1^{-1}$ could persist during the experimental treatment unless it was sustained by microzooplankton activity or some other regerative source. In the absence of simulated grazing losses this constant concentration, not depleted by simulated uptake, sustains some simulated phytoplankton growth and causes the mean simulated population growth $\left(0.022 \mathrm{hr}^{-1}\right)$ to overestimate the slower observed population growth rate $\left(0.012 \mathrm{hr}^{-1}\right)$ calculated from initial and final diatom cell counts. The effects of nitrogen depletion, however, remain evident in the simulation results. The average atomic $\mathrm{C} / \mathrm{N}$ ratio is high (17.9) and carbon to chlorophyll ratio (by weight) also high, varies between extremes of 90 and 170 (Figure 6). A comparison of these ratios with the ubservations is not possible because measurements of particulate carbon, nitrogea áld chluruphyll were not made simultaneously during the course of this experiment. 


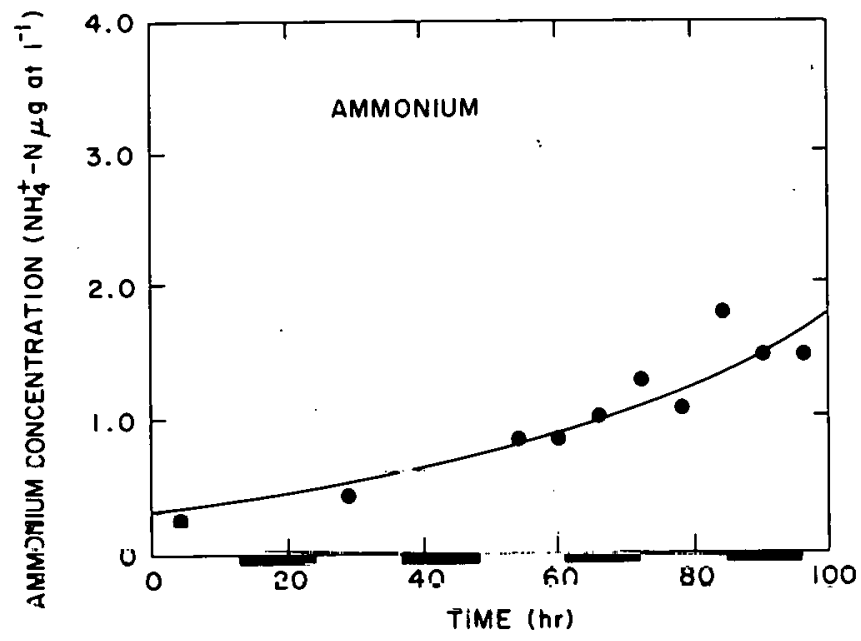

Figure 7. A comparison of the observed ammonium concentration ( $\bullet$ ) and the graph of the function, $S_{3}=.33 \exp [.017 t]$, used to specify the ammonium concentration during the course of the treatment with nitrate added as the nitrogen source. Time zero is at $0600 \mathrm{hrs}$ local time and darkened areas on the abscissa are night time periods.

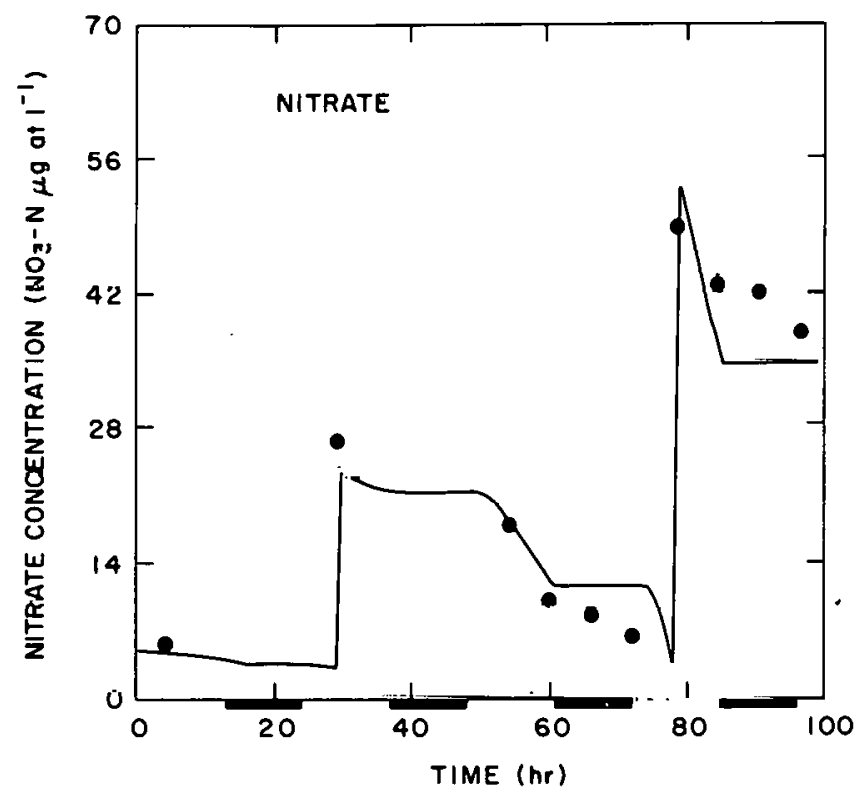

Figure 8. Observed $(\bullet)$ and simulated $(-)$ nitrate concentrations in the treatment with n1trate added as a nitrogen source. 


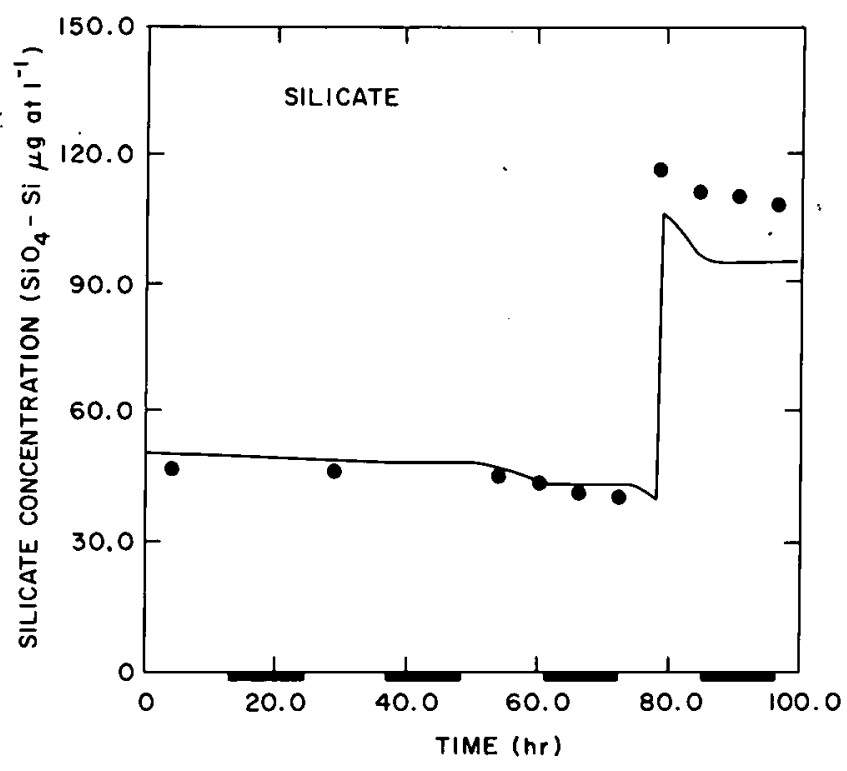

Figure 9. Observed (O) and simulated. (-) silicate concentrations in the treatment with nitrate added as a nitrogen source.

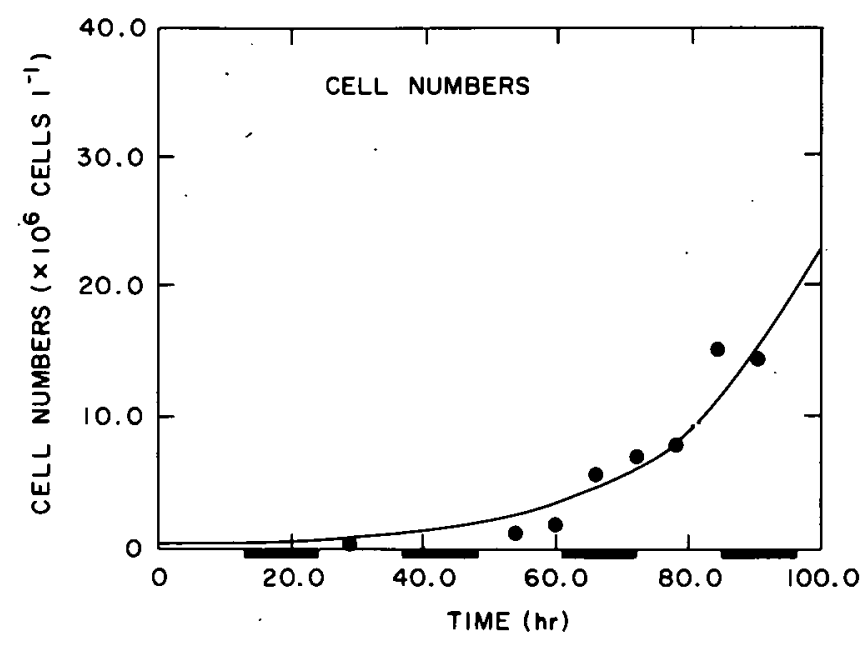

Figure 10. Observed $(\bullet)$ and simulated $(-)$ cel1 numbers in the treatment with nitrate added as a nitrogen source. 


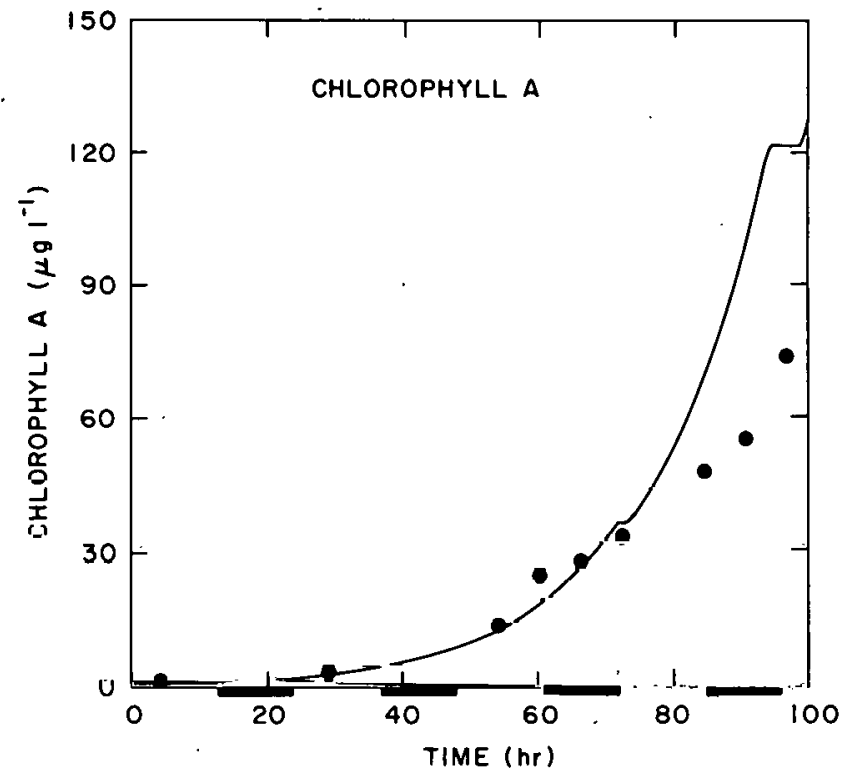

Figure 11. Observed ( $\bullet$ ) and simulated $(-)$ chlorophyll a concentrations in the treatment with nitrate added as a nitrogen source.

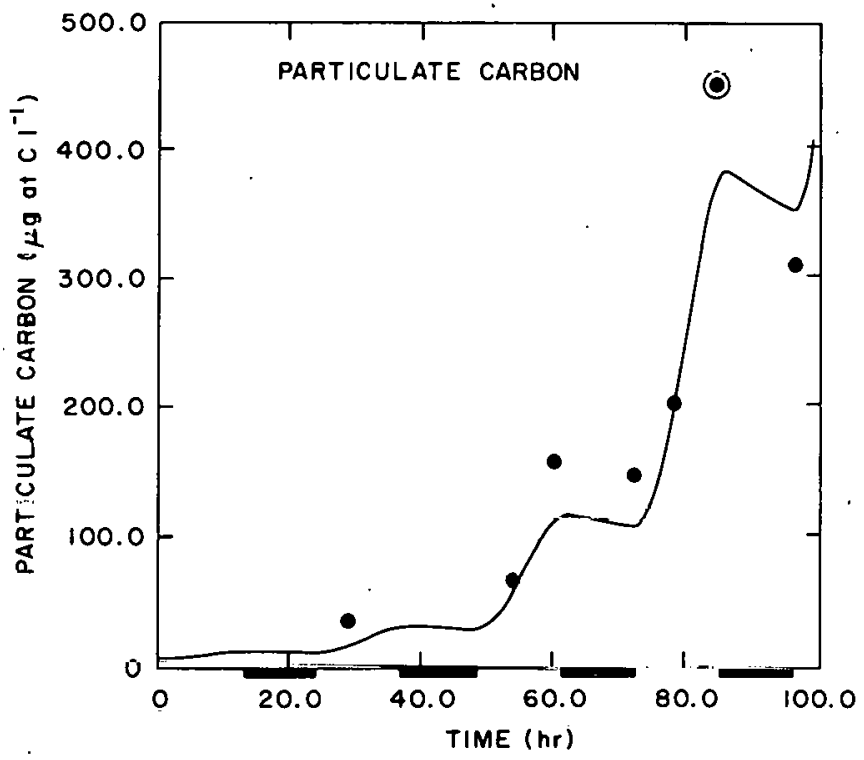

Figure 12. Observed (O) and simulated (-) particulate carbon concentrations in the treatment with nitrate added as a nitrogen source. The circled observation at 84 hours may be erroneousiy high (Banse, 1974). 


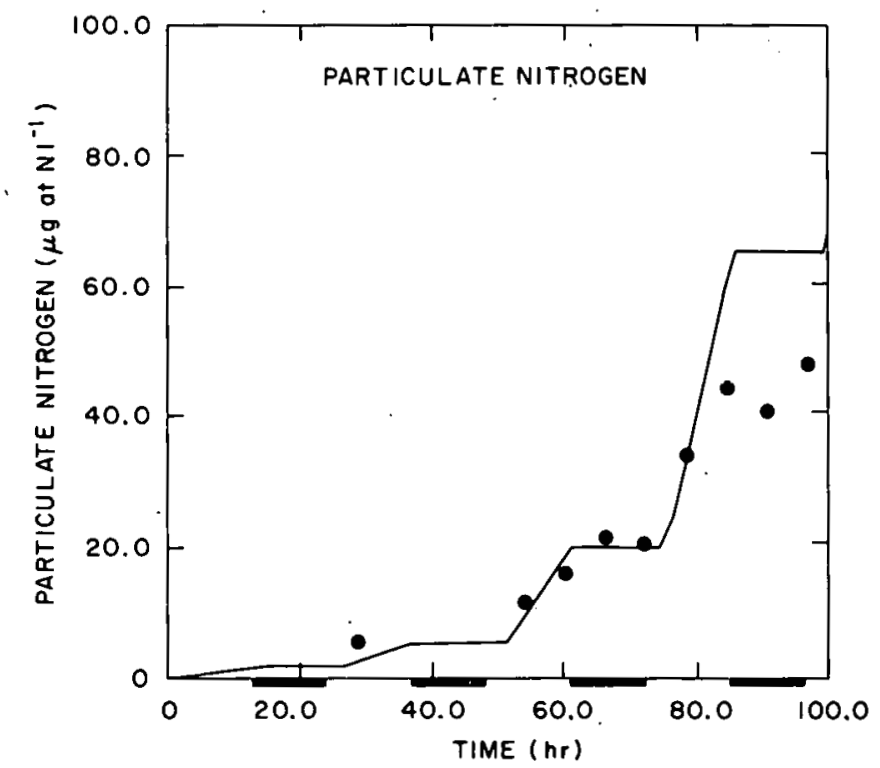

Figure 13. Observed (O) and simulated (-) particulate nitrogen concentrations in the treatment with nitrate added as a nitrogen source.

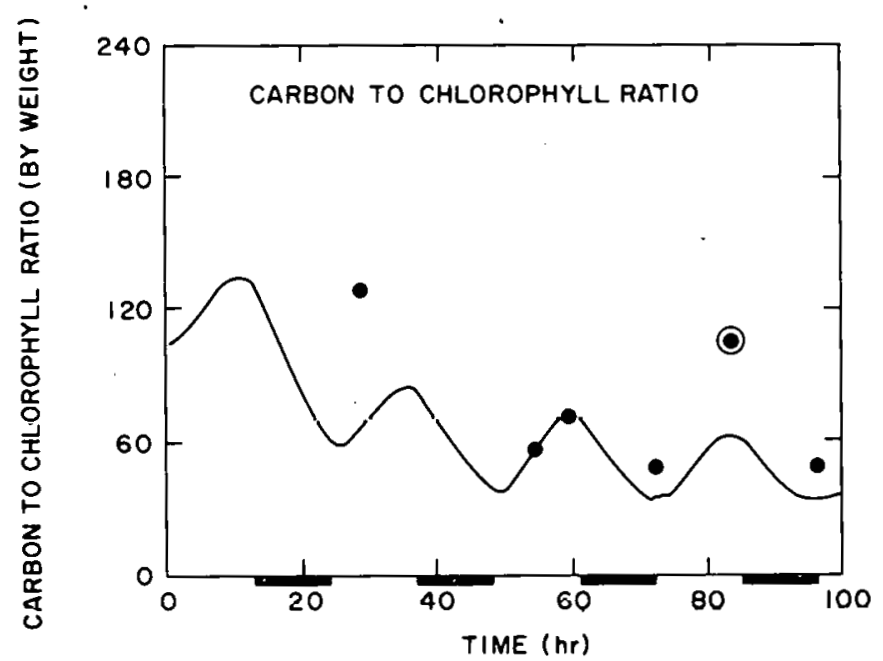

Figure 14. Observed ( $\bullet$ ) and simulated (-) values of the carbon to chlorophyll ratio (by weight) in the treatment with nitrate added as a nitrogen source. 


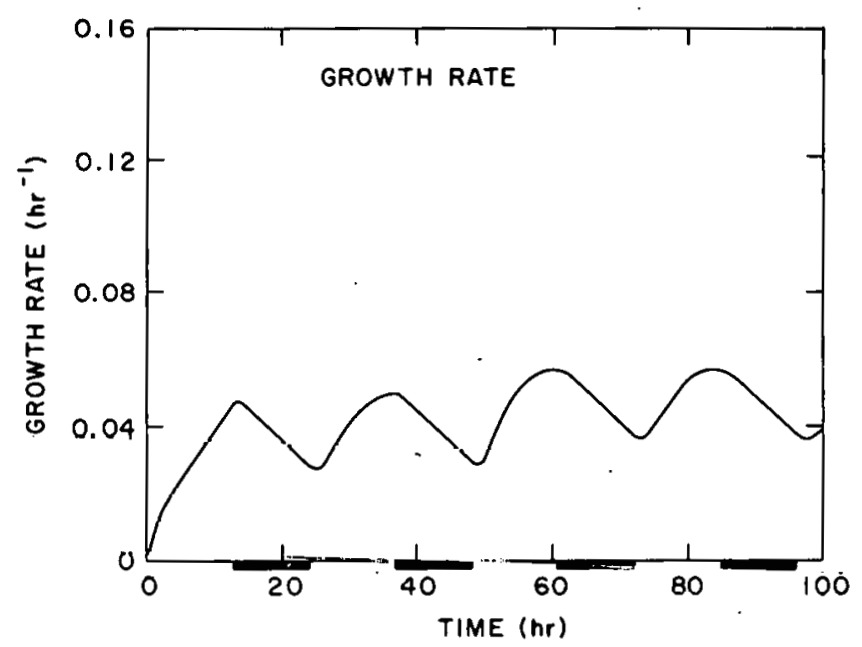

Figure 15. The simulated growth rate $\left(\mathrm{hr}^{-1}\right)$ during the course of the treatment with nitrate added as a nitrogen source. The mean observed growth rate was $0.039 \mathrm{hr}^{-1}$.

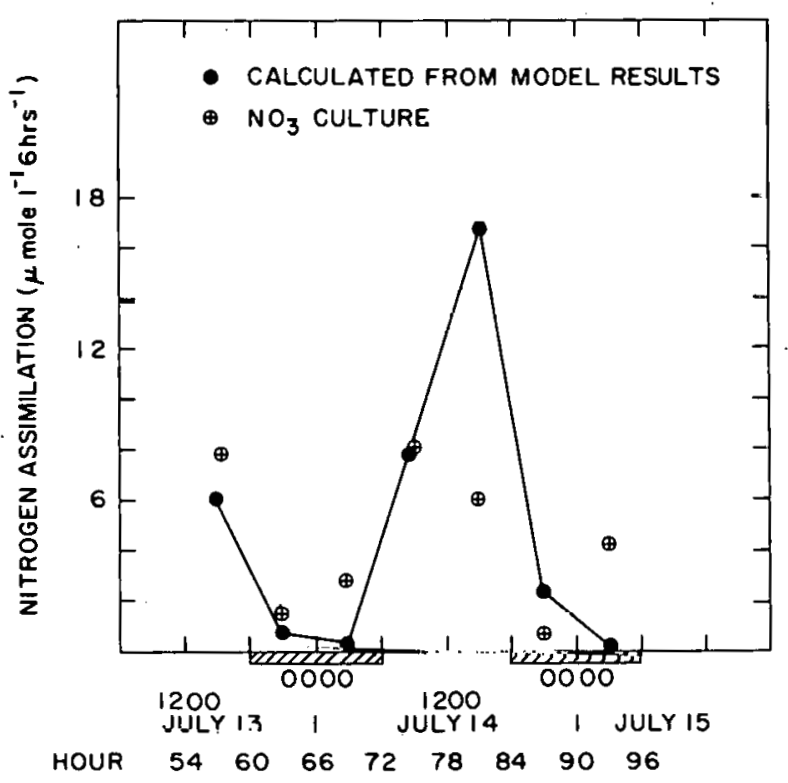

Figure 16. A comparison of measured and simulated nitrogen assimilation rates as a function of time. 
The simulated growth response for treatment 2 contrasts with the previous results. Figure 8 to 14 . show that population biomass and, consequently, nutrient uptake are much higher during treatment 2 with an added inorganic nitrogen source. Increases in simulated cell numbers, phytoplankton chlorophyll, carbon and nitrogen and decreases in nitrate and silicate concentrations correspond with measured changes occurring during the first 70 to 80 hours of the 96 hour experimental period of treatment 2. A depletion of vitamin $B_{12}$ occurred during treatment 2 after 72 hours (Eppley, Carlucci, et al. 1971) and may have been responsible for decreases in some physiological rates, particularly chlorophyll synthesis, after that time. Model growth and uptake equations are not functions of vitamin concentration and do not express rate decreases due to vitamin depletion. A divergence of some of the simulated results and observations after 70 hours may be due to the absence of vitamin sensitive functions in the model and again may also be attributable to the lack of grazing functions in the model equations.

The observed phytoplankton cell division rate was $0.039 \mathrm{hr}^{-1}$ and the mean simulated rate is $0.042 \mathrm{hr}^{-1}$. Silica was the factor initially limiting simulated cell division rate, but carbon, through light limitation, became the most limiting factor after 13 hours in the simulation. Observed phytoplankton cell division was partially synchronous and most cells divided in the afternoon and early evening. The simulated growth rate also varies periodically (Figure 15) and highest rates occur in the late afternoon. Other examples of diel periodicities occurring in phase within both the experiment and the simulation 
are changes in the carbon to chlorophyll ratio (Figure 14) and nitrogen uptake rate (Figure 16 ). The measured and simulated nitrogen uptake rates are for 6 hour intervals between sampling times and are expressed as the quotient of the nutrient concentration decrease occurring during the 6 hour interval and the mean particulate nitrogen concentration.

\subsection{Discussion}

A comparison of the available observations with the simulated results suggest that many characteristics of phytuplauktuin growth are represented in the model. One of the interesting features of buth the experiment and the simulation is the occurrence of diel variability in physiological rates and chemical composition. Unlike Walsh's (1975) treatment of multiple nutrient regulation in a phytoplankton growth model, none of the uptake parameters in this model ale specified as periodic functions of time. The periodic behavior produced by the model is not due to explicit periodic forcing of the uptake functions, but occurs as a consequence of the relationship between carbon and nutrient cell quotas and the periodic variation of solar radiation directly affecting the carbon quota.

This model remains, however, an extremely simplified paradigm unable to completely account for some growth characteristics. For example, the periodic variation in simulated nitrate uptake rate has been described (Figure 16). The assimilation of nitrogen by phytoplankton populations is known to be light dependent (Grant 1967; Grant and Turner 1969; MacIsaac and Dugdale 1972) and often, as in the culture experiment, showo a diel periodicity with higher rates of assimilation occurring during the day and lower rates occurring during the 
night (Eppley, et a1. 1970; Eppley, Rogers.and McCarthy 1971). The model results indicate, however, that simulated nitrogen uptake is higher than observed during the day and ceases completely for some period at night. Falkowski (1975) showed that nitrate uptake is correlated with the hydrolys is of ATP and suggested that ATP is the rate limiting substrate in the dark at non-limiting nitrate concentrations. The $\Lambda T P$ necessary to maintain nitrate uptake could be produced by either photosynthesis in the light or respiration in the dark. Future models with a stronger biochemical basis, perhaps including high energy phosphate fluxes might better resolve the details of this type of physiological periodicity.

An important feature of this model is that cell division and biosynthetic processes such as nutrient assimilation and carbon fixation are separate, but related functions. These functions have been explicitly represented in an attempt to account for the characteristics of each process and to more clearly show how the success of a population could depend on simple process interrelationships and to conditions in the external environment. For example, when cell division occurs at a specific rate, $G$, at half the maximal rate, then

$$
G=(g / 2)\left(1-\left(d_{n} / c_{n}\right)\right)
$$

In general, the specific rate uptake rate, $v_{n}$, is

$$
v_{n}=v_{n}\left(s_{n} /\left(k_{n}+s_{n}\right)\right)
$$

At steady state, growth and uptake ratca are equal and

$$
(g / 2)\left(1-\left(d_{n} / c_{n}\right)\right)=v_{n}\left(s_{n} /\left(k_{n}+s_{n}\right)\right)
$$


Solving for $S_{n}$ gives the half-saturation constant for growth, $\mathrm{K}_{\mathrm{g}}$, or the nutrient concentration sustaining half the maximal growth rate

$$
K_{g}=s_{n}=k_{n} \frac{\left(\frac{g}{2 v_{n}}\left(1-\frac{d}{c_{n}}\right)\right)}{\left(1-\frac{g}{2 v_{n}}\left(1-\frac{d_{n}}{c_{n}}\right)\right)}
$$

This equation conveniently expresses the half-saturation constant for growth, $\mathrm{K}_{\mathrm{g}}$, as a function of the half-saturation constant, $k_{n}$, fur uptake. In general, maximal uptake rates, $v_{n}$, are greater than maximal growth rates, g (see explanation following cquation [2.32]). If the ratio of maximum and minimum quotas $\left(C_{n}\right.$ and $\left.d_{n}\right)$ is constant, then the half-saturation constant for growth is given as a function of the ratio $v_{n}$ and $g$ (Figure 17).

The relationship expressed in [2.42] offers an explanation of why observed half-saturation constants for growth may be much lower than the half-saturation constants for uptake (Caperon and Meyer 19.72; Droop 1968). An implication of this result is that couparisons of halfsaturation constants for uptake to determine competitive advantages among phytoplankton populations at low nutrient concentrations may not necessarily be definitive. Generally, the species with the lower $k_{n}$ half-saturation constant for uptake is expected to have a competitive àdvantage over duullet at lơw nutricnt conoontrations (nugrale 1.967). However, if growth and uptake processes of phytoplankton are described by the equations of this model, a species with a higher half-saturation conslaul aud a high maximal uptake rate could out rnmpete, at low 
nutrient concentrations, another species with a lower $k_{n}$ value, but with a maximal uptake rate more nearly equal to its maximum division rate.

This phytoplankton growth model has been formulated to describe the relationships among several of the most important environmental factors affecting the physiology of primary production. It has been applied to the batch culture study to verify that its formulation is internally consistent and that it may realistically represent the effects of light or nutrient limitation important in the control of primary production in an upwelling region. In the following section, this phytoplankton growth model, and solar radiation submodel, are incorporated in a spatially and functionally more complex model of ecosystem processes of the upwelling region off northwest Africa.

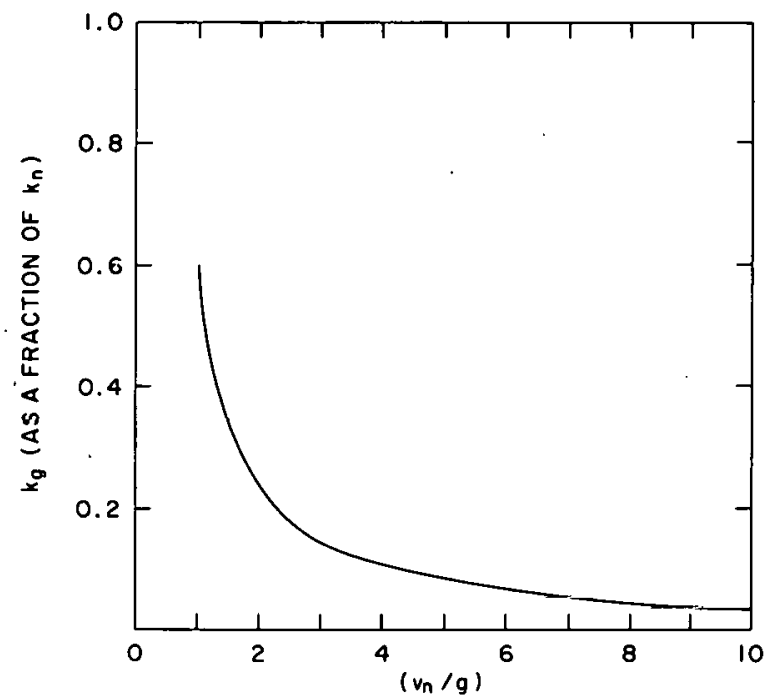

Figure 17: The half-saturation constant for growth $k$ as a function of the rat1o of maximum uptake and cell division rates. ${ }_{\mathrm{K}_{g}}$ is expressed as a fraction of the half-saturation constant for uptake. 
THE NORTHWEST AFRICA UPWELLING ECOSYSTEM MODEL

\subsection{Formulation}

The formulation of the ecosystem model is based on the experimental design of the JOINT-I expedition of the Coastal Upwelling Ecosystems Analysis program. Barber's (1977) description of JOINT-I discusses the considerations which led to the selection of the site for the field study and design for deployment of the current meters. Historical data indicated that the region near Cap Blanc (Figure 18) is characterized by a pattern of relatively consistent upwelling occurring over a shallow continental shelf with a sharp shelf break at at $\sim 100 \mathrm{~m})$ and a steep continental slope. Hydrographic and air reconnaissance surveys made prior to the cruise and an analysis of JOINT-I data by Mittelstaedt et al. (1975) indicate that the region is also characterized by a high degree of longshore uniformity with little three dimensional structure.

If it is asoumed that upwelling in the InTNT-T study area occurs as a two dimensional process then [2.1] can be written as

$$
\frac{\partial S}{\partial t}=\frac{\partial K_{x}(\partial S / \partial x)}{\partial x}+\frac{\partial K_{z}(\partial S / \partial z)}{\partial z}-\frac{\partial(u S)}{\partial x}-\frac{\partial(w S)}{\partial z}+R
$$

where

$$
\begin{aligned}
x, z= & \text { spatial coordinates with } x \text { positive offshore and } z \\
& \text { positive vertically downwards; } \\
u, w= & \text { velocity components in the } x \text { and } z \text { directions, } \\
& \text { respectively; }
\end{aligned}
$$




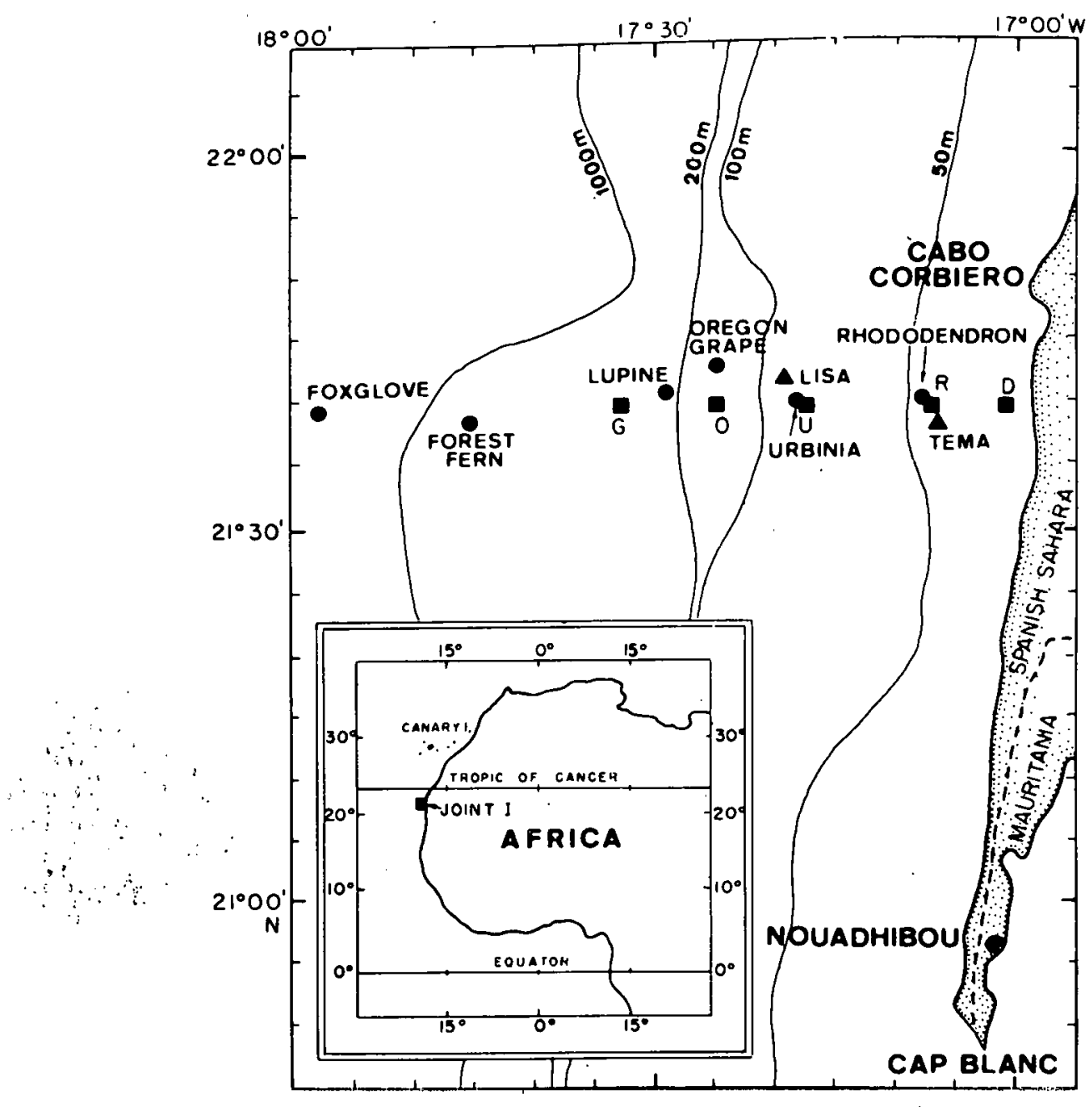

Figure 18. Location of the JOINT-I study. The circles and triangles indicate the position of moored current meter arrays and meteorological towers. The squares indicate the locations on the $21^{\circ} 40^{\prime} \mathrm{N}$ transect where productivity and hydrographic stations were repeated1,y occupied. From Barber (1977). 


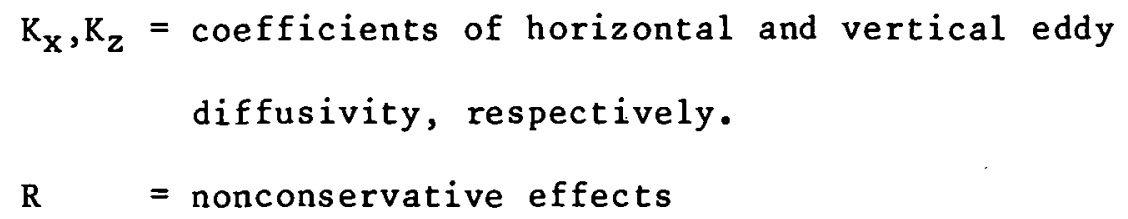

A set of similar equations is used to describe changes in the distribution of each variable in this ecosystem model. The first four terms on the right represent the turbulent mixing and advection effects of the circulation and are functionally similar for all variables at a given location. The nonconservative $\mathrm{R}$ term, however, represents changes due to biological and chemical interactions and is usually different for each variable at a given location, Therefore, the nonconservative interactions will be discussed separately following a description of the physical circulation system. The spatial segmentation convention, definition of the boundary conditions and the numerical methods used to integrate the equations are discussed in Appendices $I$ and II.

3.1a Physical Circulation. Mittelstaedt et al. (1975) describe the general flow patterns in the northwest $\Delta$ frican upwelling region. They show that alongshore flow near the coast was characterized by an equatorward surface current with speeds of $10-20 \mathrm{~cm} \mathrm{~s}^{-1}$ extending over much of the shelf ( $\sim 40 \mathrm{~km}$ wide) and a poleward undercurrent between 200 and $300 \mathrm{~m}$ depth along the slope moving northward at a mean speed of $10 \mathrm{~cm} \mathrm{~s}^{-1}$. The strongest vertical velocities on the order of $10^{-2} \mathrm{~cm}$ $s^{-1}$ occurred near the bottom at the shelf break (between 100 and 150 m). Rising water became a part of the subsurface onshore flow and upwelled into the surface layer on the shelf and near the coast. 
In order to formulate and run the ecosystem model it is necessary to quantitatively represent the above largely qualitative description of the circulation. One approach to the problem of rationally quantifying the flow field is to utilize the results from a hydrodynamic model (Wroblewski 1977). When development of this ecosystem model was begun, the model of Hamilton and Rattray (1978) was the only structurally compatible hydrodynamic model to have been applied to the northwest African upwelling region. It was therefore used to generate the flow fields required in the ecosystem model.

The Hamilton and Rattray hydrodynamic model, to be referred to as the physical submodel, solves the equations of continuity, mass and momentum conservation for a continuously stratified coastal region with variable shelf topography, given the wind stress and offshore density profile. The equations of the physical submodel and are listed in Appendix V. For further details of the mathematical formulation and the numerical methods used see Hamilton and Rattray (1978).

Beginning at initial time $t=0$ in the physical submodel, a wind stress is impulsively applied to a circulation system with level isopycnals. At every iteration ( $\Delta t=30$ minutes) the physical submodel generates a new $u, v, w$ flow field as the system spins-up. Because alongshore gradients are ignored in the ecosystem model only the $u$ and $w$ components of the flow at each iteration are used in the ecosystem model.

The grids of both models are arranged in a vertical plane normal to the coast, but the grid spacing is variable in the ecosystem model 
and regular in the circulation submodel. Ecosystem model grid spacing varies from $5 \mathrm{~km} \times 5 \mathrm{~m}$ nearshore to $20 \mathrm{~km} \times 20 \mathrm{~m}$ offshore below $60 \mathrm{~m}$ (Figure 19). The $5 \mathrm{~km} \times 10 \mathrm{~m}$ regular grid of the physical submodel maps easily onto the system model grid, and simplified the task of maintaining continuity when the physical submodel results were post processed prior to use in the ecosystem model.

Hamilton and Rattray (1978) indicate that the physical submodel results "are not meant to be a detailed simulation since no attempt has been made to tune the model to the data." However, from a comparison of hydrographic sections and current meter data they conclude that the correspondence between the model and field data are reasonable considering the simplifications made in the model. With a constant equatorward wind stress of 1 dyne $\mathrm{cm}^{-2}$ the physical submodel generates a sequence of flow fields similar to the observed upwelling circulation. Examples of the calculated flow fields after 2, 5, and 10 days constant wind stress are shown in Figures 20 to 22. For comparison, Figure $23 a$ is a schematic diagram of the mean upwelling circulation from Mittelstaedt, et al. (1975). Mittelstaedt, et al. (1975) measured a decrease in shoreward transport inside the shelf break and therefore showed upwelling occurring over the entire shelf. In substantial agreement with this observation the physical submodel generates upweilling flow into the basè of the euphotic żone over most of the shelf and at the shelf break after a spin-up time of several days. A maximum upwelling velocity of $2.8 \times 10^{-2} \mathrm{~cm} \mathrm{~s}^{-1}$ near the bottom at the shelf break is of the same order as the maximum suggested by Mittelstaedt 


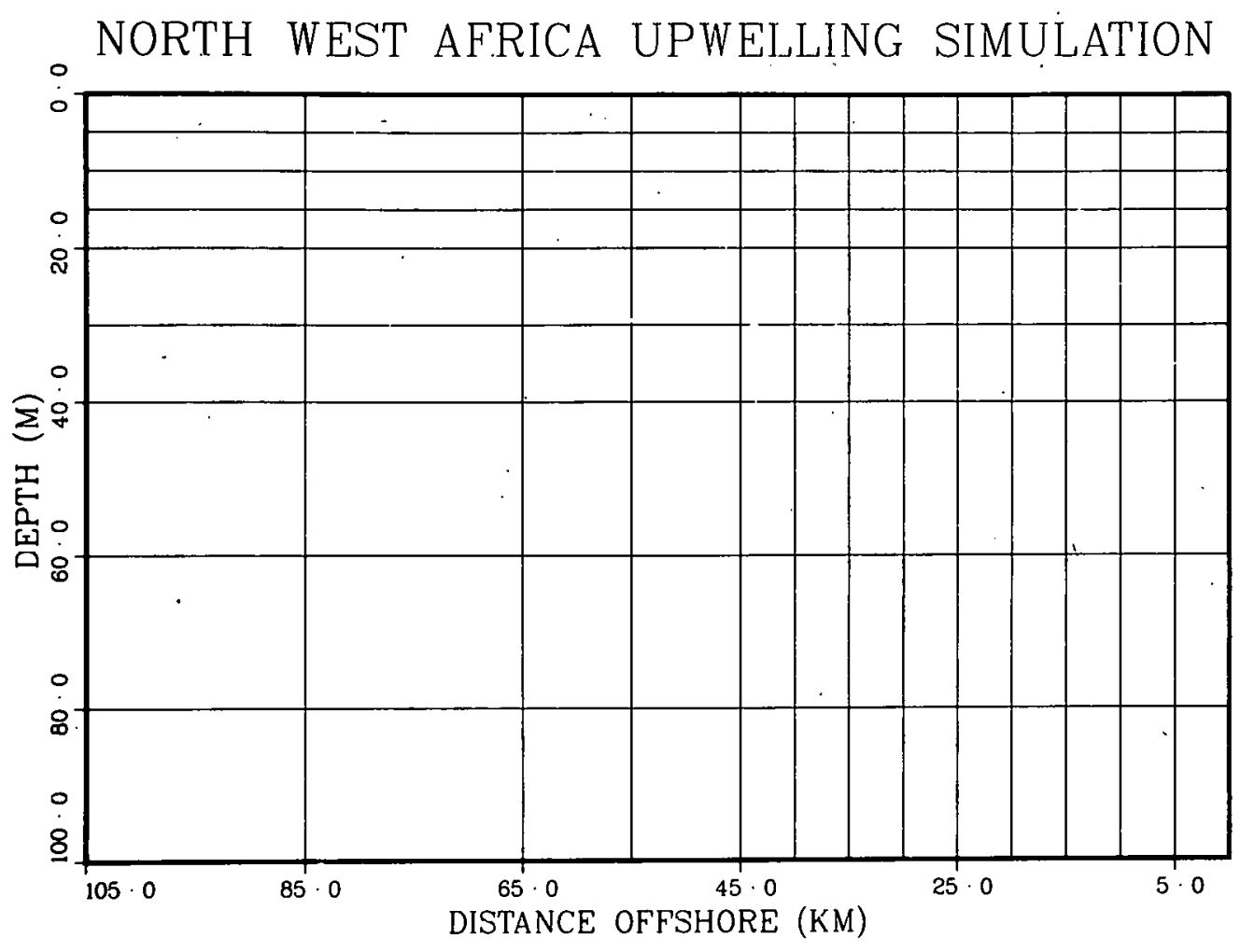

Figure 19. The grid system of the system model. The grid spacing varies from $5 \mathrm{~km}$ in the horizontal by $5 \mathrm{~m}$ in the vertical nearshore to $20 \mathrm{~km}$ by $20 \mathrm{~m}$ in the offshore area below $60 \mathrm{~m}$.

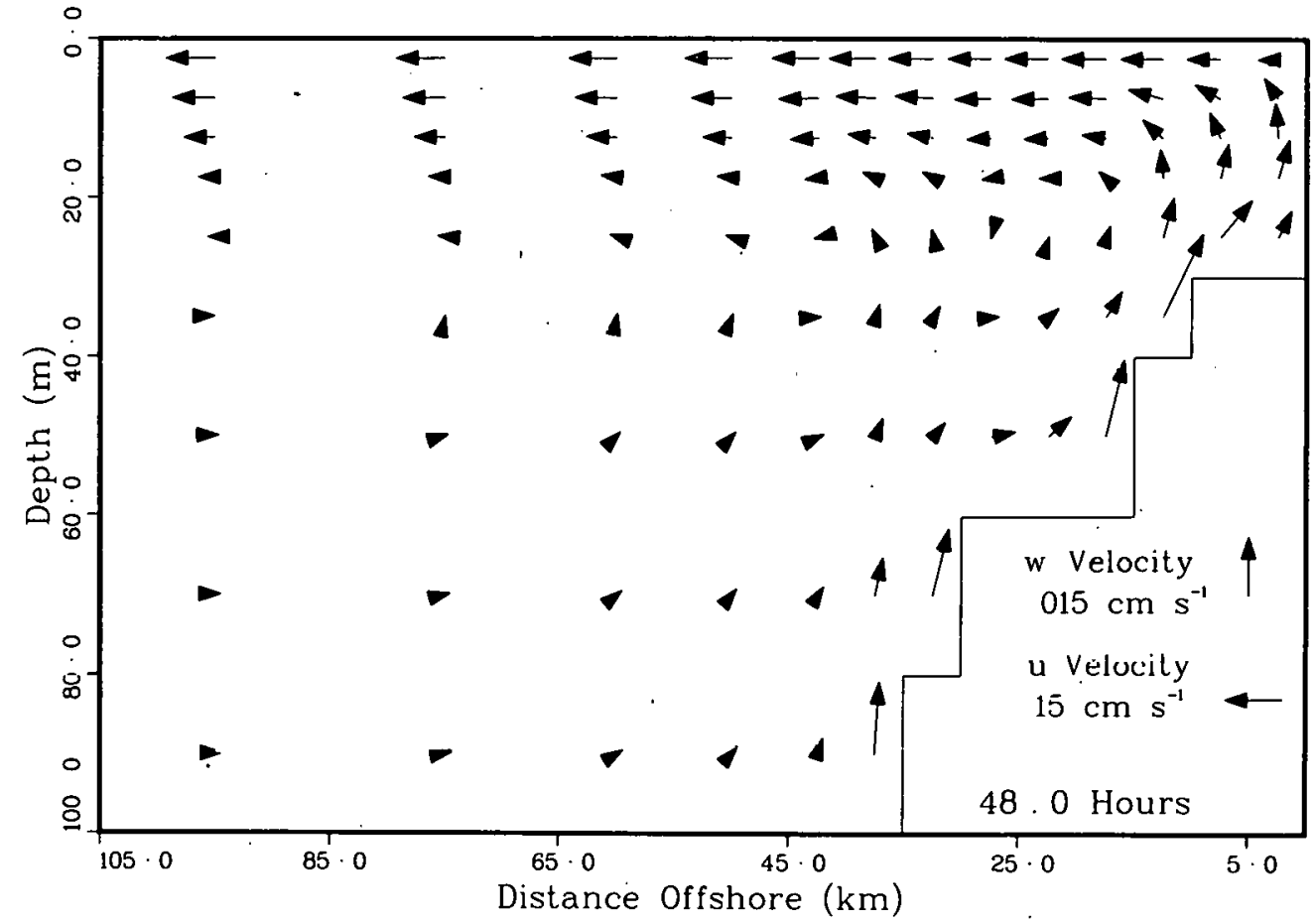

Figure 20. Resultant current velocity vectors plotted from horizontal and vertical currents in the circulation submodel after 2 days simulation time. 


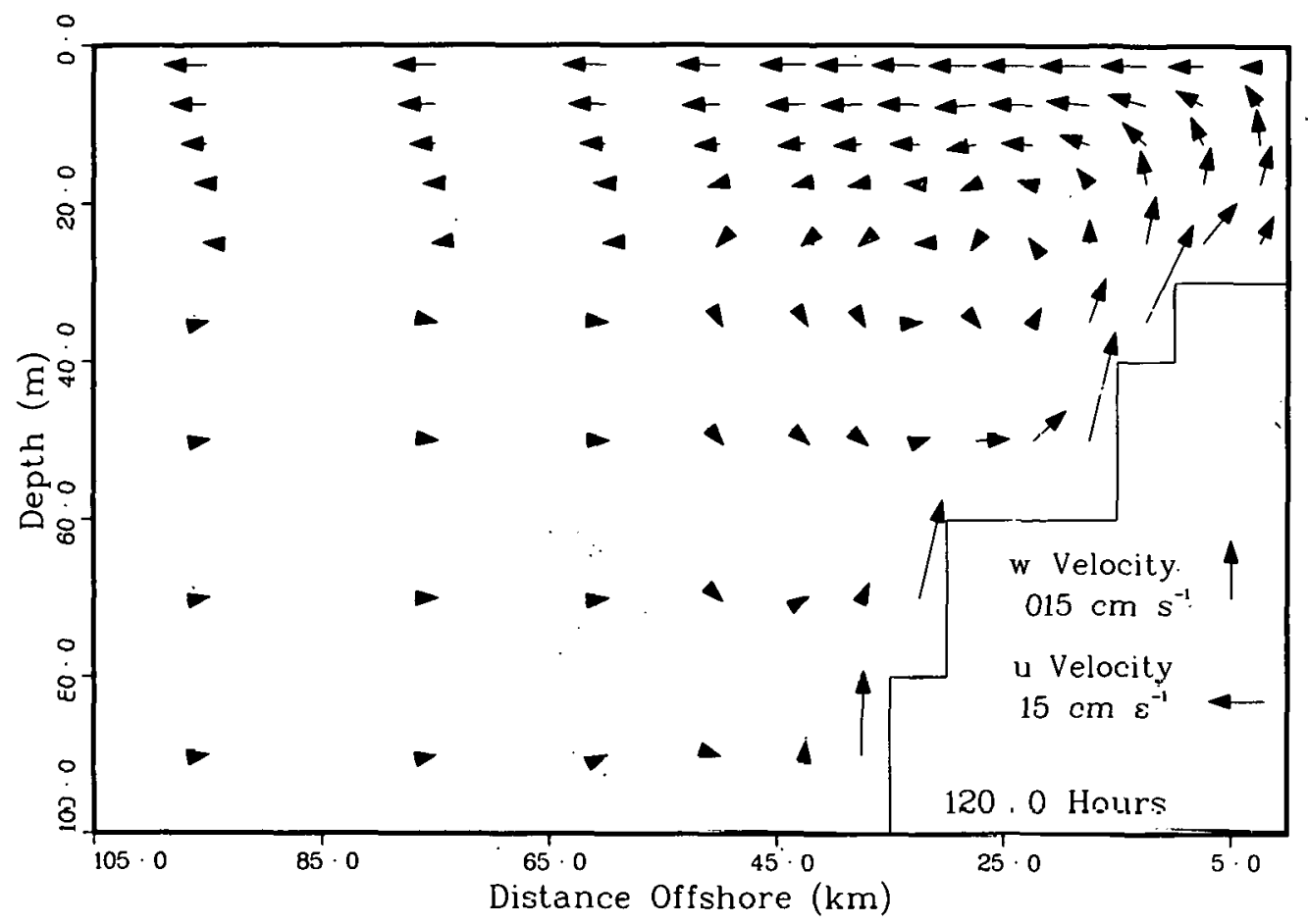

Figure 21. Kesultant current velocity vectors plotted from horizontal. and vertical currents in the circulation submodel after 5 days simulation time.

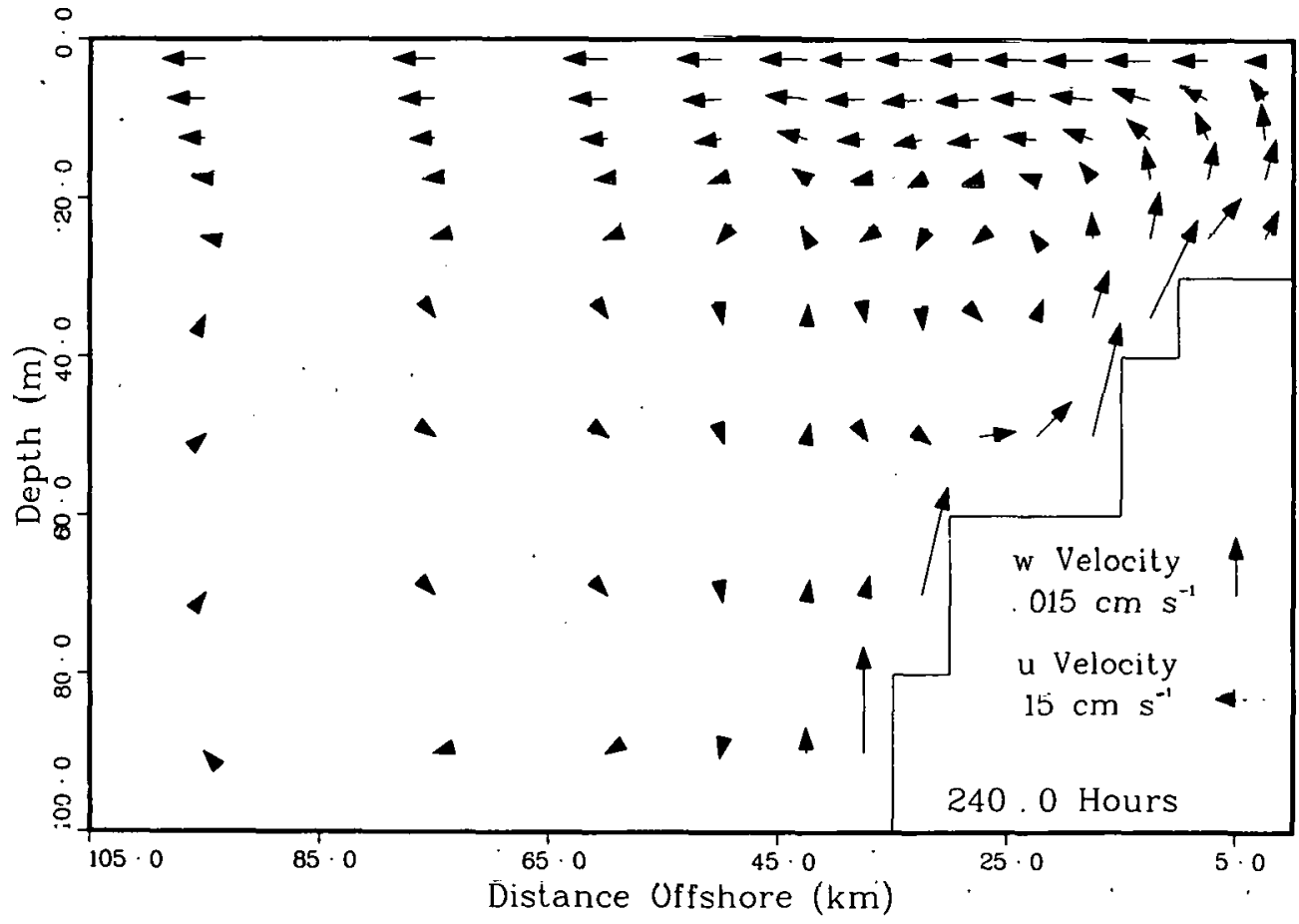

Figure 22. Resultant current velocity vectors plotted from horizontal and vertical currents calculated in the circulation submodel after 10 days simulation time. 
(a)

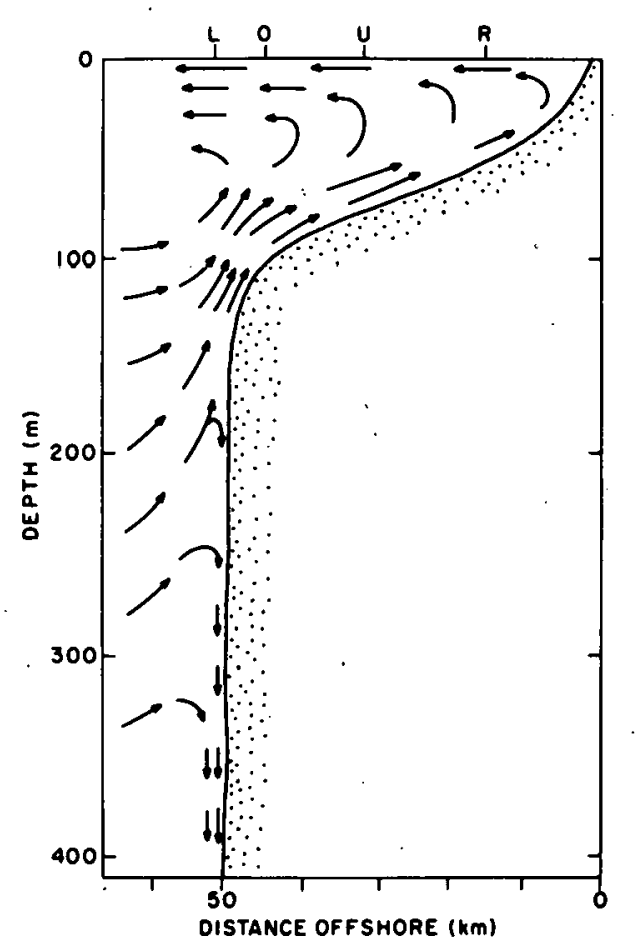

Figure 23(a) (b)

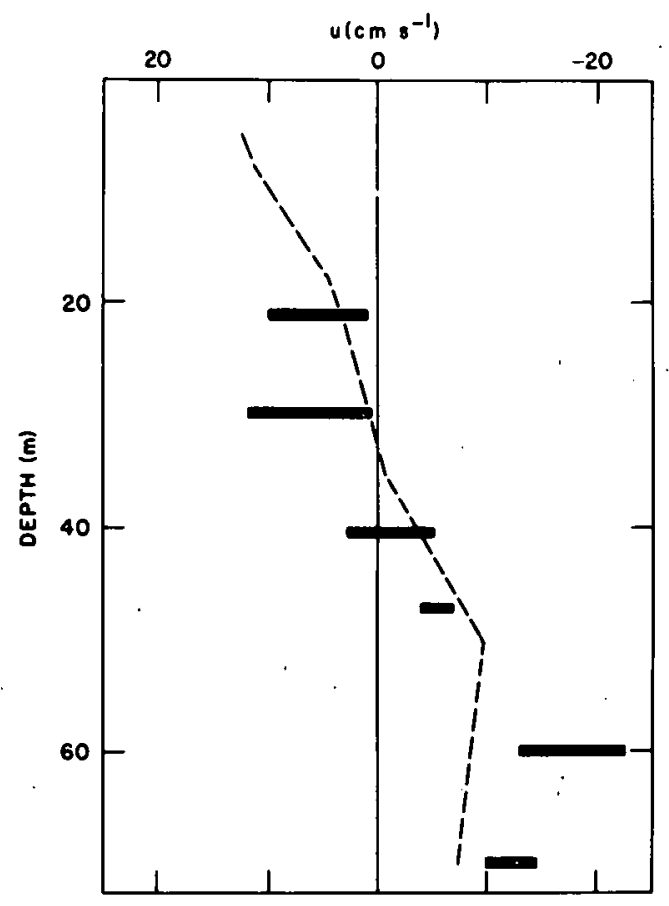

Figure 23(b)

Figure 23

A schematic diagram showing the mean cross shelf flow during active upwelling in the JOINT-I study area. From Mittelstaedt, et al. (1975). . The letters at the top of the illustration show the location of current meter moorings identified in Figure 18. A comparison of simulated and observed onshore-offshore flows. The dashed line is the $u$ component of the velocity profile generated by the upwelling circulation submodel after 10 days simulation time $30 \mathrm{~km}$ offshore. The horizontal bars show the ranges of 24.8 hour mean values of the $u$ component during periods of well developed upwelling circulation obtained from current meter measurements $32 \mathrm{~km}$ offshore. The current meter observations are based on Figure 10 in Mittelstaedt, et al. (1975). 
et al. (1975). The mean simulated offshore flow over the shelf reaches $10.5 \mathrm{~cm} \mathrm{~s}^{-1}$ in the upper $10 \mathrm{~m}$ and is approximately equal to the observed maximum which averaged $10 \mathrm{~cm} \mathrm{~s}^{-1}$. In Figure $23 \mathrm{~b}$, a comparison is made of current meter measurements $32 \mathrm{~km}$ from the coast with the $u$ velocity profile at $x=30 \mathrm{~km}$ in the physical submodel. The comparison shows the computed velocities occur within or near the ranges of measured i velocities. The zero crossing for both measured and computed velocities is at about 30 to $40 \mathrm{~m}$. Although some discrepancies exist in this comparison and in other comparisons discussed by Hamititon and Kattray (1978) the Aegree of similarity supports the couclusivu that the physical submodel provides for the ecosystem model a useful representation of an upwelling circulation which is similar in many respects to the circulation measured during JOINT-I.

One unusual. feature of the upwelling circulation observed during JOINT-I, not reproduced in the physical submodel, was the occurrence of a northward flowing surface current at the offshore boundary of the upwelling regime (Mittclotacdt et al. 1975). Its position varied between approximately 100 to $40 \mathrm{~km}$ offshore with changes in the strength and direction of the winds. During occasional intervals of weak winds unfavorable to upwelling, the offshore transport diminished and the northward surface current moved shoreward. 'l'he northward surface current may arise from far field regional influences rather than the local wind forcing (Mittelstaedt et al. 1975) so it should not be an expected feature in the physical submodel. The physical submodel, 
therefore, most plausibly describes the spin up or development of active upwelling with the northward surface current in an of fshore position. Future simulation studies designed to reproduce all of the actual sequence of 1974 upwelling events discussed by Barton et al. (1977) will have to consider the variability in the position of this offshore boundary current, or be spatially confined to the shelf region.

Turbulent mixing processes are parameterized in the eddy coefficients $K_{x}$ and $K_{z}$ in [3.1] and are specified, as constants in space and time. A horizontal mixing coefficient, $K_{x}$, of $1.2 \times 10^{6} \mathrm{~cm}^{2} \mathrm{~s}^{-1}$ is assumed in all simulation cases. The vertical mixing coefficient, $\mathrm{K}_{z}$, was usually $1 \mathrm{~cm}^{2} \mathrm{~s}^{-1}$, and thus equivalent to the values used in previous models of other upwelling systems (Walsh 1975; Wroblewski 1977). In one case $K_{z}$ was increased to $40 \mathrm{~cm}^{2} \mathrm{~s}^{-1}$ to investigate the effect of strong mixing. Preliminary test cases showed that the $K_{z}$ value used in this strong mixing case is near the upper limit allowing a stable solution given the time and space differencing conventions of the model. Results from other preliminary cases, run with intermediately valued vertical mixing coefficients, were qualitatively similar so only the extreme cases of 1 and $40 \mathrm{~cm}^{2} \mathrm{~s}^{-1}$ are presented here. A $\mathrm{K}_{\mathrm{z}}$ value of $125 \mathrm{~cm}^{2} \mathrm{~s}^{-1}$ has been reported for the upper mixed layer by Halpern (1977), but values this high could be accommodated in the model only afler extensive changes to the space differencing or velocity data otoragc and retrieval scliemes used in the model. Use of the higher and perhaps more realistic eddy coefficients for the mixed layer would also 
require that values for eddy coefficients in the less turbulent areas also be defined. The data are not available to support such a differentiation and a maximum useable value of $40 \mathrm{~cm}^{2} \mathrm{~s}^{-1}$ value is therefore assumed throughout the simulated space.

3.1b Biological Interactions. The nonconservative terms of the state equations are defined below. Equations [3.2] to [3.9] are the phytoplankton-nutrient state equations with the effects of grazing, physiological mortality or nutrient regeneration included. Equations [3.10] to [3.18] supplement the phytoplankton growth equations and define phytoplankton quotas and uptake or synthesis rates. Grazing rates of the zooplankton are defined in [3.19-3.20], and [3.21-3.22] define grazing rates of the fish. The symbol conventions are the same as those used in the phytoplankton growth model. All symbols are defined as a group in Appendix IV and are individually discussed in the rationale following the equations.

$$
\begin{array}{ll}
\mathrm{R}(\text { Silcate }) & =-\mathrm{V}_{1} \mathrm{P}_{1}+\mathrm{r}_{1} \\
\mathrm{R}(\text { Nitrate }) & =-\mathrm{V}_{2} \mathrm{P}_{4}+\mathrm{r}_{2} \\
\mathrm{R}(\text { Ammonium }) & =\mathrm{P}_{4}\left(-\mathrm{V}_{3}+\beta_{3} Z+\gamma_{3} \mathrm{~F}\right)+\mathrm{r}_{3} \\
\mathrm{R}\left(\begin{array}{c}
\text { Phytoplankton }) \\
\text { Silica }
\end{array}\right. & =\mathrm{P}_{1}\left(\mathrm{~V}_{1}-\mathrm{Z}-\mathrm{F}-\mathrm{m}\right) \\
\mathrm{R}\left(\begin{array}{c}
\text { Phytoplankton } \\
\text { Nitrogen }
\end{array}\right) & =\mathrm{P}_{4}\left(\mathrm{~V}_{4}-\mathrm{Z}-\mathrm{F}-\mathrm{m}\right)
\end{array}
$$




$$
\begin{aligned}
& { }^{\mathrm{R}}\left(\begin{array}{l}
\text { Phytoplankton } \\
\text { Carbon }
\end{array}\right)=\mathrm{P}_{5}\left(\mathrm{~V}_{5}-\mathrm{Z}-\mathrm{F}-\mathrm{m}\right) \\
& \text { R/ } \left.\begin{array}{l}
\text { Phytoplankton } \\
\text { Chlorophyll }
\end{array}\right)=\mathrm{P}_{6}\left(\mathrm{~V}_{6}-\mathrm{Z}-\mathrm{F}-\mathrm{m}\right) \\
& { }^{\mathrm{R}}\left(\begin{array}{l}
\text { Phytoplankton } \\
\text { Cell Numbers }
\end{array}\right)=\mathrm{N}(\mathrm{G}-\mathrm{Z}-\mathrm{F}-\mathrm{m}) \\
& c_{n}=P_{n} / N \quad \text { for } n=1,4,5,6 \\
& \begin{aligned}
G & =0 \quad \text { if } C_{n} \leq d_{n} \\
& =\text { minimum of }[g(c-d) / C \text { for } n=1,4,5
\end{aligned} \\
& v_{1}=v_{1}\left(s_{1} /\left(k_{1}+s_{1}\right)\right) \quad \text { if } c_{1}<c_{1} \text { and } v_{1}<G \\
& =0 \quad \text { otherwise } \\
& v_{2}=v_{2}^{\prime}\left(s_{2} /\left(k_{2}+s_{2}\right)\right) \quad \text { if } c_{4}<c_{4} \text { and } v_{4}<G \\
& =0 \quad \text { otherwise } \\
& v_{2}^{\prime}=v_{2}-a_{3} \cdot s_{3} \\
& v_{3}=v_{3}\left(s_{2} /\left(k_{3}+s_{3}\right)\right) \quad \text { if } c_{4}<c_{4} \text { and } v_{4}<G \\
& \mathrm{v}_{4}=\mathrm{v}_{2}+\mathrm{v}_{3} \\
& \mathrm{v}_{5}=\left(\left(\mathrm{Q}_{\max } \cdot \mathrm{I}_{\max } \cdot \mathrm{K}_{\mathrm{c}} \cdot \mathrm{C}_{6}\right) \cdot\right. \\
& \left.\left(\exp \left[-I_{z} / I_{\max }\right]-\exp \left[-I_{0} / I_{\max }\right]\right) /\left(K_{t} \cdot z\right)\right) \\
& -\left(f_{5}+b_{5} \cdot G\right) \text { if } C_{5}<c_{5} \text { and } V_{5}<G \\
& =0 \\
& \text { olherwlse }
\end{aligned}
$$




$$
\begin{aligned}
P_{6} V_{6} & =e_{6} \cdot V_{4} \\
& =P_{6}\left(g\left(c_{4}-d_{4}\right) / C_{4}\right) \\
& =0
\end{aligned}
$$$$
z=\left(q_{5} L_{5}+\lambda j_{5} L_{5}\right) / P_{5}
$$$$
L_{5}=\psi P_{5}+\varepsilon
$$$$
F=\left(w_{5} \cdot M_{5}\right) / P_{5}
$$$$
M_{5}=\theta \cdot P_{5}+\tau
$$

$$
\begin{aligned}
& \text { if } n=4 \text { is minimum in [3.11] } \\
& \text { if } n=1 \text { or } n=5 \text { is minimum in [3.11] } \\
& \text { if } \mathrm{c}_{6} \geq \mathrm{c}_{6} \text { and } \mathrm{v}_{6} \geq \mathrm{G}
\end{aligned}
$$

\subsection{Rationale}

3.2a Incident Solar Radiation and Submarine Light Attenuation.

Estimates of incident solar radiation are calculated with the submodel used in the phytoplankton growth model. Simulated clear-day solar radiation totaling $6651 \mathrm{y} \mathrm{d}^{-1}$, occurring over a 12.4 hour light day, on 9 April, the approximate midpoint of the JOINT-I expedition, is assumed to be representative of the cruise period. The incident radiation measured ahoard the ATLANTIS II averaged $610 \mathrm{ly}^{-1}$ (Barber and Huntsman 1975). The $9 \%$ difference between observed and simulated values can be attributed to occasional cloudiness and shading of the pyranometer by the mast of the ship. Simulated subsurface photosynthetically active radiation totals $310 \mathrm{ly}^{-1}$ (approximately 59.6 einst $\mathrm{m}^{-2} \mathrm{~d}^{-1}$ ) and is $47 \%$ of the subsurface cotal.

Light penetrating the sea surface is attenuaced by seawater, phytoplankton chlorophyl1, and ocher substalices. Equation [2.?7] expressing the total attenuation as the sum of three partial extinction coefficients is rewritten here

$$
K_{t}=K_{w}+K_{c} \cdot P_{6}+K_{d} \cdot X
$$


The extinction coefficient of seawater, $\mathrm{K}_{\mathrm{w}}=0.04 \mathrm{~m}^{-1}$ is known (Lorenzen 1972), and the attenuation due to chlorophyll $\mathrm{K}_{\mathrm{c}} \bullet \mathrm{P}_{6} \mathrm{can}$ be approximated if $\mathrm{K}_{\mathrm{c}}=0.016 \mathrm{~m}^{2}(\mathrm{mg} \mathrm{Chl} \mathrm{a})^{-1}$ (Bannister 1974) and the chlorophyll concentration, $\mathrm{P}_{6}$, is known. The attenuation due to other substances, $K_{d} \cdot X$, may be significant (Lorenzen 1972) and must be explicitly defined in the model.

Estimates of $\mathrm{K}_{\mathrm{d}} \bullet \mathrm{X}$ for the model have been obtained from measurements of light attenuation and chlorophyll made on the ATLANTIS II. Three of the four terms of the equation for total attenuation are known and the fourth, $\mathrm{K}_{\mathrm{d}} \bullet \mathrm{X}$ is calculated by difference. Horizontally constant mean values of $K_{d} \bullet X$ for the cruise period (Table 2) are used in the ecosystems model except in the nearshore $5 \mathrm{~km}$ region. where attenuation is high and $K_{d} \cdot X$ equals $0.73 \mathrm{~m}^{-1}$ and $0.35 \mathrm{~m}^{-1}$ for the $0-5 \mathrm{~m}$ and 5-10 m depth intervals, respectively. The high turbidity of the nearshore region caused by high levels of resuspended mineralized particles may be a permanent feature of this upwelling region, even when upwelling occurs over the inner shelf (A. Morel, personal communication). 3.2b Phytoplankton. A preliminary analysis of the phytoplankton samples taken during JOINT-I indicates that the phytoplankton community was composed mainly of diatoms and coccolithophorids. Thalassiosira, Chaetoceros, Dactyliosolen, Leptocylindrus, Nitzschia and Rhizosolenia species were the domiant diatoms, and Coccolithus, Syracosphaera and Pontosphaera species were the dominant coccolithophorids (T. Cowles, D. Blasco, personal communication). Although the coccolithophorids were sometimes numerically abundant, phytoplankton rate measurements 
Table 2. The vertical distribution of the mean partial extinction coeffirient, $K_{d} X$, aterlbucable lu subslances other than caswater dind chlorophyl1. Values listed are averages calculated trom JüNT-I chlorophyll and submarine light measurements made along the transect ac $21^{\circ} 40^{\prime} \mathrm{N}$. Measurements made within $5 \mathrm{~km}$ nf the coast are not included in these averages.

$\begin{array}{cc}\text { Depth Interval } & \kappa_{\mathrm{d}} \mathrm{X} \\ (\mathrm{m}) & \left(\mathrm{m}^{-1}\right) \\ 0-5 & 0.21 \\ 5-10 & 0.13 \\ 10 \cdots 15 & 0.11 \\ >15 & 0.08\end{array}$


made during JOINT-I did not differentiate between diatoms and coccolithophorids. On the basis of literature data (mainly for Coccolithus and Syracosphaera $(=\underline{\text { Cricosphaera }}=\underline{\text { Hymenomonas }}$ species $)$, diatoms are typically larger (Strathman 1967) and have higher maximum growth rates. (Eppley, et al. 1969b; Eppley 1970) and may therefore be the more trophodynamically important of the two phytoplankton groups found during JOINT-I. Because of the significance of diatoms in other upwelling regions and because the physiological rates and higher trophic level interactions of the diatoms and coccolithophorids were not differentiated in the JOINT-I data, only diatoms are represented in the model equations.

The phytoplankton growth and uptake functions used in the northwest African ecosystem model are, with minor changes, the same as those in the previously discussed phytoplankton growth model. Results from preliminary simulations run with some specific sequences of growth limiting conditions not represented in the batch culture experiment showed that the phytoplankton growth equations could yield unrealistically high C/N ratios approaching 100. Banse's (1974) interpretation of available data on the carbon to nitrogen ration in phytoplankton suggests, however, that a maximum $\mathrm{C} / \mathrm{N}$ of 17.5 is more realistic, and this value is used as a limiting condition in the ecosystems model. In the equations this condition is included in a redefinition of $c_{5}$, the minimum carboñ quota, as

$$
c_{5}=\operatorname{minimum} \text { of }\left(c_{5}, 17.5 \cdot c_{4}\right)
$$


where

$c_{4}$ is the phytoplankton nitrogen quota.

Another change is the addition to the phytoplankton:growth equations of a term for physiological death. This form of natural mortality may be potentially significant in the aphotic zone (Lehman et al. 1975), but actual rates are not well known. The death rate, $m=$ $0.0042 \mathrm{hr}^{-1}$ used by Wroblewski (1976) is also used in this model whenever the cell division rate is less than $0.0001 \mathrm{hr}^{-1}$. The deach rate is otherwise assumed to be zero.

A final difference herwent llie lwo sets of phytoplankton equations is related to the need to segment space in the ecosystem model. Photosynthetic fixation of carbon is calculated in the second model using the same function [2.30] as in the phytoplankton growth model For convenience, the function is rewritten here as

$$
\begin{aligned}
P(z)= & \left(Q_{\max } I_{\max } K_{c} P_{6}\right) \cdot \\
& \left(\exp \left[-I_{z} / I_{\max }\right]-\exp \left[-I_{0} / I_{\max }\right]\right) /\left(K_{t} z\right) \quad[2.30]
\end{aligned}
$$

For each spatial segment of the system model, $I_{0}$ and $I_{Z}$, the photosynthetically active light available at the top and bottom, respectively, of each segment, must be defined before a photosynthesis rate is calculated. In the first layer, $I_{0}$ is the light penetrating the sea surface. For each spatial segment in the surface layer lhe light, $I_{z}$, at the bottom boundary of each seyment is caleulated ac

$$
I_{z}=I_{0} \exp \left[-\left(K_{w}+K_{c} P_{6}+K_{d} X\right) z\right]
$$


where

$K_{w}, K_{c}$, and $K_{d} X$ are the partial extinction coefficients

previous $1 \mathrm{y}$ discussed;

$\mathrm{P}_{6}$ is the chlorophyll concentration in each spatial segment;

$z$ is the thickness ( $m$ ) of the depth interval.

$I_{z}$ may be different in each spatial segment depending on the chlorophyll concentration and the attenuation of light attributable to other substances. $I_{z}$ values for the bottom boundary of each segment are stored temporarily during the calculation procedure. The model calculations are done layer by layer, beginning at the surface, so the $I_{z}$ values stored as bottom boundary values for the segments in the first layer become the upper boundary, $I_{0}$, values for the segments immediately beneath. This procedure is repeated for each layer until the bottom layer is reached during each iteration. If coefficients of light attenuation vary horizontally the light profile of each vertically segmented column is unique and the calculations of light intensity must therefore begin at the surface. If calculations were to begin at the bottom layer, as in the AUGUR simulation program (Morishima et a1. 1974), light intensities in the subsurface layers can not be correctly calculated because the integrated attenuation due to chlorophyll and other substances in the space above cannot be considered.

3.2c Zooplankton. Blackburn (1975a) has described in some detail the JOINT-I zooplankton sampling procedures. In summary, vertical net hauls were made from $200 \mathrm{~m}$ or the bottom, whichever was less, to the 
sea surface with a pair of nonclosing Bongo plankton nets. The net mouth diameter was $60 \mathrm{~cm}$ and the mesh size was $102 \mu$. Samples obtained with the nets were combined and filtered through a series of sieves to yield subsamples of zooplankton in four size ranges of approximately $100-200,200-500,500-1000$, and $>1000 \mu$. One quarter of each subsample was weighed wet, oven dried at $60^{\circ} \mathrm{C}$ for 24 hours or longer and then weighed dry. Portions of the dry weight sample were reweighed and then incinerated in a muffle furnace for 24 hours or longer before weighing the ash residue and by difference obtaining the weight of dry organic matter.

Many of the zooplankton samples were contaminated with phytoplankton. Estimates of phytoplankton contamination in the zooplankton net tows are based on fluorometric measurements of chlorophyll extracted from $0.5 \mathrm{ml}$ subsamples of each tow. The weight of chlorophyll in each subsample was converted to an equivalent weight of carbon, assuming a carbon:chlorophyl1 ratio of 40.5:1 (Lorenzen 1968) and then to an equivalent weight of dry organic matter, assuming that carbon represents $43 \%$ of the dry organic matter of phytoplankton (Cushing et al. 1958).

A comparison of the weights of phytoplankton and zooplankton dry organic matter (Tables $3 a$ and $3 b$ ) shows that the phytoplankton were a variable and sometimes significant source of contamination in the zooplankton organic matter in the $100-500$ and $500 \mu$ size fractions. For the 100-500 $\mu$ fraction it averaged $7 \%$ of the zooplankton organic matter weight. 
Table 3a. Organic weight of zooplankton collected during JOINT-I over the continental shelf. Weights listed are corrected for contamination by phytoplankton. Phytoplankton contamination in each tow is expressed as a ratio of estimated phytoplankton and zooplankton organic matter weights $\times 100$ :

Tow No. Small Size Fraction $(100-500 \mu)$ Weight (mg $\mathrm{m}^{-2}$ )
Percent Phy toplankton Contamination

$$
\begin{gathered}
\text { Large Size } \\
\text { Fraction } \\
(>500 \mu) \\
\text { Weight } \\
\text { (mg } \mathrm{m}^{-2} \text { ) }
\end{gathered}
$$

Percent

Phy top lankton

Contamination

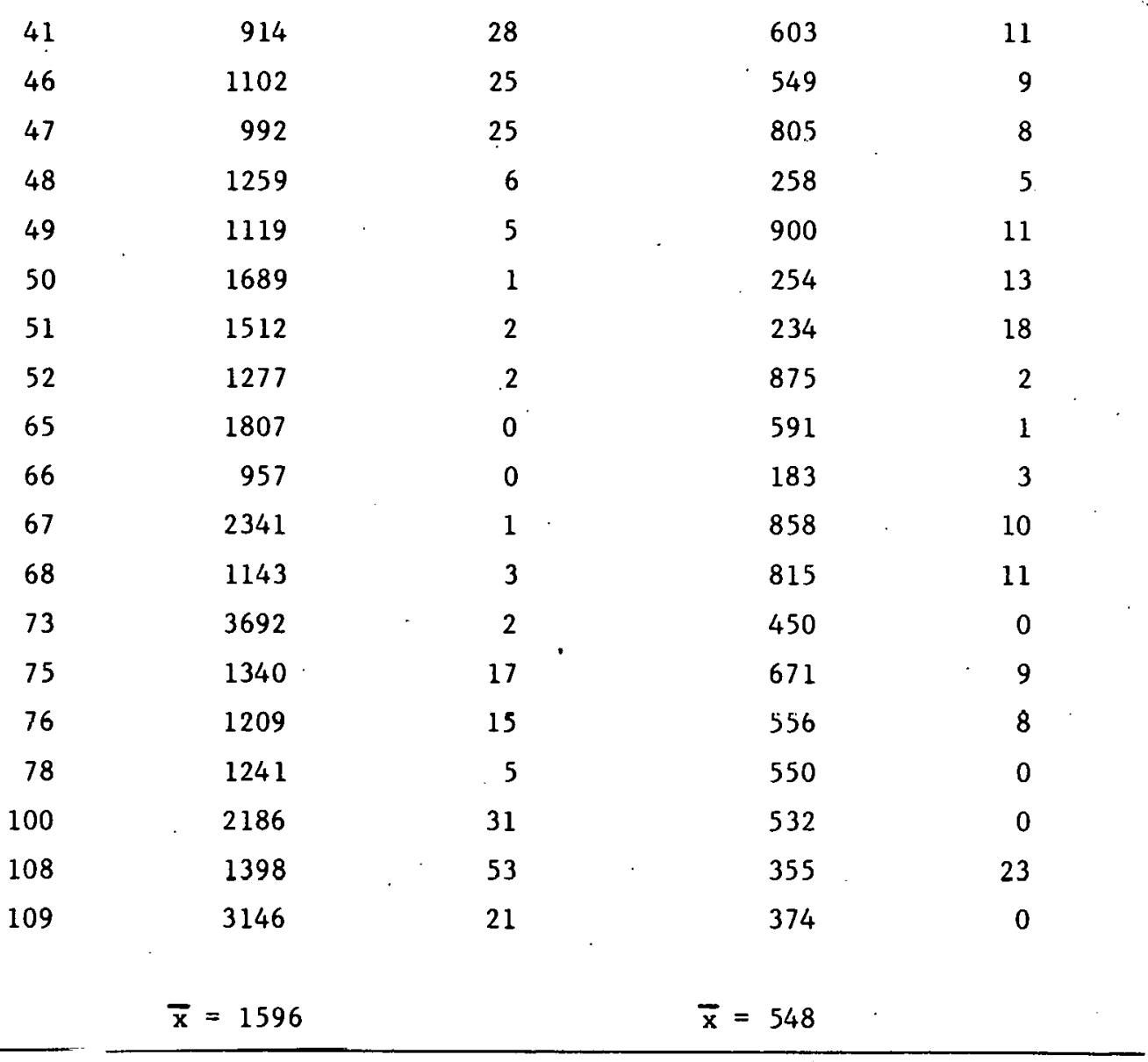


Table 3b. Organic weight of zooplankton collected seaward of the shelf break. Weights listed are corrected for contamination by phytoplankton. Phytoplankton contamination in each tow is expressed as a raliu of estimated phytoplankton to zmplankton nrganic matteg weights $x 100$.

\begin{tabular}{|c|c|c|c|c|}
\hline Tow No. & $\begin{array}{c}\text { Small size } \\
\text { Fraction } \\
(100-500 \mu) \\
\text { Weight } \\
\left(\mathrm{mg} \cdot \mathrm{m}^{-2}\right)\end{array}$ & $\begin{array}{c}\text { Petceul - } \\
\text { Phytoplankton } \\
\text { Contamination }\end{array}$ & $\begin{array}{c}\text { Large } 8 \text { iøo } \\
\text { Fraction } \\
(>500 \mu) \\
\text { Weight } \\
\left(\mathrm{mg} \cdot \mathrm{m}^{-2}\right)\end{array}$ & $\begin{array}{l}\text { Porcont } \\
\text { Phytoplankton } \\
\text { Contamination }\end{array}$ \\
\hline 44 & 1658 & 11 & 5842 & 1 \\
\hline 45 & 846 & 33 & 638 & 29 \\
\hline 54 & 923 & 0 & 3967 & 0 \\
\hline 87 & 785 & 15 & 1307 & 8 \\
\hline 101 & 1010 & 6 & 1152 & 1 \\
\hline 102 & 534 & 3 & 1820 & 1 \\
\hline & $\bar{x}=959$ & & $\bar{x}=2455$ & \\
\hline
\end{tabular}


Analyses of variance made by Blackburn.(1975a) on the CUEA wetweight zooplankton data to investigate differences in biomass by time. period, area (shelf vs. slope) and size of the zooplankton showed that smaller zooplankton were more abundant on the shelf and larger zooplankton were more abundant on the slope. The analysis also found no evidence of changes in total zooplankton abundance with time during the two-month sampling period. It is assumed that these conclusions apply to distributions of zooplankton dry organic matter expressed on a per volume bas is as well.

The zooplankton weights have been converted to zooplankton concentrations by dividing the organic weights by the volume of water filtered by the nets. Mean zooplankton organic-weight concentrations have been converted to zooplankton carbon concentrations, assuming that carbon is $50 \%$ of the organic or ash-free weiught of the zooplankton (Mullin 1969). On the shelf, mean values of $12.5 \mathrm{mg} \mathrm{C} \mathrm{m}^{-3}$ and $3.8 \mathrm{mg}$ $\mathrm{C} \mathrm{m}^{-3}$ are obtained for the 100-500 $\mu$ and $>500 \mu$ size fractions, respectively. Offshore, the net tows extended beneath the depth range of the model, but all zooplankton biomass is included within the two size classes of zooplankton as if it inhabited the upper 100 meters only. Accordingly, in the offshore region, the 100-500 $\mu$ fraction averaged $4.9 \mathrm{mg} \mathrm{C} \mathrm{m} \mathrm{m}^{-3}$ and the $>500 \mu$ size fraction averaged $12.4 \mathrm{mg} \mathrm{C}$ $m^{-3}$

The trophic relationships among the zooplankton are not well defined in the available data. Collections made off northweet $\Lambda$ frica prior to JOINT-I (H. Weikert, personal communication) showed copepods 
to be most abundant with Calanidae, Eucalanidae, Metridiidae and Temoridae the most ecologically important types. Samples taken during JOINT-I contained mainly copepods and euphausids, which may eat both phytoplankton and zooplankton (Blackburn 1975c). It is assumed in the model, however, that both size classes of zooplankton are phytophagous. The feeding rate of the large zooplankton is described by the following recilinear ingestion function proposed by Mullin, et al. (1975) based on the data of Frost (1972) for the feeding of Calanus on Thalassiosira Eluviata11s:

$$
\mathrm{L}_{5}^{\prime}=\psi^{\prime} \mathrm{N}+\varepsilon^{\prime}
$$

where

$$
\begin{aligned}
& \left.\mathrm{L}_{5}{ }^{\prime}=\text { ingestion rate per animal (cells } \operatorname{copepod}^{-1} \cdot \mathrm{hr}^{-1}\right) \text {; } \\
& N \quad=\text { food cell concentration }\left(10^{6} \operatorname{ce} 11 \mathrm{~s} \cdot 1^{-1}\right) \text {; } \\
& \psi^{\prime}=\text { a filtering constant }\left(1^{-1} \cdot \operatorname{copepod}^{-1} \cdot \mathrm{hr} \mathrm{r}^{-1}\right) \text {, } \\
& \text { if } \mathrm{N}<3.3 \times 10^{6} \text { cells } \cdot \mathrm{I}^{-1} \psi^{\prime}=4.07 \times 10^{-3} \mathrm{I}^{-1} \cdot \operatorname{copepod}^{\circ} \mathrm{hr}^{-1} \text {, }
\end{aligned}
$$

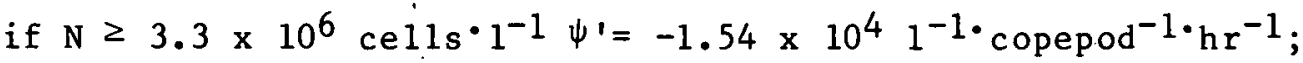

$$
\begin{aligned}
& \varepsilon^{\prime}=\text { a constant, } \\
& \text { if } \mathrm{N}<3.3 \times 10^{6} \mathrm{cells} \cdot \mathrm{I}^{-1} \varepsilon^{\prime}=622 \mathrm{cells} \cdot \mathrm{copepod}^{-1} \cdot \mathrm{hr} \mathrm{r}^{-1} \\
& \text { if } N \geq 3.3 \times 10^{6} \mathrm{ce} 11 \mathrm{~s} \cdot 1^{-1} \varepsilon^{\prime}=1.31 \times 10^{4} \mathrm{cells} \cdot \operatorname{copepod}^{-1} \cdot \mathrm{hr}^{-1}
\end{aligned}
$$

This equation can be generalized by expressing copepod individuals as copépod carbon (14.7 $\mu \mathrm{g}$ at $\mathrm{C}$ individual ${ }^{-1}$, Frost 1972) and cell concentration as carbon concentration $\left(7.83 \times 10^{6} \mu \mathrm{g}\right.$ at $\mathrm{C}$ cel1 $11^{-1}$, Frost 1972). Carbon specific ingestion may then be written as

$$
\mathrm{L}_{5}=\psi \mathrm{P}_{5}+\varepsilon
$$


where

$\mathrm{L}_{5}=$ carbon specific ingestion rate of large zooplankton

( $\mu \mathrm{g}$ at phytoplankton carbon ( $\mu \mathrm{g}$ at zooplankton carbon) ${ }^{-1} \mathrm{hr}^{-1}$ );

$\psi=$ a filtering constant $\left(1 \cdot(\mu \mathrm{g} \text { at zooplankton carbon })^{-1} \mathrm{hr}^{-1}\right)$, if $\mathrm{P}_{5}<25.85 \mathrm{\mu g}$ at $\mathrm{C} \cdot 1^{-1}, \psi=72 \times 10^{-5}$,

if $\mathrm{P}_{5} \geq 25.85 \mu \mathrm{g}$ at $\mathrm{C} \cdot 1^{-1}, \psi=-27.12 \times 10^{-6}$,

if $P_{5}<1.2 \mu g$ at $C \cdot 1^{-1}$, the grazing threshold, $\psi=0$;

$\varepsilon=$ a constant $\left(\mathrm{hr}^{-1}\right)$,

if $\mathrm{P}_{5}<25.85 \mathrm{\mu g}$ at $\mathrm{C} \cdot 1^{-1}, \varepsilon=8.6 \times 10^{-4} \mathrm{hr}^{-1}$,

if $\mathrm{P}_{5} \geq 25.85 \mu \mathrm{g}$ at $\mathrm{C} \cdot 1^{-1}, \varepsilon=1.8 \times 10^{-2} \mathrm{hr}^{-1}$,

if $\mathrm{P}_{5}<1.2 \mu \mathrm{g}$ at $\mathrm{C}^{\circ} 1^{-1}$, the grazing threshold, $\varepsilon=0$.

This expression is used in the model as the phytoplankton carbon ingestion function for the large zooplankton ( $>500 \mu \mathrm{m}$ ) with carbon concentration, $\mathrm{q}_{5}$ - It yields a maximum biomass-specific ingestion rate of $0.42 \mathrm{~d}^{-1}$ and probably underestimates the ingestion rates of the smaller zooplankton which have higher specific metabolic rates.

Many studies have shown metabolic rates of organisms to be power functions of body weight. Ikeda (1974) showed for zooplankton found in an $11.7-17.5^{\circ} \mathrm{C}$ temperature regime, similar in range to an upwelling habitat, that

$\log \gamma=0.756 \log \omega+0.127$

where

$$
\begin{aligned}
& \gamma=\text { respiration ratc }\left(\mu 10_{2} \text { animal-1 } \mathrm{hr}^{-1}\right) \text {; } \\
& \dot{\omega}=\text { body dry weight (mg animal-1). }
\end{aligned}
$$


If the mean dry weights per individual of the 100-500 $\mu$ and $>500 \mu$ size fractions are $0.00254 \mathrm{mg}$ and $0.304 \mathrm{mg}$, respectively (Smith and Whitledge 1977 ), the weight specific respiration rate for the smaller zooplankton may be a factor $\lambda=3.22$ times greater than the rate for the larger zooplankton. Assuming equivalent assimilation efficiencies, and saturating food concentrations, the weight specific ingestion rate of the smaller zooplankton is $\lambda=3.22$ times greater than the ingestion rate of the larger zooplankton and results in a maximum biomass specific ingestion rate of $1.34 \mathrm{~d}^{-1}$. In other words, the small zooplankton may ingest as much as $134 \%$ of their biomass per day. The fraction, $Z$, of the phytoplankton standing stock consumed by the large and small zooplankton combined can then be defined as

$$
z=\left(q_{5} L_{5}+\lambda j_{5} L_{5}\right) / P_{5}
$$

The products $Z P_{1},{Z P_{4}}_{4}, Z_{5}, Z_{6}, Z N$ express the losses due to zooplankton grazing of phytoplankton silica, nitrogen, carbon, chlorophyll and cell numbers, respectively.

Some fraction of the nutrients contained in the phytoplankton biomass consumed by herbivorous zooplankton and fish is excreted and returned to the environment as inorganic regenerated nutrient. This regenerative process has been identified as an important source of nutrients in both oligotrophic (Dugdale and Goering 196/; Éppley, et al. 1973) and eutrophic (Whitledge 1972) regions of the vceans. Ammonium is commonly observed to be the most important form of regenerated nitrogen. Urea is also excreted, but average molar ratios of urea to ammonium excretion commonly range belween $1: 5$ and $1: 7$, although 
Eppley, et a1. (1973) do report a ratio of $1: 2$. Both urea and ammonium can be assimilated by phytoplankton (McCarthy 1972) so neglecting urea excretion underestimates somewhat the potential effects of regeneration in sustaining primary production. Nitrogen is excreted in other forms as well, but these appear to be relatively minor sources ( $T$. Whitledge, personal communication). The contributions to the regenerated nitrogen pool by urea and other nitrogen species are probably of second order importance and will not be included in this model.

Although some zooplankton regeneration measurements were made during JOINT-I (Smith and Whitledge 1977), the rates were not methodologically related to measured amounts of food consumed. Experiments with Calanus zooplankton species (Butler, et al. 1970) have shown, however, that of the total quantity of nitrogen ingested each day, about $36 \%$ was excreted in a soluble form. If $80 \%$ of zooplanktonregenerated nitrogen is ammonium (Smith and Whitledge 1977), then $29 \%$ of the total particulate nitrogen ingested could be excreted as ammonium.

Excretion rates have been observed to be closely related in time to feeding activity (Corner, et al. 1965; Ikeda 1977), but excretion is probably not instantaneous. The function used in the model,

$$
x_{3}=B_{3} \cdot Z \cdot P_{4}
$$

where

$$
\mathrm{X}_{3}=\text { the ammonium excretion rate (1, at } \mathrm{l}^{-1} \mathrm{hr}^{-1} \text { ) }
$$


$B_{3}=$ the zooplankton ammonium excretion efficiency $\left(.29 \mu \mathrm{g}\right.$ at excreted $\cdot(\mu \mathrm{g} \text { at phyto-N ingested })^{-1}$ based on Calanus excretion experiments (Butler, et al. 1970);

$Z \cdot P_{4}=$ the rate of ingestion of phytoplankton nitrogen by zooplankton ( $\mu \mathrm{g}$ at phyto-N $\cdot 1^{-1} \cdot \mathrm{hr}^{-1}$ ), instantaneously relates excretion and ingestion and does not allow for a time lag between the two processes. The effect on the system, however, is probably quite insignificant. This function yields excretion rates equivalent to the mean measured rates of 0.0017 and $0.026 \mu \mathrm{g}$ atom $\mathrm{NH}_{3}-\mathrm{N}(\mathrm{mg} \text { dry } \omega t)^{-1} \cdot \mathrm{hr}^{-1}$ (Smith and Whitledge 1977) when the simulated ingestion rates equal $79 \%$ and $62 \%$ of assumed maximum rates for the small and large zooplankton size classes, respectively. In other words, the mean measured excretion rates occur within the range of rates attainable in the model as functions of phytoplankton nitrogen concentration.

3.2d Fish. Acoustic surveys made during JoINT-I identified two spatially distinct congregations of fish (Thorne, et al. 19/\%). Une was found associated with the upper continental slope and the other was found over the continental shelf. Egg and larval data indicated that the upper continental slope congregation was primarily horse mackeral (Trachurus spp.) and that the shelt congregation was primarily sardine ( $\underline{\text { Sardina pilchardus) with some anchovy (Engraulis encrasicholus) }}$ present (Blackburn and Nellen 1976). 
Trachurus spp. in this area are known to be primarily zooplank-: tivorous (Blackburn 1976b) and are not included in the model. Sardina, : however, are known to be functional herbivores and may have fed primarily on phytoplankton (Blackburn 1976b). The food requirements of the Sardina population can be estimated if the population biomass is known. A mean value of $48 \mathrm{~g} \mathrm{~m}^{-2}$ (wet weight) was calculated from the average fish biomass observed with the 120-kHz acoustic system during JOINT-I, between 6 April and 6 May, 1974 (Thorne, et al. 1977) over the shelf region. If the fish are $10 \%$ carbon by weight (Gulland 1970), the mean carbon biomass is $4.8 \mathrm{~g} \mathrm{C} \mathrm{m}^{-2}$. Mathisen, et al. (in press) estimate that the pelagic fish of the JOINT-I area consume between 4 and $8 \%$ of their body weight per day. If the Sardina consume $4 \%$ of their body weight per day as phytoplankton, they require approximately $0.2 \mathrm{~g} \mathrm{C} \mathrm{m}^{-2}$ day $^{-1}$ to sustain growth and meet metabolic requirements.

Mathisen, et al. (in press) show that food supply may not directly control the size of adult fish populations in the northwest African upwelling system. The $0.2 \mathrm{~g} \mathrm{C} \mathrm{m}^{-2} \mathrm{day}^{-1}$ requirement, therefore represents a maximum ration obtainable when food is relatively abundant. In general, however, the quantity of food eaten increases as the concentration of food increases until a maximum ration is reached (Ivlev 1945). In order to relate the amount ingested to the amount available, it is assumed that the fish obtain a maximum ration at the same concentration of phytoplankton carbon as the zooplankton, $25.5 \mu \mathrm{g}$ at $\mathrm{C}$ $1^{-1}$, and that the feeding threshold, $1.2 \mu \mathrm{g}$ at $\mathrm{C}^{-1}$, is also the same 
as for the zooplankton. The carbon-specific ingestion rate of the fish, expressed as a function of phytoplankton carbon concentration may then be written as

$$
\mathrm{M}_{5}=\theta \mathrm{P}_{5}+\tau
$$

where

$$
\begin{aligned}
& M_{5}=\text { carbon specific ingestion rate of the fish } \\
& \text { ( } \mu \mathrm{g} \text { at phytoplankton carbon ( } \mu \mathrm{g} \text { at } \mathrm{fish} \text { carbon) })^{-1} \mathrm{hr}^{-1} \text { ); } \\
& \theta=\text { a filtering constant }\left(1(\mu \mathrm{g} \text { at fish carbon })^{-1} \mathrm{hr}^{-1}\right) \text {, } \\
& \text { if } P_{5}<25.85 \text { lig at } C 1^{-1}, \theta=6.9 \times 10^{-5} \text {, } \\
& \text { if } P_{5}=25.85 \mu \mathrm{g} \text { at } \mathrm{C}^{-1}, \theta=1.7 \times 10^{-3} \text {, } \\
& \text { if } P_{5}<1.2 \mu \mathrm{g} \text { at } C 1^{-1} \text {, the grazing threshold, } \theta=0 \text {; } \\
& \tau=a \text { constant }\left(\mathrm{hr}^{-1}\right) \text {, } \\
& \text { if } \mathrm{P}_{5}<25.85 \mu \mathrm{g} \text { at } \mathrm{C}^{-1}, \tau=8.2 \times 10^{-5} \text {, } \\
& \text { if } \mathrm{P}_{5} \geq 25.85 \mu \mathrm{g} \text { at } \mathrm{C}^{-1}, \tau=0 \text {, } \\
& \text { if } \mathrm{P}_{5}<1.2 \mu \mathrm{g} \text { at } \mathrm{C}^{-1} \text {, the grazing threshold, } \tau=0 \text {. }
\end{aligned}
$$

The fraction

$$
F=\left(w_{5} M_{5}\right) / P_{5}
$$

of phytoplankton carbon ingested by the fish is calculated at each iteration for each spatial segment. Equivalent fractions expressed as $\mathrm{FP}_{1}, \mathrm{FP}_{4}, \mathrm{FP}_{5}, \mathrm{FP}_{6}, \mathrm{FN}$ are then subtracted from standing stocks of phytoplankton silica, nitrogen, carbon, chlurophyll, and cell numbero respectively in [3.5-3.9].

Ammonia excretion by the Sardina off northwest Africa is estimated from data for Engraulis mordax (McCarthy and Whitledge 1972) used by Walsh (1975) in a model of the Peru upwelling system. Walsh calculates 
that of the $725 \mu \mathrm{g}$ at $\mathrm{N}$ day $^{-1}$ ingested by each fish, $486 \mu \mathrm{g}$ at $\mathrm{N} \cdot \mathrm{day}^{-1}$. is excreted. If $68 \%$ of the total nitrogen excreted is ammonia (McCarthy and Whitledge 1972), then $46 \%$ of the nitrogen ingested is excreted as ammonium. This $46 \%$ fraction is included as the constant, $\gamma_{3}$, in the following function for ammonia excretion by fish

$$
\mathrm{Y}_{3}=\mathrm{Y}_{3} \cdot \mathrm{F} \cdot \mathrm{P}_{4}
$$

where

$\mathrm{Y}_{3}=$ the ammonia excretion rate $\left(\mu \mathrm{g}\right.$ at $\left.\mathrm{NH}_{3}-\mathrm{N} \cdot 1^{-1} \cdot \mathrm{hr}^{-1}\right)$;

$\gamma_{3}=$ a constant $\left(0.46 \mu \mathrm{g}\right.$ at $\mathrm{NH}_{4}-\mathrm{N}$ excreted $\cdot(\mu \mathrm{g}$ at phyto-N ingested) $)^{-1}$ );

$\mathrm{PF}_{4}=$ the rate of ingestion of phytoplankton by $\mathrm{fish}$ ( $\mu$ g at phyto-N $\left.\cdot 1^{-1} \cdot \mathrm{hr}^{-1}\right)$.

3.2e Benthos. Benthic remineralization of organic matter has been identified as a significant nutrient cycling process in the region off northwest Africa (Rowe, et a1. 1977). The dynamics of the process are presently poorly understood, so benthic regeneration is treated in this model as a boundary process occurring at a constant rate insensitive to changes in the dynamic variables of the simulated system. Rates of nutrient flux from the bottom are assumed equal to the mean rates reported by Rowe, et al. (1977). In units of $\mu g$ atoms $\cdot \mathrm{m}^{-2} \cdot \mathrm{hr}-1$ the mean fluxes are 550 for silicate, 160 for nitrate and 235 for ammonium. For spatial segments having the continental shelf as a bottom boundary, benthic nutrient fluxes contribute to nutrient concentration changes in a manner dependent on the vertical dimension of the spatial segment (i.e. in a unit of time the concentration change 
in a segment $5 \mathrm{~m}$ deep bounded by the shelf is proportionally greater than in a segment $20 \mathrm{~m}$ deep). Accordingly, the benthic regeneration functions, $r_{1}, r_{2}$, and $r_{3}$ are defined as

$$
r_{n}=h_{n} \Omega
$$

where

$$
\begin{aligned}
& h_{n}=\text { areal nutrient fluxes }\left(\mu g \text { at } \cdot \mathrm{m}^{-2} \mathrm{hr}^{-1}\right) \\
& \text { for } \mathrm{n}=1 \text {, silicate, } \mathrm{h}_{1}=550, \\
& \mathrm{n}=2 \text {, nitrate, } \mathrm{h}_{2}=160, \\
& \mathrm{n}=3 \text {, anwonium, } \mathrm{h}_{3}=235 ; \\
& \Omega=\text { a vertical scaling factor, constant for each spatial } \\
& \text { segment of a given vertical dimension; } \\
& \text { for a segment } 20 \mathrm{~m} \text { deep, } \Omega \text { is defined as } \\
& \Omega=(1 / 20 \mathrm{~m}) \text { ( } 1 \mathrm{~m} / 1000 \text { iters) }=5 \mathrm{x} 10^{-5} \mathrm{~m}^{2} \cdot 1 \text { iter }{ }^{-1} ; \\
& \text { for spatial segments not bounded below by the continental } \\
& \text { shelf, } \Omega=0 \text {. }
\end{aligned}
$$

\subsection{Results}

Rcoulte from three simulated cases are presented below. Recall that these cases are related by a common set of boundary and initial conditions and functional relationships among the biological components. (Boundary and initial conditions common to the three cases are defined in Tables 5 and 6 of Appendix II.) The differences among cases are due Lu llie alsence or oecurrence of cimulated upwelling and differences in the intensity of vertical mixing occurring over a ten day period. During the 10 day simulation period, the distribution of 
variables do not, in general, reach steady states. However, the observed variability in the physical forcing of the system occurs at 10 day or shorter intervals, so a comparison of theoretical steady states, if and when they are reached in the model, would be of limited value.

A comparison of results from the first and second cases illustrates the effects of upwelling. The first case was run with weak mixing and no advection and the second case was run with weak mixing and the time sequence of advective fields generated by the physical submodel. In both of these simulations, vertical eddy coefficients are set as constants to $1 \mathrm{~cm}^{2} \mathrm{~s}^{-1}$. This value is equivalent to those used in previous simulation studies of the upwelling systems off Peru (Walsh 1975) and Oregon (Wroblewski 1977). Vertical mixing may have been more intense off Africa during JOINT-I than off Oregon and Peru. Accordingly, results are presented for a third simulation case run with the same circulation scheme as the second case, but with vertical eddy coefficients of $40 \mathrm{~cm}^{2} \mathrm{~s}^{-1}$. The results presented from the three simulation cases are limited to variables routinely measured at hydrographic stations during JOINT-I to permit comparisons between simulated and observed distributions. The discussion will therefore focus on the distributions of nitrate, ammonium and chlorophyll.

3.3a A Case with Weak Mixing and No Advection. Figures 24 to 30 show nitrate, ammonium and chlorophyll distributions after 0,120 , and 240 hours $(0,5$ and 10 days $)$ timc in the case with no advection. 


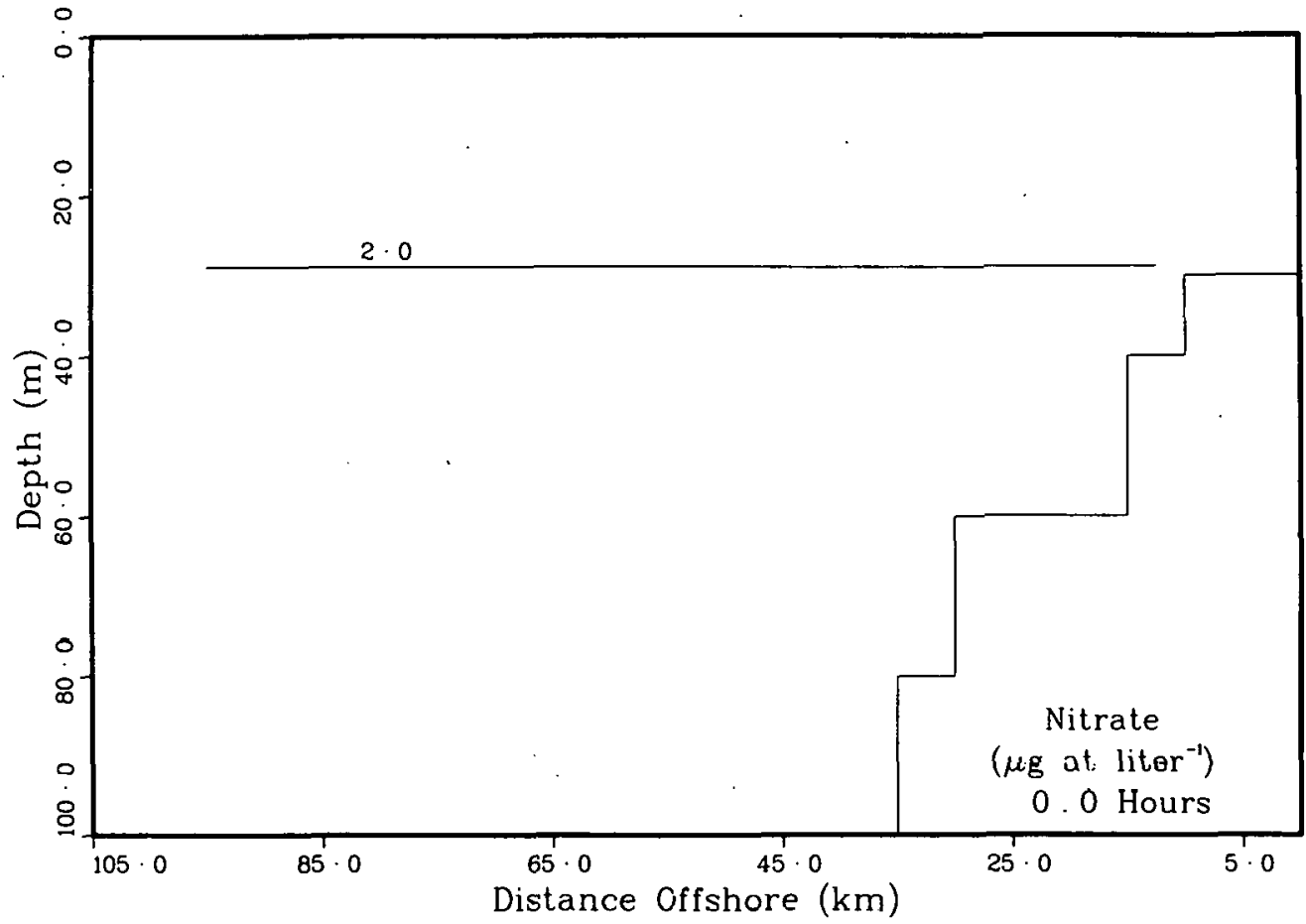

Figure 24. The initial nitrate distribution. Above $30 \mathrm{~m}$ the concentration $1 \mathrm{~s} 1.48 \mu \mathrm{g}$ at $1^{-1}$ and below $30 \mathrm{~m}, 2.84 \mathrm{\mu g}$ at $1^{-1}$. Contour interval is $2 \mu \mathrm{g}$ at $1^{-1}$.

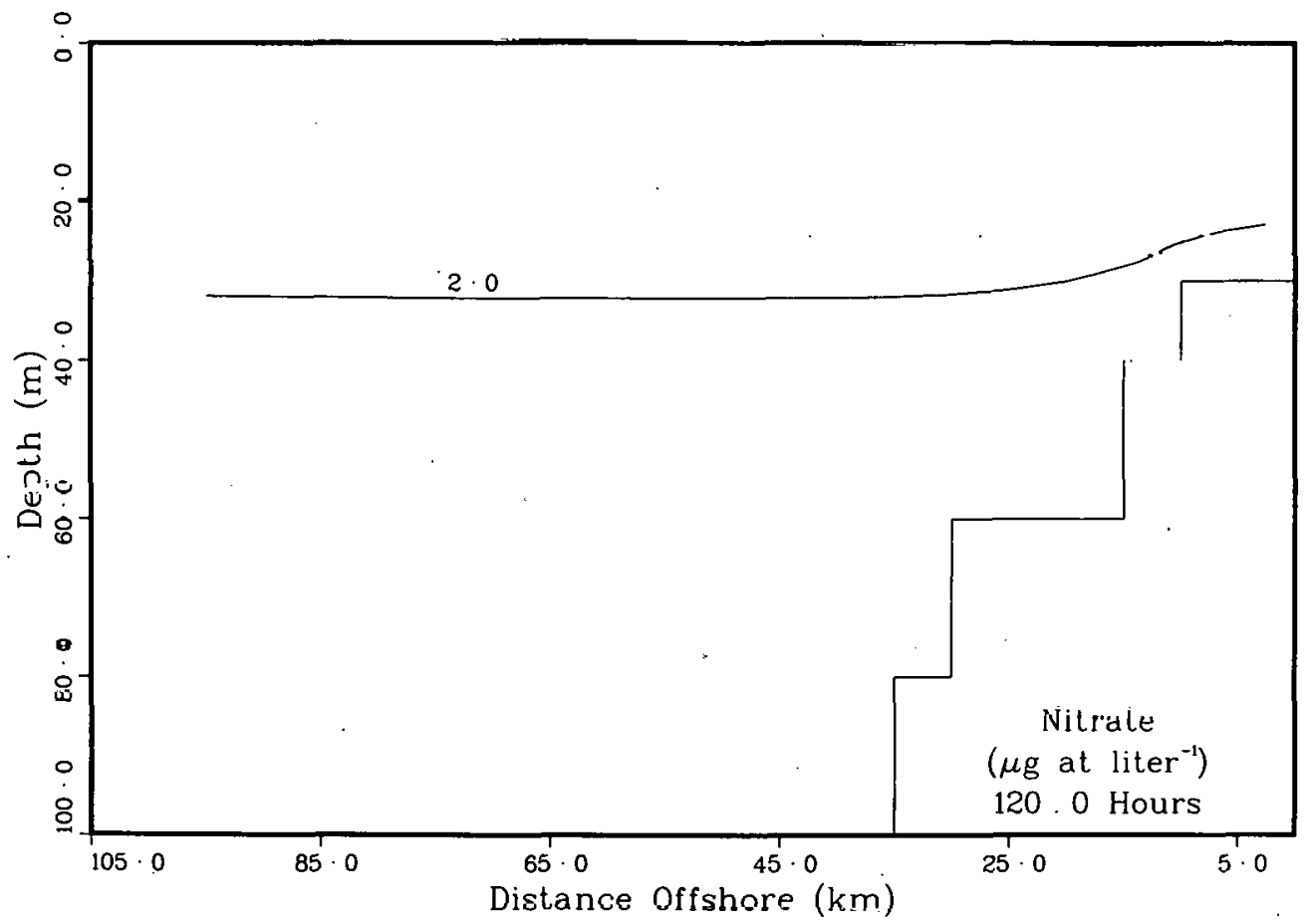

Figure 25. The nitrate distribution after 5 days in the case without upwelling, $\mathrm{K}_{2}=1 \mathrm{~cm}^{2} \mathrm{~s}^{-1}$. Contour interval is $2 \mu \mathrm{g}$ at $\mathrm{l}^{-1}$. 


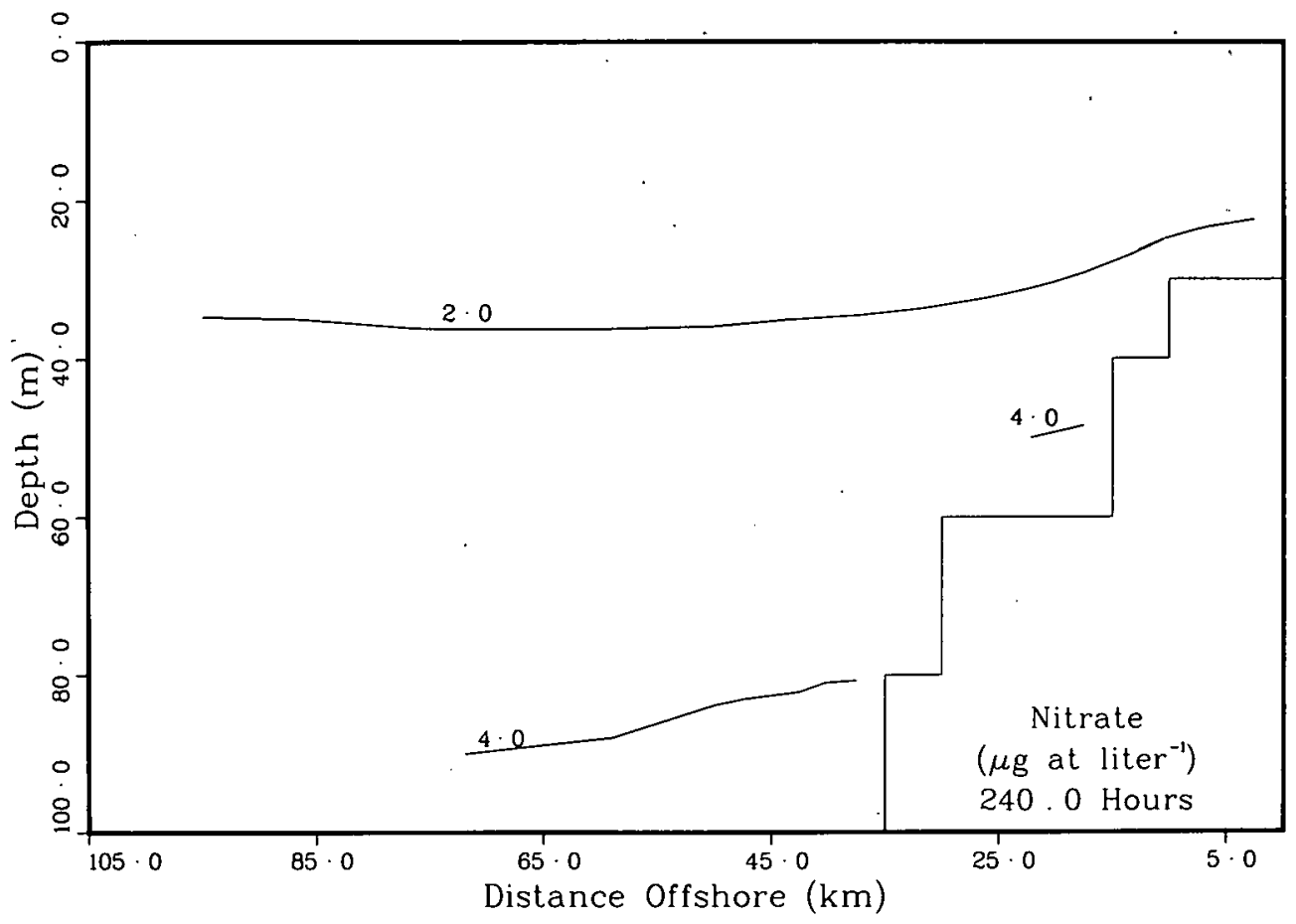

Figure 26. The nitrate distribution after 10 days in the case without upwelling, $\mathrm{Kz}=1 \mathrm{~cm}^{2} \mathrm{~s}^{-1}$. Contour interval is $2 \mu \mathrm{g}$ at $1^{-1}$.

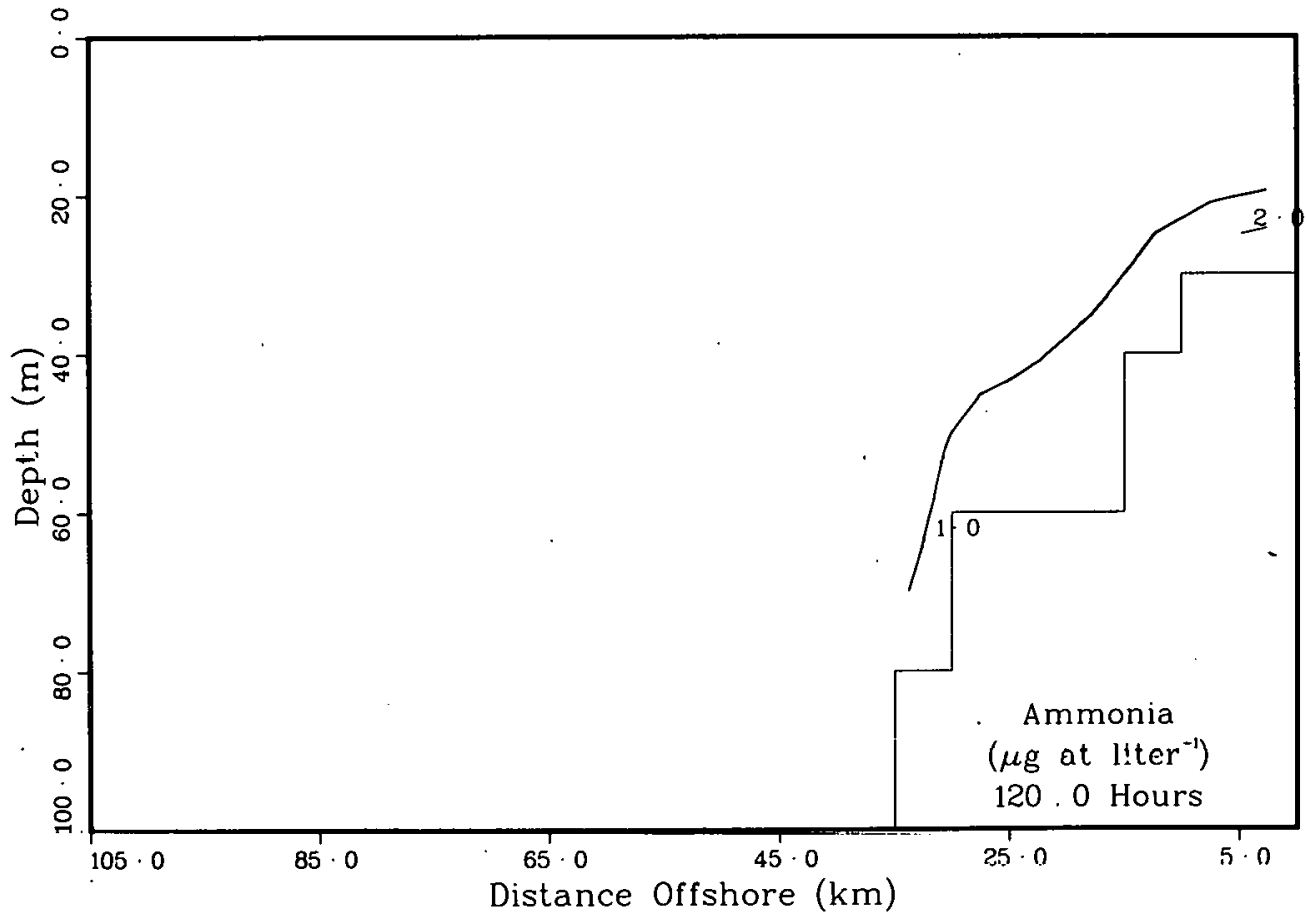

Figure 27. The ammonium distribution after 5 days in the case without upwelling, $K_{z}=1 \mathrm{~cm}^{2} \mathrm{~s}^{-1}$. Contour interval is $1 \mu \mathrm{g}$ at $\mathrm{I}^{-1}$. 


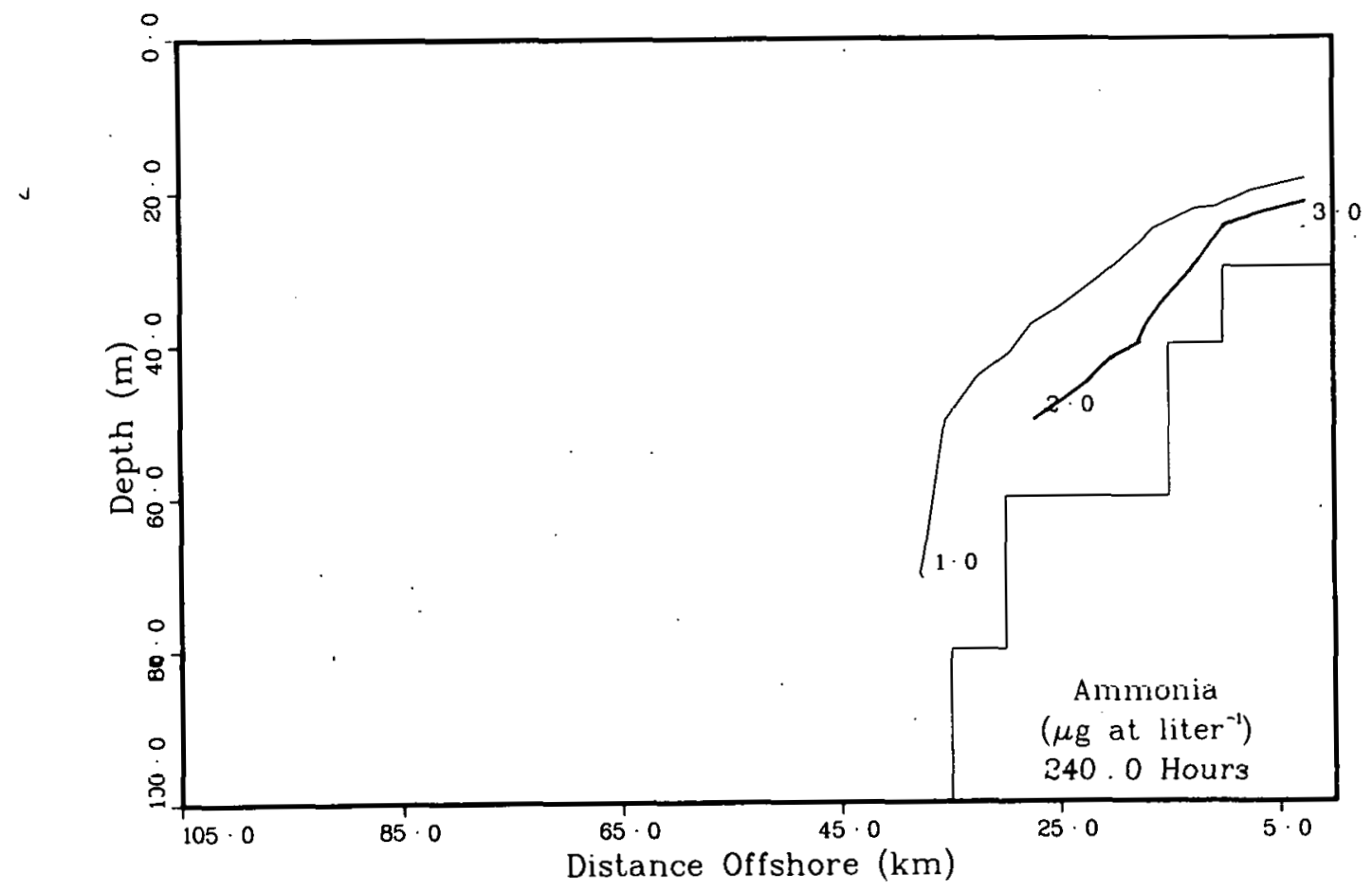

Figure 28. The anmunium distribution after 10 days in the case without upwelling, $K_{z}=1 \mathrm{~cm}^{2} \mathrm{~s}^{-1}$. Contour interval is $1 \mathrm{\mu g}$ at $1^{-1}$.

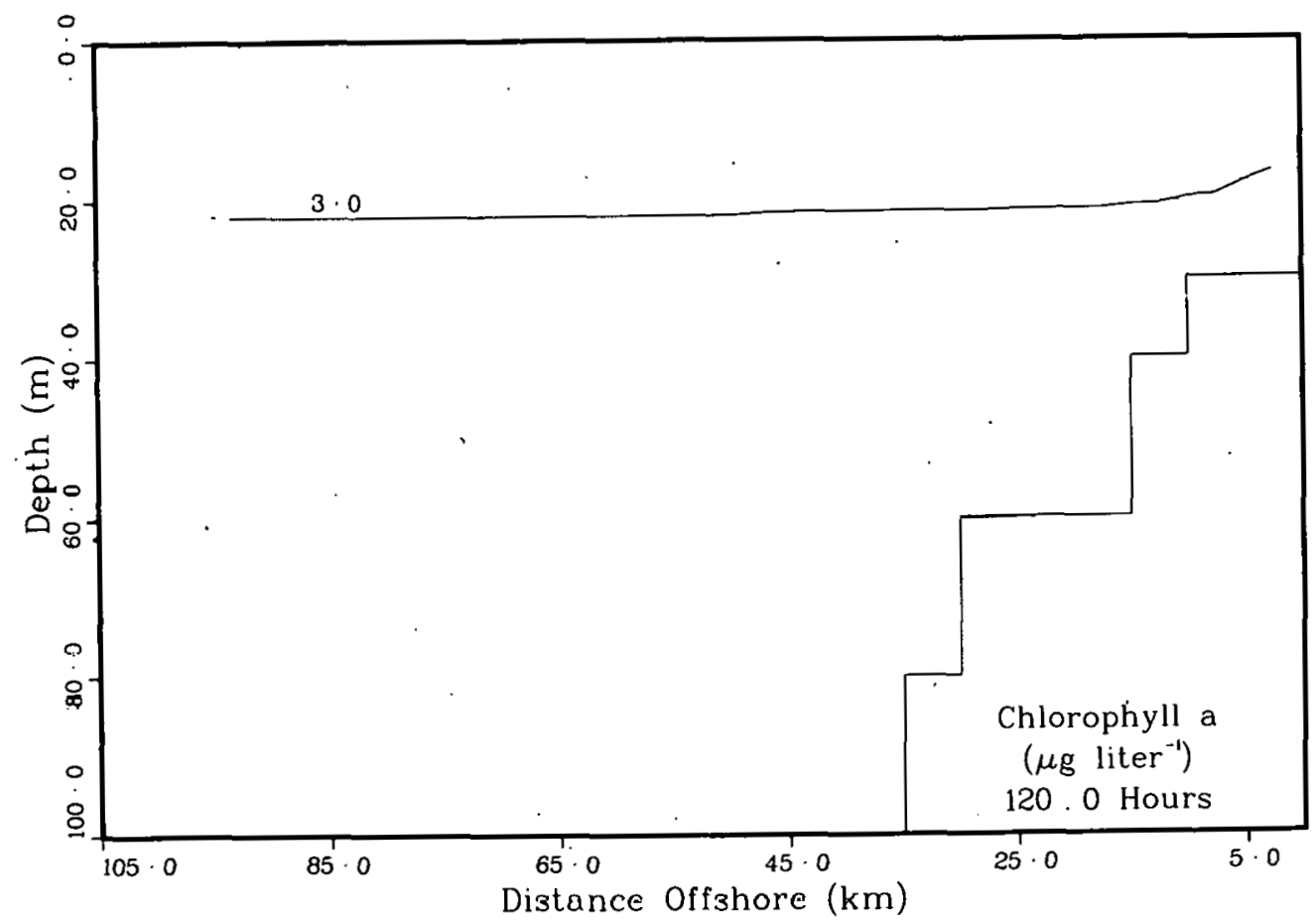

Figure 29. The chlorophyl1 a distribution after 5 days in the case

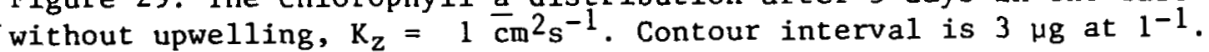




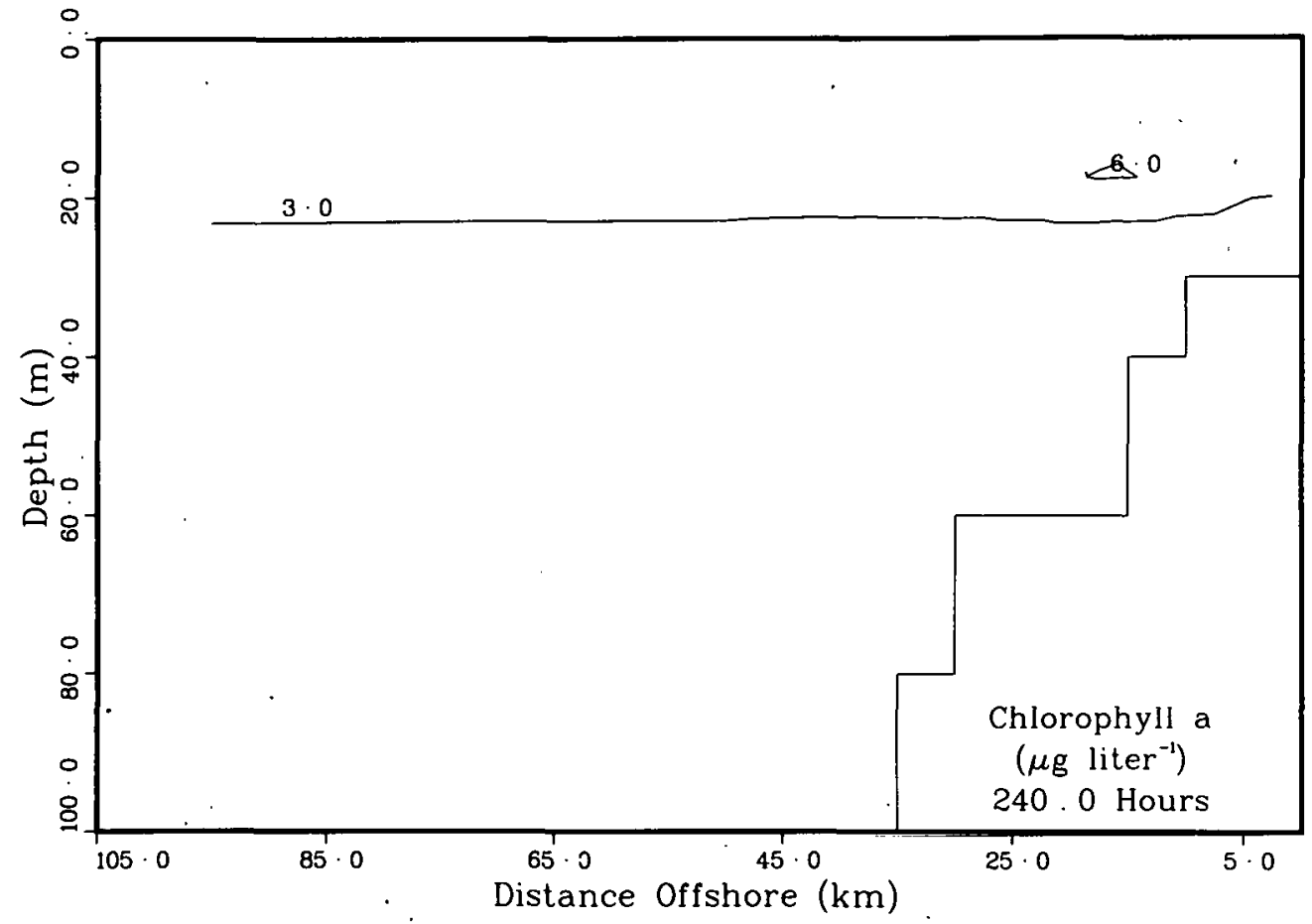

Figure 30. The chlorophyll a distributon after 10 days in the case without upwelling, $\mathrm{K}_{\mathrm{z}}=1 \mathrm{~cm}^{2} \mathrm{~s}^{-1}$. Contour interval is $3 \mu \mathrm{g}$ at $1^{-1}$. 
Figure 24 is an example of the initially horizontal two layer distributions represented in Tables 5 and 6 of Appendix II describing the initial conditions for all cases simulated. With no upwelling, nitrate becomes depleted in the upper $20 \mathrm{~m}$ due to phytoplankton uptake, except in the nearshore region where phytoplankton growth is reduced by turbidity in the water column (Figure 25-26). Nitrate concentrations increase at depth and near the continental shelf due to benthic regeneration and some diffusion through the lower boundary off the shelf. As a consequence of the high uptake of nitrate by phytoplankton, seaward of the tubid region near shore and the benthic regeneration of nitrate over the shelf, the nitrate isolines tend to slope upwards near the coast as if upwelling were occurring. The concentrations of ammonium also increases near the bottom over the shelf. From an initial concentration of $0.35 \mu \mathrm{g}$ at $\mathrm{NH}_{3} 1^{-1}$ below $30 \mathrm{~m}$, ammonium increases to greater than $3 \mu \mathrm{g}$ at $\mathrm{NH}_{3} 1^{-1}$ in the turbid nearshore region near the bottom (Figure 28 ).

Diagnostic information listed during the simulation (see Appendix III) indicated that chlorophyll concentrations, initially $1.45 \mu \mathrm{g}$ Ch 1 $1^{-1}$ above $30 \mathrm{~m}$, increase until phytoplankton growth is limited by a lack of inorganic nitrogen. Growth is reduced due to turbidity in the extreme inshore region, but a subsurface chlorophyl1 maximum develops over the shelf where benthic regeneration and vertical mixing supply nutrients to the base of the euphotic zone (Figure 30 ). The mean nel primary production in the upper $20 \mathrm{~m}$ initially exceeds, by a factor of 8.3 the mean vertically integrated ingestion of phytoplankton carbon 
by all zooplankton and fish. As phytoplankton production decreases due to nutrient limitation, herbivorous ingestion eventually equals primary production. Total herbivorous ingestion subsequently exceeds net primary production by a factor of 2.7 during day 5 and by a factor of 11.1 during day 10 .

3.3b A Case with Advection and Weak Vertical Mixing. The effects of upwelling are most evident when the results of this simulation (Figures 31-34), run with the sequence of upwelling flow fields generated in the physical submodel, are compared with the results of the case with no advection in the previous section (Figures 24-30). After 10 days in the case without upwelling, the initial $1.48 \mu \mathrm{g}$ at $1^{-1}$ nitrate concentration in the $0-30 \mathrm{~m}$ layer declines to a mean $0.35 \mu \mathrm{g}$ at $1^{-1}$ and the mean concentration from $30-100 \mathrm{~m}$ increases slightly from 2.84 to $3.09 \mu \mathrm{g}$ at $1^{-1}$. After an equivalent period with upwelling, the mean nitrate concentration is $1.44 \mu \mathrm{g}$ at $1^{-1}$ above $30 \mathrm{~m}$ and $4.39 \mu \mathrm{g}$ at $1^{-1}$ below. Chlorophyll concentrations also increase in response to upwelling. Figures 33-34 show a region of maximum concentrations. developing over the outer shelf and spreading seaward with time. From an initial concentration of $1.45 \mu \mathrm{g} \mathrm{Chl} 1^{-1}$ mean chlorophyll concentrations above $30 \mathrm{~m}$ increase to $4.88 \mu \mathrm{g} 1^{-1}$ after 10 days time. Increases in chlorophyll concentrations are accompanied by increases in the rate of primary production over the shelf. After 5 days in the case without upwelling, net primary productivity integrated over the $20 \mathrm{~m}$ surface layer averages $0.16 \mathrm{~g} \mathrm{C} \mathrm{m}^{-2} \mathrm{~d}^{-1}$ and continues to decline in the case without upwelling. In contrast, net production 


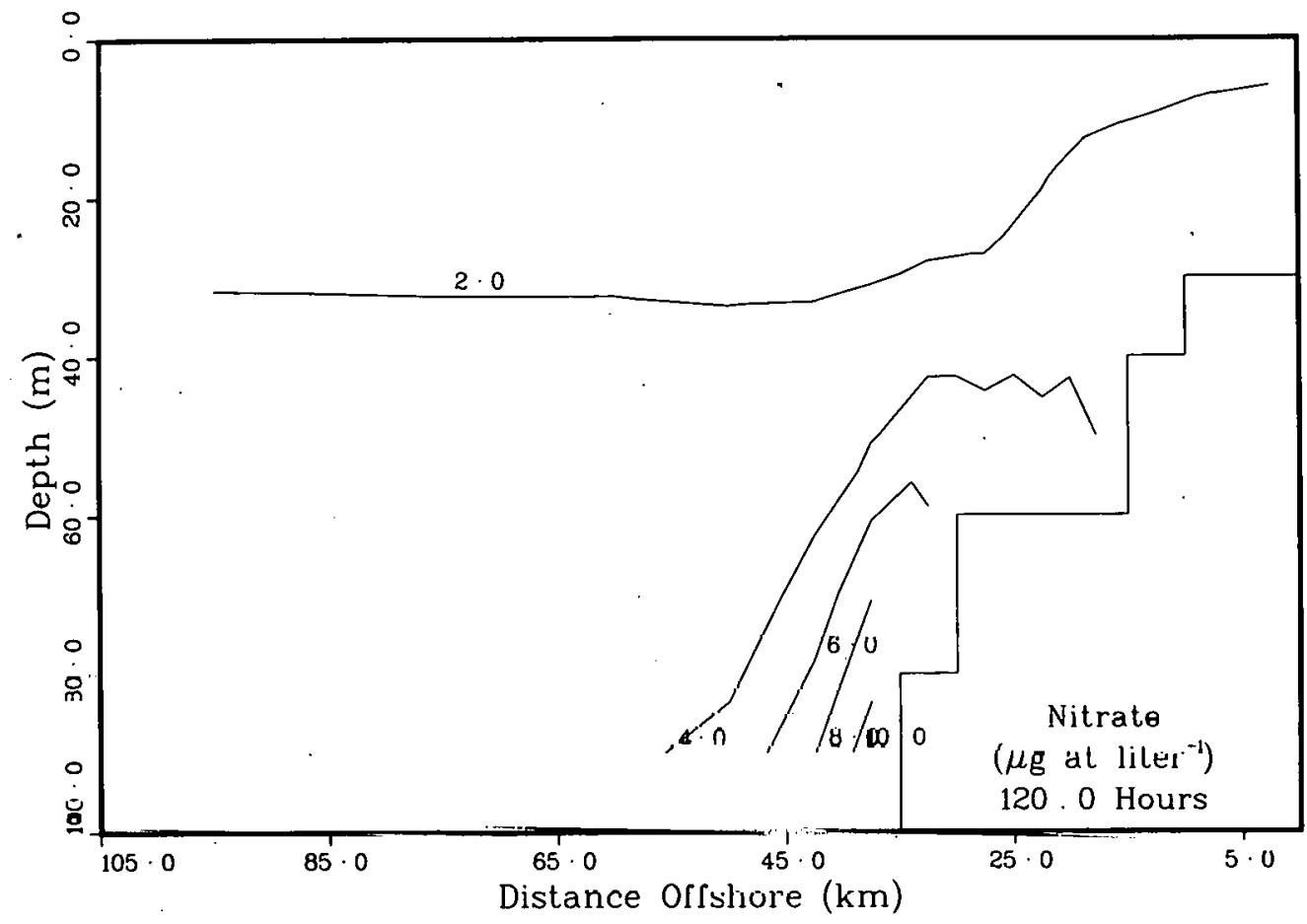

Figure 31. The nitrate distribution after 5 days in the case, with upwelling $\mathrm{K}_{z}=1 \mathrm{~cm}^{2} \mathrm{~s}^{-1}$. Concentrations exceeding $10 \mathrm{\mu g}$ at $1^{-1}$ appear near the intersection of the shelf with the bottom boundary. Contour interval is $2 \mu \mathrm{g}$ at $1^{-1}$.

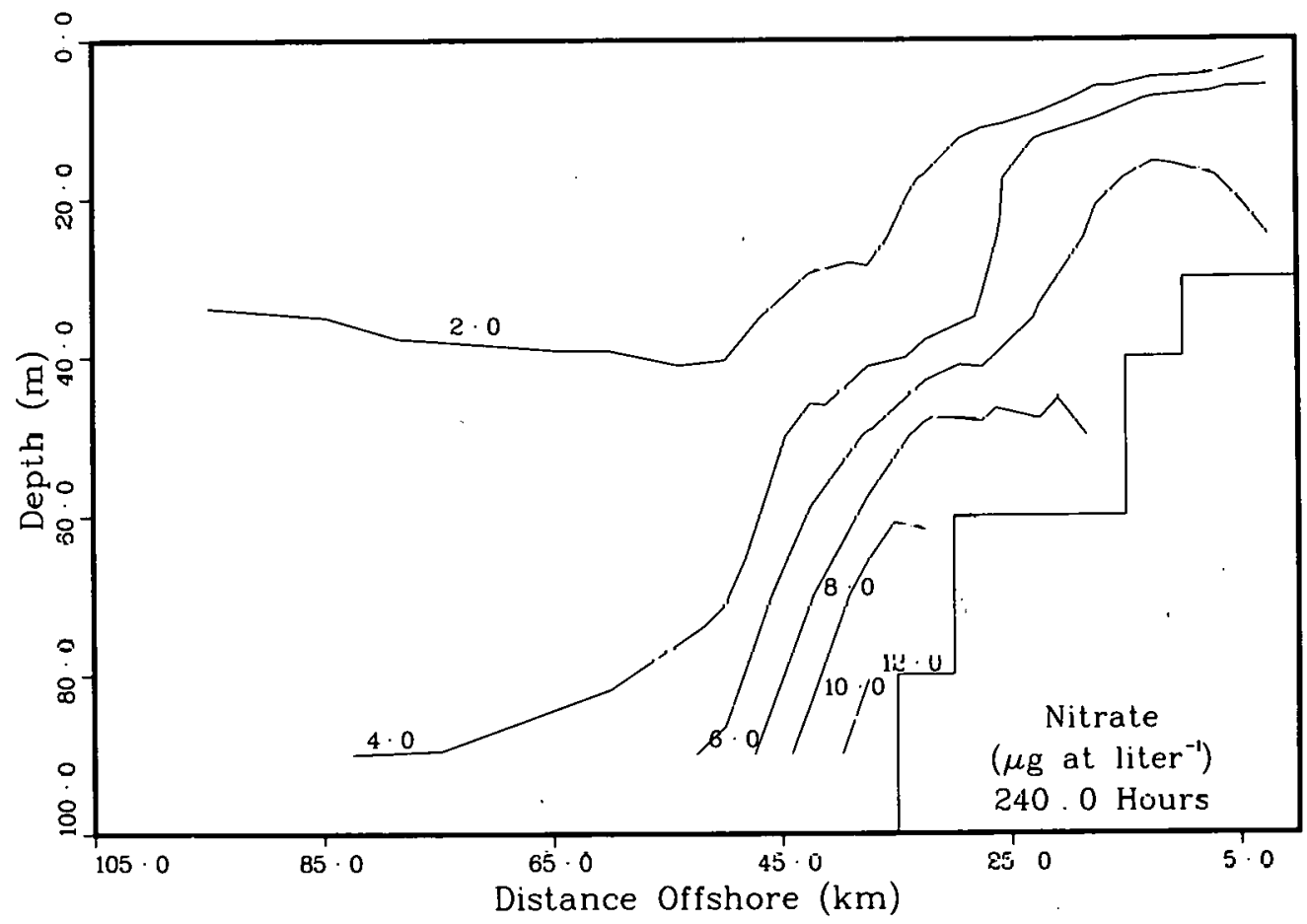

Figure 32. The nitrate distribution after 10 days of upwelling with $\mathrm{K}_{\mathrm{z}}=1 \mathrm{~cm}^{2} \mathrm{~s}^{-1}$. Contour interval is $2 \mu \mathrm{g}$ at $1^{-1}$. 


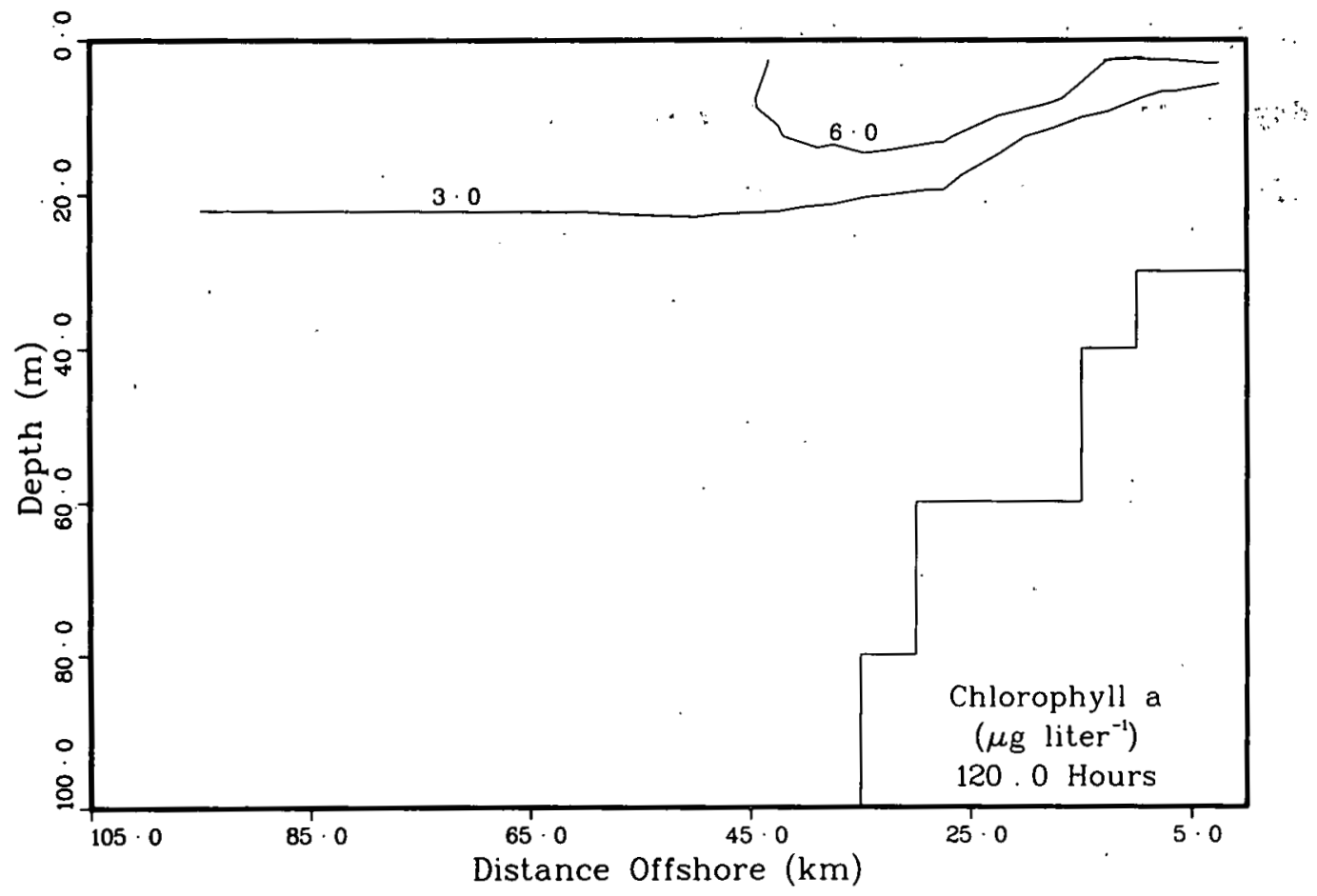

Figure 33. The chlorophyll a distribution after 5 days of upwelling with $\mathrm{K}_{\mathrm{z}}=1 \mathrm{~cm}^{2} \mathrm{~s}^{-1}$. Contour interval is $3 \mu \mathrm{g}^{-1}$.

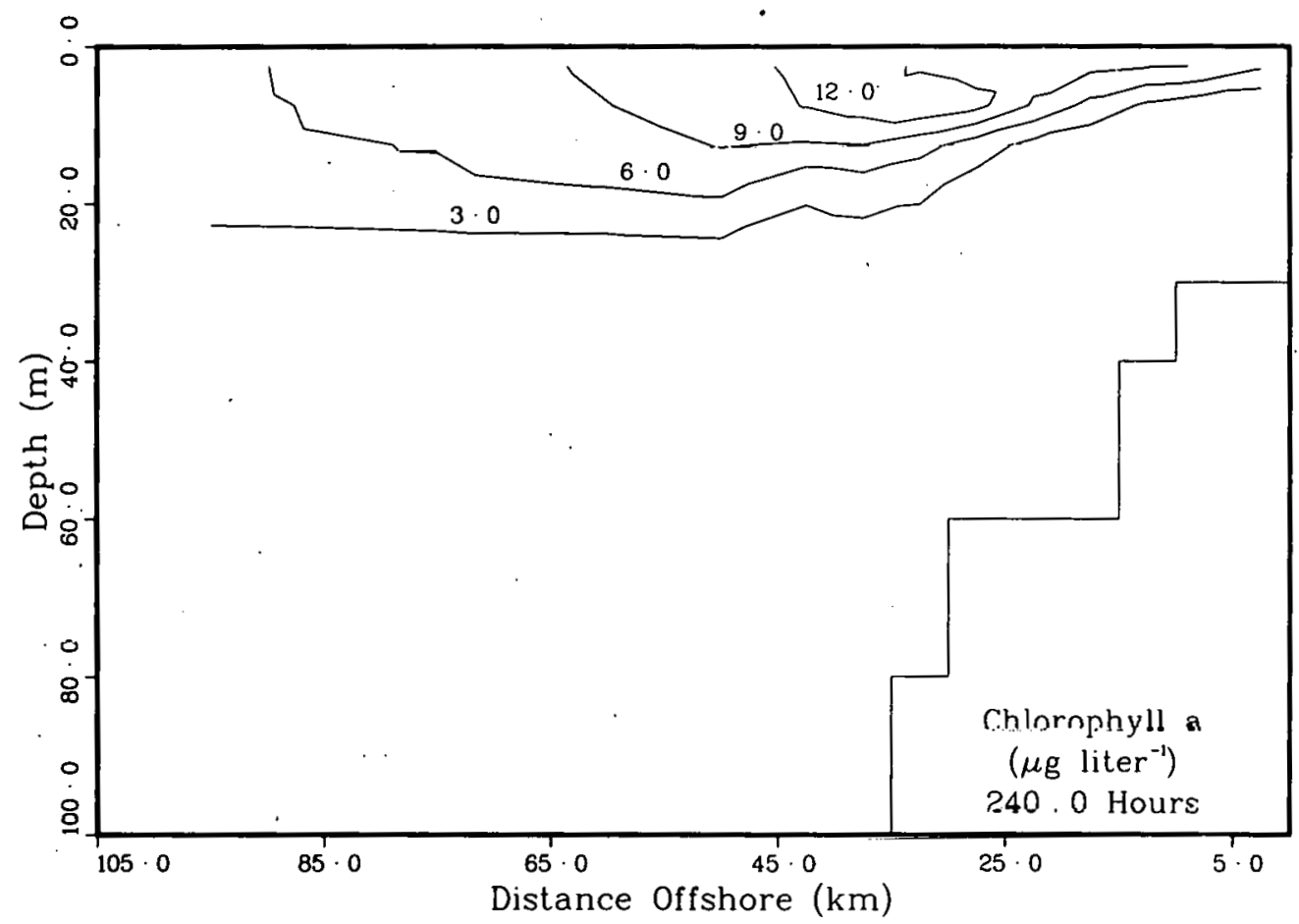

Figure 34. The chlorophy 11 a distribution after 10 days of upwelling with $\mathrm{K}_{z}=1 \mathrm{~cm}^{2} \mathrm{~s}-\mathrm{T}$. Contour interva1 is $3 \mu \mathrm{g} 1^{-1}$. 
across the shelf ranges between 0.7 to $3.7 \mathrm{~g} \mathrm{C} \mathrm{m}^{-2} \mathrm{~d}^{-1}$ after the tenth day in the upwelling case. The highest rates occur about $20 \mathrm{~km}$ offshore over the midshelf region.

Vertically integrated herbivorous ingestion averages $0.25 \mathrm{~g} \mathrm{C} \mathrm{m}^{-2}$ $\mathrm{d}^{-1}$ after 10 days of upwelling, and is slightly less than the average of $0.33 \mathrm{~g} \mathrm{C} \mathrm{m}^{-2} \mathrm{~d}^{-1}$ after the same time in the non-upwelling case. Herbivorous ingestion is a function of phytoplankton carbon concentration and the small difference between cases is due mainly to the presence of slightly higher phytoplankton carbon concentrations at mid-depths in the case without upwelling. Mean phytoplankton carbon concentrations between 30 and $50 \mathrm{~m}$ average $4.48 \mu \mathrm{g}$ at $\mathrm{C} 1^{-1}$ without upwelling and $3.70 \mu \mathrm{g}$ at $\mathrm{C}^{-1}$ with upwelling. Phytoplankton carbon concentrations are all above the $1.2 \mu \mathrm{g}$ at $C 1^{-1}$ grazing threshold in the case without upwelling between 30 and $50 \mathrm{~m}$, but in the case with upwelling they are below the threshold in $18 \%$ of the $30-50 \mathrm{~m}$ depth region nearest the coast where upwelling and consequent dilution of phytoplankton concentration is most intense. The ammonium distribution is also affected by dilution due to upwelling. Concentrations exceeding $2.0 \mu \mathrm{g}$ at $1^{-1}$ occur only within $5 \mathrm{~km}$ of the coast after 10 days in the case with advection.

3.3c A Case with Advection and Strong Vertical Mixing. Simulated distributions of nitrate (Figures 35,36 ) and chlorophyl1 (Figures 37 , 38) illustrate the effects of upwelling accompanied by strong vertical mixing parameterized in vertical eddy coefficicnts of $40 \mathrm{~cm}^{2} \mathrm{~s}^{-1}$. Strong vertical mixing results in higher nitrate concentrations in the 


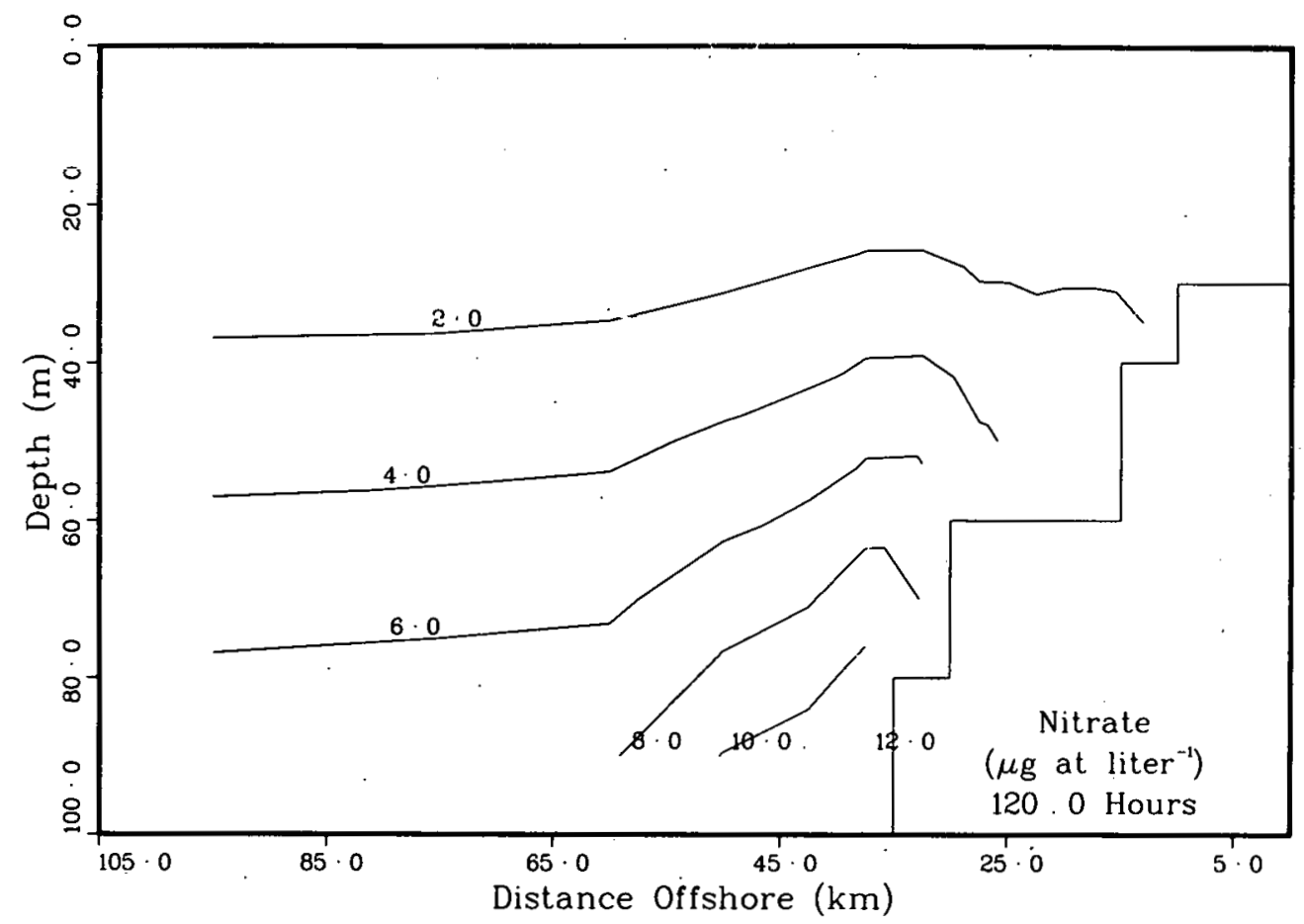

Figure 35. The nitrate distribution after 5 days of upwelling with $K_{z}=40 \mathrm{~cm}^{2} \mathrm{~s}^{-1}$. Contour interval is $2 \mathrm{\mu g}$ at $1^{-1}$.

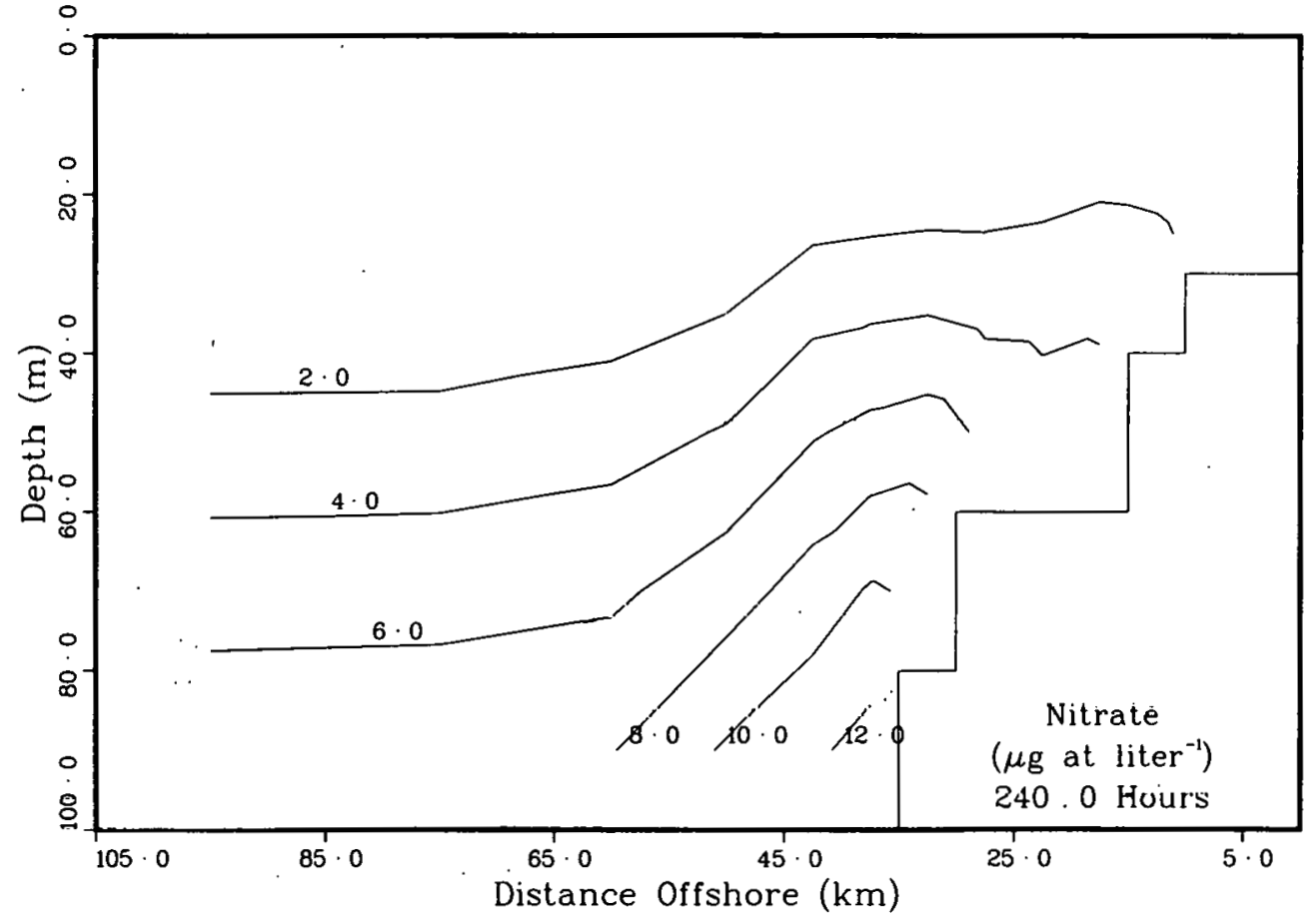

Figure 36 . The nitrate distribution after 10 days of upwelling with $\mathrm{K}_{z}=40 \mathrm{~cm}^{2} \mathrm{~s}^{-1}$. Contour interval is $2 \mu \mathrm{g}$ at $1^{-1}$. 


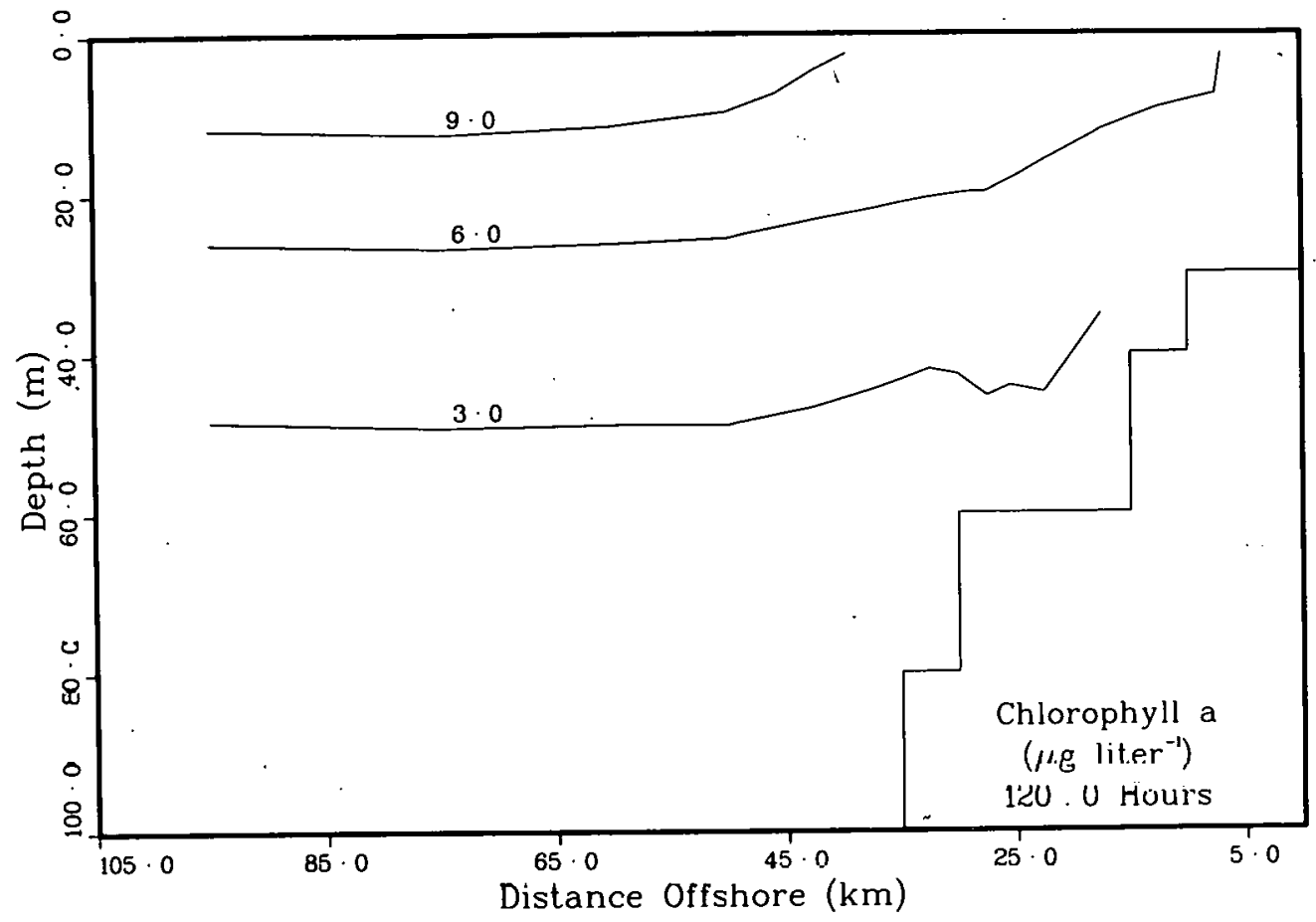

Figure 37. The chlorophyll a distribution after 5 days of upwelling with $\mathrm{K}_{\mathrm{z}}=40 \mathrm{~cm}^{2} \mathrm{~s}-\mathrm{T}$. Contour interval is $3 \mu \mathrm{g} 1^{-1}$.

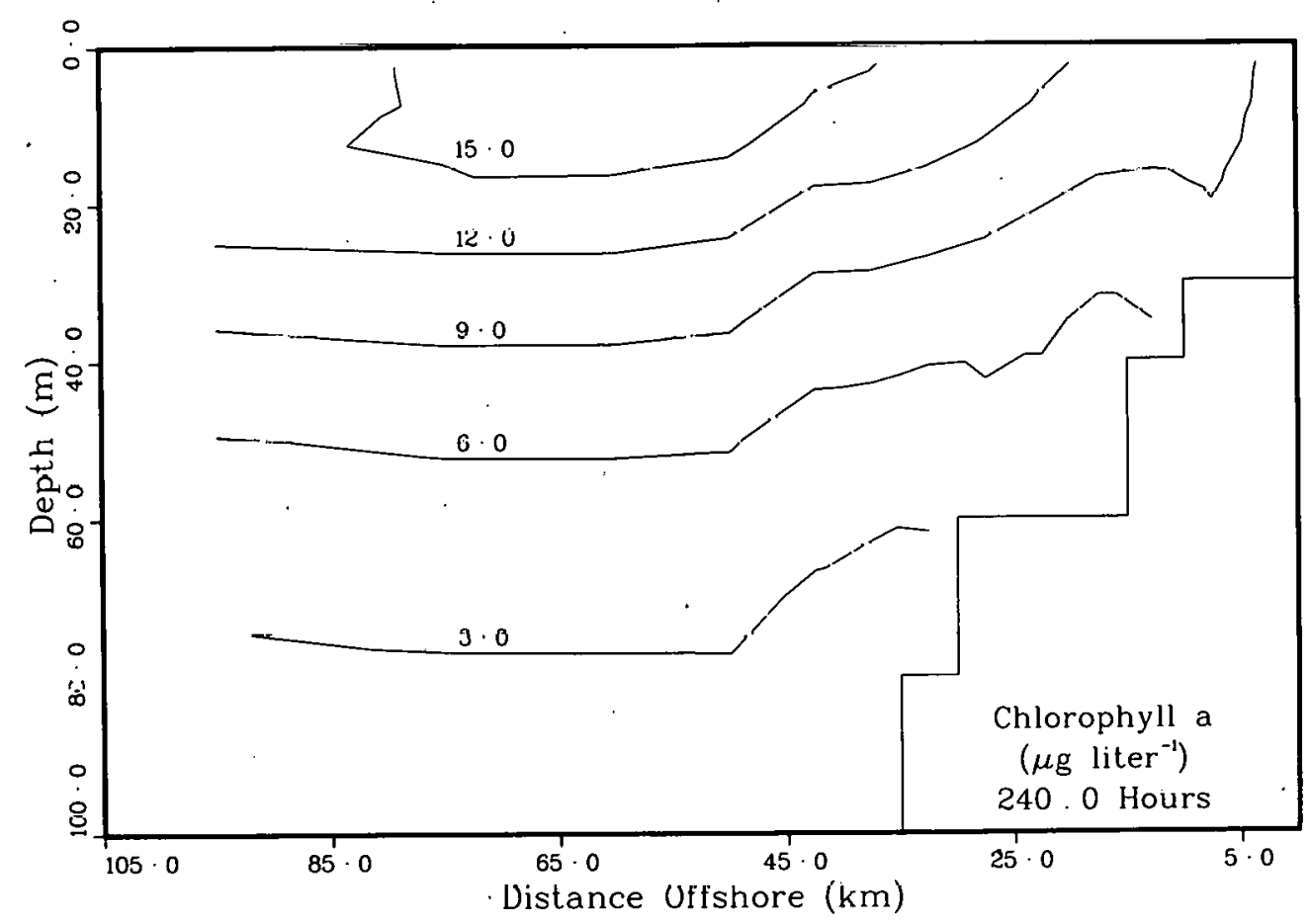

Figure 38. The chlorophy 11 a distribution after 10 days of upwelling with $\mathrm{K}_{\mathrm{z}}=\mathrm{cm}^{2} \mathrm{~s}^{-1}$. Contour interval is $3 \mu \mathrm{g} 1^{-1}$. 
offshore subsurface regions. In the previous weak mixing case with vertical eddy coefficients equal to $1 \mathrm{~cm}^{2} \mathrm{~s}^{-1}$, the mean nitrate concentration below $30 \mathrm{~m}$ after day 5 is $3.48 \mu \mathrm{g}$ at $1^{-1}$ and $4.39 \mu \mathrm{g}$ at $1^{-1}$ after day 10 . With vertical eddy coefficients of $40 \mathrm{~cm}^{2} \mathrm{~s}^{-1}$, the mean 30-100 m nitrate concentration is $5.36 \mu \mathrm{g}$ at $1^{-1}$ after day 5 and $5.41 \mu \mathrm{g}$ at $1^{-1}$ after day 10 .

The increased nutrient flux supports higher rates of primary production in the case with strong vertical mixing. After 5 and 10 days of upwelling in the weak mixing case, the mean net primary productivity integrated over the surface $20 \mathrm{~m}$ is affected by nitrogen limitation and the mean was 0.62 and $0.89 \mathrm{~g} \mathrm{C} \mathrm{m}^{-2} \mathrm{~d}^{-1}$, respectively. With the eddy coefficients increased to $40 \mathrm{~cm}^{2} \mathrm{~s}^{-1}$, productivity averages $3.92 \mathrm{~g} \mathrm{C} \mathrm{m}^{-2} \mathrm{~d}^{-1}$ after day 5 and $5.28 \mathrm{~g} \mathrm{C} \mathrm{m}^{-2} \mathrm{~d}^{-1}$ after day 10. Apparently the growth-stimulating effects of an improved nutrient environment are greater than the adverse effects that increased mixing has on the light environment for the phytoplankton.

The higher rates of primary production result in generally higher chlorophyll concentrations in the strong mixing case. With eddy coefficients of $1 \mathrm{~cm}^{2} \mathrm{~s}^{-1}$, the mean chlorophyll concentrations above $30 \mathrm{~m}$ increases from $3.91 \mu \mathrm{g} \mathrm{Chl} 1^{-1}$ after the first day to $4.88 \mu \mathrm{g} \mathrm{Chl} 1^{-1}$ after the tenth day. With the higher vertical eddy coefficients, the mean chlorophyl1 concentration above $30 \mathrm{~m}$ is $7.23 \mu \mathrm{g} \mathrm{Chl} 1^{-1}$ after day 5 and $12.56 \mu \mathrm{g} \operatorname{Ch} 11^{-1}$ after day 10. 
The vertically integrated ingestion of phytoplankton carbon by zooplankton and fish averages $0.79 \mathrm{~g} \mathrm{C} \mathrm{m}^{-2} \mathrm{~d}^{-1}$ after 10 days time. Ingestion is greatest in this case because relatively high phytoplankton concentrations above the grazing threshold $\left(1.2 \mu \mathrm{g}\right.$ at $\left.\mathrm{C}^{-1}\right)$ occur over a broad depth range. The upwelling-induced dilution of phytoplankton concentrations at mid-depths which occurred in the previous case is apparently compensated for by the downward mixing of phytoplankton from the surface layers. Strong vertical mixing also results in a reduction of the ammonium concentration maximum near the conat and botcom over the shelf. Maximum concentrations do not exceed $1 \mathrm{Hg}$ at $1^{-1}$ during the 10 day simulation period.

\subsection{Discussion}

The three cases depict responses of initially identical biological systems to different physical regimes, which are at times observed within the eastern boundary currents. The results from the first case without upwelling describe the transition towards an oligotrophic state. Without an advective nutrient input the phytoplankton remove nutrients from the euphotic zone until population growth is limited by nutrient supply from regenerative sources and slow turbulent input from below. An interesting feature of this simulation with eddy coefficients of $1 \mathrm{~cm}^{2} \mathrm{~s}^{-1}$ is the development of a subsurface chlorophy11 maximum at the base of the euphotic zone where the rale of nutrient supply is relatively high. The subsurface maximum extends offshore, but is most apparent over the shelf where the vertical nutrient gradient is greatest. These results suggest that subsurface chlorophyll 
maxima in oligotrophic systems may be biologically dynamic features not necessarily associated with vertical density gradients. A topic for future investigation is the extent to which the vertical position and intensity of density gradients as expressed in spatially variable eddy coefficients modify the subsurface chlorophyll maximum and the availability of nutrients higher in the euphotic zone.

A qualitative comparison of the first case with either of the cases run with advection shows that the model represents a number of expected differences between non-upwelling and upwelling regimes. Simulated upwelling increases nutrient concentrations in the euphotic zone and supports higher rates of primary production. Although the model may qualitatively depict an intuitively satisfactory biological response to upwelling, it was designed to quantitatively assess the effects of upwelling off northwest Africa. A comparison of simulated results with observations from the actual system reveals that significant differences exist between the actual and simulated systems.

The differences occur in both the weak and strong mixing cases with upwelling as phytoplankton concentrations become higher and nutriient concentrations become lower than observed during JOINT-I. As an example, compare the measured nitrate (Figure 39) and chlorophy 11 (Figure 40) distributions taken on 23-24 March 1974 after a 10-12 day period of strong equatorward wind stress with the nitrate (Figures 32 and 36) and chlorophyll (Figure 34 and 38) distributions after 10 days of simulated upwelling in the weak and otrong mixing caocs. In both cases, simulated chlorophyll concentrations in the surface layers are 
generally higher and nitrate concentrations lower than observed.

A comparison of the mean measured onshore-offshore distributions of nitrate and chlorophyll in the euphotic zone with the mean euphotic zone concentrations after 10 days of simulated time also illustrates similar differences (Figures 41 and 42). The purpose of the following discussion is to identify possible physical or biological factors in the model that may be responsible for these differences.

During JULN'L-1, one of the characteriscic features of the dis= tribution of nutrients was the occurrence of elevated ammonium concentrations ranging from 0.5 to $3.0 \mathrm{\mu g}$ at $1^{-1}$ within approximately $15 \mathrm{~km}$ of the coast. Codispoti and Friedrich (in press) have attempted to explain the origins of this feature and identify the reasons for its variability. They conclude its origins are probably related to a local net regenerative production of ammonium in excess of losses due to biological and physical transport processes. Other possible, but discounted, origins are alongshore advection of ammonium into the region from a nonlocal source or ammonium release from wind blown Sahara sand. A consideration of the observed and simulated ammonium distributions will show that the relatively high simulated phytoplankton biomass and low simulated nutrient concentrations cannot reasonably be attributed to differences between the actual and simulated physical regimes. Results from the simulation experiments support the hypothesis that the high ammonium concentrations could be a locally generated feature. Neither the alongshore advection feature nor the dissolution of ammonium from eand are included in the model formulatinn. 

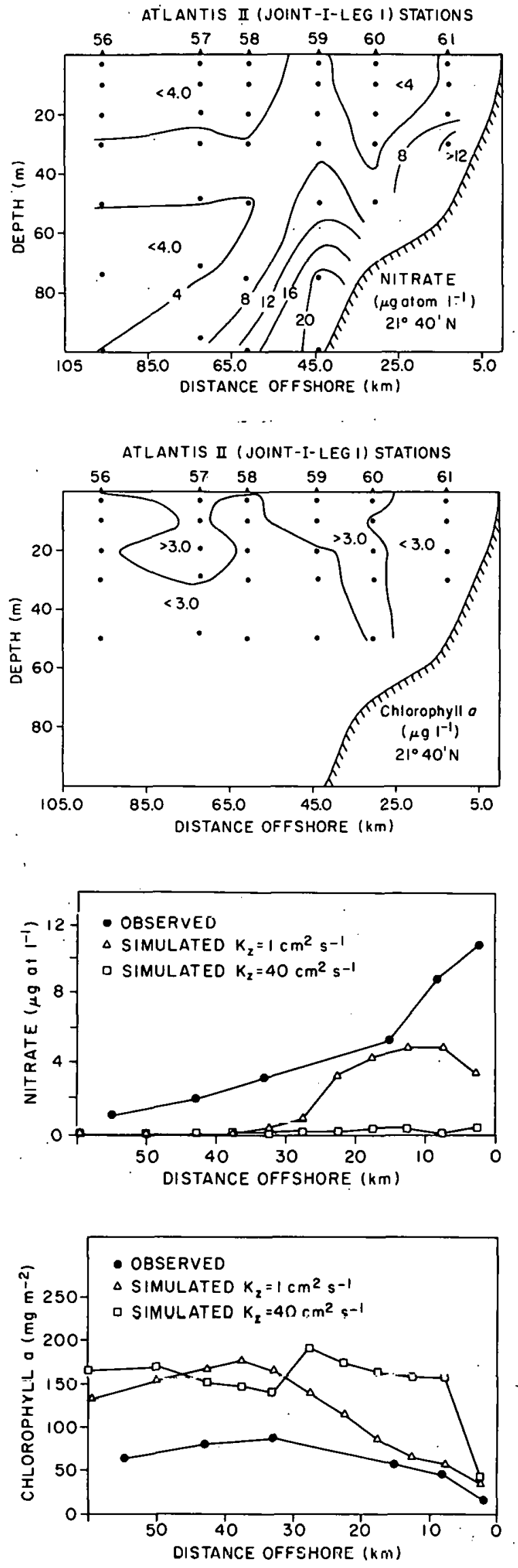

Figure 39. The distribution of nitrate at $21^{\circ} 40^{\prime} \mathrm{N}$ on 23-24 March, 1974, during JOINT I.

Figure 40 . The distribution of chlorophy 11 at $21^{\circ} 40^{\prime} \mathrm{N}$ on 23-24 March, 1974, during JOINT-I.

Figure 41. Observed and simulated onshore-offshore distributions of nitrate concentrations. Measured concentrations are averages over the euphotic zone for the JOINT-I cruise period, March-May, 1974 (From Huntsman and Barber, 1977.) Simulated concentrations are mean euphotic zone concentrations after 10 days simulation time. The depth of the euphotic zone in the simulation cases is defined for each column as the depth of the bottom boundary of the deepest segment where daily phytoplankton carbon fixation exceeds respiration.

Figure 42. Observed and simulated onshore-offshore distributions of chlorophyl1 a concentrations. Measured concentrations are averages over the euphotic zone for the JOINT-I cruise period, March-May, 1974 (From Huntsman and Barber, 1977). Simulation concentrations are averages for the euphotic zone as defined for Figure 41 . 
From initial concentrations of $0.24 \mu \mathrm{g}$ at $1^{-1}$ above $30 \mathrm{~m}$, and $0.35 \mu \mathrm{g}$ at $1^{-1}$ below, and despite dilution from upwelling source waters with $0.13 \mu \mathrm{g}$ at $1^{-1}$, all simulation experiments show a net production of ammonium occurring over some of the shelf region. Increases in simulated ammonium concentration tend to be greatest in the nearshore highly turbid region where maximum concentrations ranging from 0.81 to $3.04 \mu \mathrm{g}$ at $1^{-1}$ occurred in all three cases simulated (e.g., Figures 27 and 28 ). In agreement with the posstble sources " of vaidability suggested by Codispoti and Friedrich, the higher stmulated concenlralions occur when physical transport processes and phytoplankton growth are lowest (Figure 28). Conversely, lower concentrations occur when phytoplankton uptake rates.. and dilution by upwelling of low ammonia water are maximized. Although some characteristics of the high ammonium concentrations beneath the euphotic zone are accounted for by the model, the simulated ammonium concentrations in the surface layers are generally lower than the observed concentrations. Mean simulated ammonium concentrations in the surface 10 meters do not exceed $1.5 \mu \mathrm{g}$ at $1^{-1}$ in any of the simulation experiments, although concentrations of that magnitude were comnon in the surface layers near the coast. More intense upwelling would improve the agreement between observed and simulated distribuliuns of nitrate and chlorophyll because higher nitrate concentrations and lower chloropyhll concentrations would occur in the simulations if advection were increased (Walsh 1975). However, the comparison of the simulated cases shows that incrcaocd advection or mixing would further decrease the already 
low surface ammonium concentrations. It is unlikely, therefore, that the illustrated differences between observed and simulated distributions of nutrients and phytoplankton can be attributed to differences between actual and simulated physical conditions. The alternative explanations remaining are that the simulated phtytoplankton growth rates are greater and/or the phytoplankton loss rates are lower than the actual rates.

Given a set of initial conditions comparable to the mean JOINT-I conditions, simulated rates of net primary production do not significantly overestimate the rates measured by Huntsman and Barber (1977). They report that primary production generally varied between 1 and $3 \mathrm{~g}$ $\mathrm{c} \cdot \mathrm{m}^{-2} \cdot \mathrm{d}^{-1}$. In a separate short term simulation, initialized with the JOINT-I mean observed values listed in Table 4 (Appendix II), net carbon production occurring during 24 hours ranges from $0.98 \mathrm{~g} \mathrm{C}^{-\mathrm{m}^{-2}}$ $\mathrm{d}^{-1}$ inshore to $3.3 \mathrm{~g} \mathrm{C} \cdot \mathrm{m}^{-2} \cdot \mathrm{d}^{-1}$ over most of the shelf and offshore. areas. Simulated assimilation numbers ranging from $11 \mathrm{mg} C \cdot(\mathrm{mg} \mathrm{Chl}$ a) $\mathrm{d}^{-1}$ in the inshore turbid region to $31 \mathrm{mg} \mathrm{C}$ (mg Chl a) $\mathrm{d}^{-1}$ further offshore are calculated from the 24 hour net primary production integrated over the surface $20 \mathrm{~m}$ and a mean chlorophyll concentration estimated from initial and final chlorophyll concentrations integrated over the same depth interval in the model. Assimilation numbers measured by Huntsman and Barber over the interval between 0900 and 1500 houpo normally range from 2 to $1 \mathrm{mg}$ C. (mg Ch1 a)-l-hr-1. Tho relationship they found between incubations in natural light at 6 and 24 hour periods $\left(\mathrm{C}_{24}=1.72 \times \mathrm{C}_{6} \cdot 0.27\right)$ can be used to convert the 
observed range of hourly rates to average daily rates of approximately 20 to $41 \mathrm{mg} \mathrm{C} \cdot(\mathrm{mg} \cdot \mathrm{Chl} a) \cdot \mathrm{d}^{-1}$. Observed rates in these units compare more directly with the 11 to $31 \mathrm{mg} \mathrm{C} \cdot(\mathrm{mg} \mathrm{Chl} \text { a })^{-1 \cdot \mathrm{d}^{-1}}$ range calculated in the model for average JOINT-I conditions.

A broad range of environmental conditions, including onshore-. offshore nutrient gradients within the surface layers, is created in some of the other cases simulated. For example, after 10 days simulation time in the upwelling case with weak vertical mixing, the mean nitrate concentration in the upper $20 \mathrm{~m}$ was $4.10 \mu \mathrm{g}$ at $1^{-1}$ within $20 \mathrm{~km}$ of the coast and $1.06 \mu \mathrm{g}$ at $1^{-1}$ from 25 to $45 \mathrm{~km}$ offshore. The mean assimilation numbers calculated from simulated net primary productivity and chlorophyll concentrations integrated over these same regions are $50.1 \mathrm{mg} \mathrm{C} \cdot(\mathrm{mg} \mathrm{ChI} \mathrm{a})^{-1} \cdot \mathrm{d}^{-1}$ in the high nutrient area and $11.2 \mathrm{mg} \mathrm{C} \cdot(\mathrm{mg}$ Chl a $)^{-1} \cdot d^{-1}$ in the lower nutrient area further offshore. The greater of these rates, for the high nutrient area, exceeds the average observed values, but is within the 40 to $80 \mathrm{mg} \mathrm{C} \mathrm{(mg} \mathrm{Chl} \mathrm{a)} \mathrm{d}^{-1}$ range observed during periods of diminished winds and presumably moderate mixing. The high simulated assimilation number in the weak mixing case exceeds the short term simulated number for the mean JOINT-I conditions and a similar number calculated for the strong mixing case because most of the chlorophyll is near the surface in the weak mixing case. More light is attenuated by non-chlorophyll components and less remains for photosynthesis when the chlorophyll is more evenly distributed throughout the euphotic zone. 
Huntsman and Barber (1977) report that some variability in assimilation efficiency can be attributed to light-shade adaptation, but this process is not entirely represented in the current formulation of the model. For a given light intensity and vertical chlorophyll distribution, changes in the simulated carbon-specific rate of photosynthesis (mg $\left.\mathrm{C} \cdot(\mathrm{mgC})^{-1} \cdot \mathrm{d}^{-1}\right)$ do occur when the chlorophyll per cell changes. However, the chlorophyl1-specific rate of photosynthesis (mg $c \cdot(m g ~ C h I$ a) ${ }^{-1} \cdot d^{-1}$ ) does not change if $Q_{\max }$ and $I_{\max }$ are constants in [2.03]. These parameters remain constant in this formulation, because the light-shade adaptation process has not yet been adequately theoretically resolved. The problem of parameterizing the process has been encountered by others and one solution used in simulation studies by Jamart, et al. (1977) and Steele and Frost (1977) is to force photosynthetic parameters to change as a function of maximum daily incident light intensity on a seasonal time scale. This solution unfortunately leaves the mechanism for the change undefined in biological terms and, in any event, is probably not appropriate for light-shade adaptation occurring at the time scale of this model. The absence of a lightshade adaptation mechanism in this model is not, however, particularly significant. Without the light-shade adaptation process, simulated rates underestimate light-adapted primary production rates measured on JOINT-I during the infrequent and brief calm periods.

The above analysis suggests that the formulation of environmental characteristics and phytoplankton growth functions of the model are resonable and should not intrinsically overestimate the observed rates of primary production. If the simulated rate of phytoplankton increase 
is not intrinsically high, then the loss rates must be low. Rates of phytoplankton physiological mortality are generally assumed to be slow in comparison to rates of growth and uptake. The rate used in this model $\left(\mathrm{m}=0.0042 \mathrm{hr}^{-1}\right)$ is equivalent to the rate used by Wroblewski (1977) in a model of upwelling off Oregon and is similar to sinking. loss rates assumed by other authors. For example, Steels and Frost (1977) assume the sinking rate to be a function of nutrient concentration and refer to Epley, el al. (1967) to obtain a maximum sinking rate of $1 \mathrm{~m} \mathrm{~d}^{-1}$ for non-growing cells $10 \mu$ in diameter. In the 5,10 , and 20 , thick layers of this model, a $1 \mathrm{~m} \mathrm{~d}^{-1}$ sinking rate could result in local losses of phytoplankton as high as $0.008,0.005$, and 0.002 $\mathrm{hr}^{-1}$, respectively. These sinking rates approximate the assumed mortality rate for non-growing phytoplankton in this model and would not significantly alter the simulated results if they were used in place of the assumed mortality function. Unless phytoplankton physiological mortality occurs at a rate much higher than presently believed, it has a relatively minor effect on the distribution of phytoplankton and nutrients at the time and space scales of this model.

Losses of phytoplankton to herbivorous zooplankton and fish are the possible processes remaining in the model's formulation which could reduce the rates of simulated primary production. The amount of phytoplankton lost to grazing is dependent on the areal biomass, vertical distribution and species and age composition of the herbivurus population. Data are available for estimates of areal biomass, but lacking for estimates nf vertical distribution and population composition. Specifications for the vertical distribution and composition of the 
herbivores in the model are based on simple assumptions and allow for the vertically homogenous distributions of one type of herbivorous fish and two size classes of herbivorous zooplankton. More elaborate specifications in the absence of a more complete data set would be arbitrary and unwarranted.

If zooplankton and fish were concentrated in the upper layers of the model where phytoplankton growth rates and biomass are greatest, losses to grazing would increase and agreement between calculated and observed distributions in the previous examples would improve. The magnitude of the effects on phytoplankton and nutrient distributions resulting from a vertical migration of the herbivore biomass varies as a function of the vertical phytoplankton distribution and concentration. If all herbivores were concentrated in the upper $30 \mathrm{~m}$ after 10 days time in the simulation experiments, losses to grazing would approximately triple in the weak mixing case and approximately double in the strong mixing case. The rates of net primary production in the surface layers of these cases remain greater than the increased ingestion rates. It is unlikely, therefore, that migratory behavior alone can completely account for the differences between observed and simulated results.

The species and age composition of the zooplankton population are parameterized in the model as a function of the size of the organisms. Two size classes are represented and size-specific ingestion rates are defined in relation to the expected size-specific metabolic rate estimates for each class. Differences in grazing behavior related to the composition of the zooplankton may be even larger than assumed in the 
model. Steele and Frost (1977) have recently published a more detailed formulation for the size-specific characteristics of filter feeding zooplankton. They propose an ingestion function which, if used in this model would yield, for the smaller zooplankton, a size-specific ingestion rate, a factor $\lambda=4.9$ (see [3.26] greater than rates for the large zooplankton; a size-specific effect $53 \%$ greater than the value assumed. The effects of size may be further underestimated, because unweighted arithmetic mean weights are used to describe the two classes of grazers whose ingestion rates increase geometrically as an inverse function of size. Simulated ingestion rates may also be low if very small or soft bodied herbivores have been inefficiently sampled and represented. Unfortunately, the magnitude of size, species, or age specific effects not included in this model cannot be reliably estimated with the available data.

A number of previous simulation studies concerned with lower trophic level dynamics have encountered, but not necessarily emphasized, the problems associated with representing the herbivorous components of marine ecosystems. O'Brien and Wroblewski (1973) in a study of a region off West Florida cited data for zooplankton biomassspecific ingestion rates ranging from 0.10 to $0.60 \mathrm{day}^{-1}$, but apparent ly tound it necessary to use a value of $1.51 \mathrm{day}^{-1}$ to produce reasonable ecological efficiencies with a simulated final zooplankton biomass approximately one half of the phytoplankton biomass. A sensitivity analysis of a non-spatial version of the model at steady state suggests the importance of grazing control and it shows their results 
to be more sensitive to parameter changes related to zooplankton processes than any others.

In a subsequent study of the upwelling system off Oregon, Wroblewski (1977) cites and uses a maximum zooplankton ingestion rate of $0.48 \mathrm{~d}^{-1}$. His analys is of the model equations "show the parameters describing zooplankton grazing, egestion, and excretion are the most important... in determining the steady state concentrations". of nitrate, ammonium, detritus and phytoplankton and zooplankton biomass. He concludes that his model successfully reproduces several of the observed biological and chemical features off Oregon, but does not discuss or quantitatively compare with observations his remarkably high simulated distributions of zooplankton biomass. After 10 days simulation time, the zooplankton biomass is approximately equal to or double the phytoplankton biomass over most of the euphotic zone. Data for Oregon were not available, but a comparison of the Peru, Baja California and northwest Africa upwelling ecosystems by Walsh (1976) suggests that phytoplankton concentrations in the euphotic zones of these upwelling systems may exceed mean zooplankton biomass concentrations by a factor of ten or more.

In Walsh's (1975) simulation model of the Peru upwelling system both herbivorous zooplankton and fish are represented. As in the present model of upwelling off northwest Africa, Walsh uses field measurements of zooplankton biomass and laboratory measurements of grazing a maximum ingestion rate of $0.29 \mathrm{~d}^{-1}$ ) to estimate losses of phytoplankton to the zooplankton. The anchoveta are assumed to have a maximum specific ingestion rate of $0.65 \mathrm{~d}^{-1}$; a rate similar to the $0.04 \mathrm{~d}^{-1}$ 
rate for Sardina in the model of upwelling off northwest Africa. The wet weight estimate of fish biomass Walsh uses in the autumn upwelling plume off Peru is approximately $1 \times 10^{3} \mathrm{~g} \mathrm{~m}^{-2}$ or a factor of 20 larger than the estimated Sardina population off Africa. Walsh makes the biomass estimates from echogram and schooling geometry arguments that, according to his figures, would place half of the total Peruvian anchoveta biomass in a single upwelling plume constituting $8 \%$ of the total Peruvian upwelling area estimated by Ryther (1969) or $1 \%$ of the total area estimated by Cushing (1960). Walsh then found it necessary to arbitrarily introduce a grazing threshold of $3.0 \mu \mathrm{g}$ atoms phytoplankton nitrogen $1^{-1}$ (equivalent to a chlorophyll concentration of 3.8

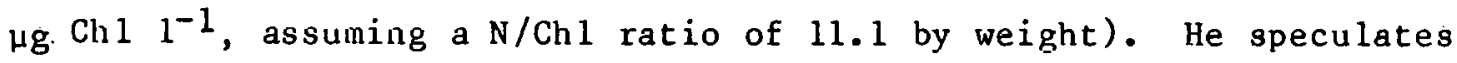
that such a large threshold "is essentially a parameterization of the inability of the herbivore submodel to resolve horizontal scales of prey patchiness of less than $10 \mathrm{~km}, "$ but a simpler alternative explanation is that the anchoveta biomass is too high. Whatever the explanation, it is clear that a more objective definition of the grazing stress for the Peru upwelling system is needed.

In a study of phytoplankton growth and nutrient distribution of $f$ the northwestern U.S. coast, Jamart, et al. (1977) also acknowledged that one of the less satisfying aspects of their work was the necessity of "altering the grazing pressure to make fine adjustments during the numerical simulations." They specitied a somewhat arbitrary maximum zooplankton ingestion rate of $2.0 \mathrm{~d}^{-1}$ and even then the values of zooplankton biomass used in the model were about two to three times greater than the observed values. When the sensitivity of this type 
of lower trophic level model to changes in grazing parameters is considered, the uncertainties associated with the estimates of the zooplankton biomass and rate parameters are unacceptably large for predictive analysis. They suggest that one of the contributions of their theoretical study is that it "emphasizes the need for a more accurate knowledge of the feeding rate and the spatial and temporal distribution of zooplankton." The results from this simulation study of upwelling off northwest Africa reinforces the statement of Jamart, et a1. (1977). This analysis has shown that the behavioral characteristics of the herbivores fundamentally affect the biological response to upwelling and that uncertainties associated with estimates of herbivore biomass and vertical migratory and feeding behavior are critical to an adequate representation of ecosystem functions. While O'Brien and Wroblewski (1973) and Wroblewski.(1977) showed that grazing may be the most dynamic process of marine ecosystems, this analysis, by a process of elimination, shows that it may also be the most poorly understood.

\subsection{Summary and Conclusions}

A two dimensional model of upwelling and its effects on nutrient and phytoplankton fields has been developed. In it, a phytoplankton population is defined by a set of variables for cell numbers and particulate carbon, nitrogen, chlorophyll and silica. Phytoplankton grnwth rate is simulated as a function of conccntrations of nitrate, ammonium, and silicate and intensity of photosynthetically active radiation. Grazing losses occur to one species of herbivorous fish and two size classes of zooplankton. 
Several simulation experiments have been run to study the effects of upwelling in the northwest African coastal ecosystem. Time varying habitat characteristics are defined by independent submodels for physical circulation and solar radiation.

Comparisons of simulation results with measurements made during the JOINT-I expedition during 1974 suggest that some observed characteristics may occur as consequences of interactions expressed in the model. Simulations show a flux of nutrient rich water into the euphotic zone supporting high rates of primary production seaward of a turbid nearshore region. High ammonium concentrations, observed in the nearshore region, are shown in the simulations to be sensitive to physical circulation processes and phytoplankton uptake rates.

Given comparable environmental conditions, simulated and observed intrinsic rates of phytoplankton growth are approximately equal. However, rates of primary production during simulated upwelling exceed significantly the losses attributed in the model to phytoplankton physiological mortality and ingestion by herbivores. An underestimate of the significance of grazing related to the vertical distribution of biomass and feeding behavior of the zooplankton is identified as the factor responsible for the discrepancey between observed and simulated conditions. 
Aird, T.J. 1972. SPSS Subprogram NONLINEAR Manual No. 313 (Vogelback Computing Center, Northwestern University, Evanston, I11.).

Bannister, T.T. 1974a. Production equations in terms of chlorophyll concentration, quantum yield and upper limit to production. Limnol. Oceanogr. 19:1-12.

Banse, K. 1974. On the interpretation of data for the carbon-tonitrogen ratio of phytoplankton. Limnol. Oceanogr. 19:695-699.

Banse, K. 1976. Rates of growth, respiration and phytosynthesese of anicellular algae as related to cell size - a review. J. Phycol. $12: 135-140$.

Barber, R.T. 1977. The JOINT-I expedition of the Coastal Upwelling Ecosystems Analysis Program. Deep-Sea Res. 24:1-6.

Barber, R. T. and S. A. Huntsman. 1975. JOINT-I carbon, chlorophyll and light extinction-R/V Atlantis II Cruise 82. Data Report 14 Coastal Upwelling Ecosystems and Analysis Program.

Barton, E.D., A. Huyer, R. L. Smith. 1977. Temporal variation observed in the hydrographic regime near Cabo Corbeiro in the northwest African upwelling region, February to April 1974. Deep-Sea Res. 24:7-24.

Beckett, R. and J. Hurt. 1967. Numerical Calculations and Algorithms, McGraw Hill, New York.

Bella, D.A. and W.E. Dobbins. 1968. Difference modelling of stream pollution. Sanitary Engineering Division, ASCE 94:995-1016.

Bella, D.A. and W.J. Grenney. 1970. Finite-difference convective errors. Sanitary Engineering Division, ASCE 96:1361-1375.

Bierman, V.J., Jr., F.H. Verhoff, T.L. Poulson, and M.W. Tenney. 1973. Multi-nutrient dynamic models of algal growth and species competition in eutrophic lakes, p. 89-109. In E.J. Middlebrooks, et al. (eds.) Modelling and Eutrophication Process, Ann Arbor Sci.

Blackburn, M. 1975a. Small-scale distribution of zooplankton in an upwelling area off northwest Africa. Fourth Symposium of Baltic Marine Biologiste, Gydnia, Poland.

Blackburn, M. 1975b. Summary of existing information on nekton of Spanish Sahara and adjacent regions, northwest Africa. Coastal Upwelling Ecosystems Analysis, Tech. Rep. 8, 49'p. 
Blackburn, M. 1975c. Distribution of animal biomasses of different trophic levels in a coastal upwelling area: preliminary results from the CUEA program. Prepared for the Working Symposium on the Prediction of Sound Scattering in the Oceans from Physical/ Chemical/Biological Information, 10-14 November 1975, Asilomar, Monterey, California.

Blackburn, M. and W. Nellen. 1976. Distribution and ecology of pelagic fishes studied from eggs and larvae in an upwelling area off Spanish Sahara. Fish. Bull. 74:885-896.

Butler, E.I., E.D.S. Corner, S.M. Marshall. 1970. On the nutrition and metabolism of zooplankton VII seasonal survey of nitrogen and phosphorous excretion by Calanus in the Clyde Sea-area. J. Mar. Biol. Assoc. U.K. 50:525-560.

Caperon J. 1967. Population growth in micronrganisms limiter hy fond supply. Ecology 48:715-722.

Caperon, J. 1969. Time lag.in population growth response of Isochyrsis galbana to a variable nitrate environment. Ecology 50:188-192.

Caperon, J. and J. Meyer. 1972. Nitrogen-limited growth of marine phytoplankton II. Uptake kinetics. and their role in nutrientlimited growth of phytoplankton. Deep-Sea Res. 19:619-632.

Carpenter, E.J. and R.R,L. Guillard. 1971. Intraspecific difference in nitrate half-saturation constants for three species of marine phytoplankton. Ecology 52:183-185.

Codispoti, L.A. and G.E. Friedrich. (In press.) Local and mesoscale influences on nutrient variahility in the northwest African upwelling region near Cabo Corbeiro. Deep-Sea Res.

Conway, H.L. 1977. Interactions of inorganic nitrogen in the uptake and assimilation by marine phytoplankton. Mar. Biol. 39:221-232.

Corner, E.D.S., C.B. Cowey and S.M. Marshall. 1965. On the nutrition and metabolism of zooplankton. III. Nitrogen excretion by Calallus. J. Mar. Biol. Assoc. U.K. 45:429-442.

Cushing, D.H. 1971. Upwelling and the production of fish. Adv. Mar. Biol. $9: 25,5-334$.

Cushing, D.H., G.F. Humphrey, K. Banse, T. Laevasta. 1958. Report of the committee on terms and equivalents. Rap. Proc.-Verb. Cons. Perm. Internat. Explor. Mer 144:15-16. 
Droop. M.R. 1968. Vitamin B 12 and marine ecology. IV. The kinetics of uptake growth and inhibition in Monochrysis luther. J, Mar. Biol. Assoc. U.K. 48:689-733.

Droop, M.R. 1973. Some thoughts on nutrient limitation algae. J. Phycol. 9:264-272.

Droop. M.R. 1974. The nutrient status of algal cells in continuous culture. J. Mar. Biol. Assoc. U.K. 54:825-55.

Droop. M.R. 1975. : The nutrient status of algal cells in batch culture. J. Mar. Biol. Assoc. U.K. 55:541-555.

Dugdale, R.C. 1967. Nutrient limitation in the sea: Dynamics, identification, and significance. Limnol. Oceanogr. 12:586-695.

Dugdale, R.C. and J.J. Goering. 1967. Uptake of new and regenerated forms of nitrogen in primary productivity. Limnol. Oceanogr. $12: 196-206$.

Dugdale, R.C: and J.J. MacIsaac. 1971. A computational model for the uptake of nitrate in Peru upwelling region. Invest. Pesq. $35: 299-308$.

Eppley, R.W. 1970. Relationships of phytoplankton species distribution to the depth of the distribution of nitrate. Scripps Inst. of Oceanogr. Bull. 17:43-50.

Eppley, R.W. 1972. Temperature and phytoplankton growth in the sea.. Fish. Bul1. 70:1063-1085.

Eppley, R.W., A.F. Carlucci, O. Holm-Hansen, D. Kiefer, J.J. McCarthy, E. Venrick, and P.M. Williams. 1971. Phytoplankton growth and composition in shipboard cultures supplied with nitrate, ammonium, or urea as the nitrogen source. Limnol. Oceanogr. 16:741-751.

Eppley, R.W., J.L. Coatsworth, and L. Solorzano. 1969a. Studies of nitrate reductase in marine phytoplankton. Limnol. Oceanogr. $14: 194-205$.

Eppley, R.W., R.W. Holmes, and J.D.H. Strickland. 1967. Sinking rates of marine phytoplankton measured with a fluorometer. J. Exp. Mar. Biol. Ecol. 1:191-208.

Eppley, R.W., T.T. Packard, and J.J. MacIsaac. 1970. Nitrate reductase in marine Peru Current phytoplankton. Mar. Biol. 6:195-199.

Eppley, R.W. and E.H. Renger. 1974. Nitrogen assimilation of an oceanic diatom in nitrogen-limited continuous culture. J. Physol. $10: 15-23$. 
Eppley, R.W., E.H. Renger, E.L. Venrick, and M.M. Mullin. 1973. A study of the plankton dynamics and nutrient cycling in the central gyre of the North Pacific Ocean. Limnol. Oceanogr. 18:534-551.

Eppley, R.W., J.N. Rogers, and J.J. McCarthy. 1969. Half-saturation constants for uptake of nitrate and ammonium by marine phytoplankton. Limnol. Oceanogr. 14:912-920.

Eppley, R.W., J.N. Rogers, J.J. McCarthy, 1971. Light/dark periodicity in nitrogen assimilation of the marine phytoplankters Skeletonema costatum and Coccolithus huxley: in N-limited chemostat culture.' J. Phycol. 7:150-154.

Eppley, R.W. and W.H. Thomas. 1969. Comparison of half-saturation "constants" for growth and nitrate uptake of marine phytoplankton. J. Phycol. 5:375-379.

- Falkowski, P.G. 1975. The mechanisms and energetics of nitrate uplake by marine phytoplankton. Ph.D. Thesis, University of British Culumbia.

Falkowski, P.G. 1975. Nitrate uptake in marine phytoplankton: Comparison of half-saturation constants from seven species. Limnol. Oceanogr. 20:412-41,7.

Frost, B.W. 1972. Effect of size and concentration of food particles on the feeding behavior of the marine planktonic copepod Calanus pacificus. Limnol. Oceanogr. 17:805-815.

Fuhs, G.W. 1969. Phosphorous content and rate of growth in diatoms Cyclotella nana and Thalassiosira fluvlatilis. J. Thycol. 5:312-321.

Goering, J.J., P.M. Nelson and J.A. liartèr. 1973. Silicic acid uptake by natural populations of marine phytoplankton. Deep-Sea Res. $20: 777-789$.

Goering, J.J., D.D. Wallen, and R.M. Nauman. 1970. Nitrogen uptake by phytoplankton in the discontinuity layer of the eastern subtropical Pacific ocean. Limnol. Oceanogr. 15:789-796.

Grant, B.R. 1967. The action of light on nilrate and nitrite assimilation by the marine chlorophyte, Danaliella tertiolecta

(Batcher). J. Gen. Milcrubiul. 48:379-387.

Grant, B.R. and I.M. Turner. 1969. Light-simulated nitrate and nitrite assimilation in several species of algae. Comp. Biochem. Physiol. 29:995-1004.

Gulland, J.A. 1970. Food chain studice and some problems in world fisheries, pp. 296-315. In Marine Food Chains, J. H. Steele, Ed., University of Calif. Press, Berkeley. 
Halpern, D. 1977. Description of wind and upper ocean current and temperature variations on the continental shelf off northwest Africa during March and April 1974. J. Phys. Oceanogr. 7:422-430.

Hamilton, P. 1975. A numerical model of the vertical circulation of tidal estuaries and its application to the Rotterdam Waterway. Geophys. J. R. astr. Soc. 40:1-21.

Hamilton, P. and M. Rattray Jr. 1978. A numerical model of the depth dependent wind driven upwelling circulation on a continental shelf. J. Phys. Oceanogr. 8:437-57.

Harbaugh, J.W. and G. Bonham-Carter. 1970. Computer Simulation in Geology, 573 pp., Wiley-Interscience, New York.

Harper, M.E. 1972. Development and application of a multi-parametric mathematical model of water quality. University of Washington, $\mathrm{Ph} . \mathrm{D}$. Dissertation.

Harrison.' P.J., H.L. Conway, T.C. Dugdale. 1976. Marine diatoms grown in chemostats under silicate or ammonium limitation. I. Cellular chemical composition and steady state growth kinetics of Skeletonema costatum. Mar. Biol. 35:177-186.

Healey, F.P. 1973. Inorganic nutrient uptake and deficiency in algae. CRC Critical Reviews in Microbiology, Sept. 1973, pp. 69-113.

Hitchcock, G.L. 1977. The concentration of particulate carbohydrate in a region of the west Africa upwelling zone during March, 1974. Deep-Sea Res. 24:83-94.

Huntsman, S.A. and R.T. Barber. 1977. Primary production off northwest Africa: the relationship to wind and nutrient conditions. Deep-Sea Res. 24:35-48.

Ikeda, T. 1974. Nutritional ecology of marine zooplankton. Mem. Fac. Fish. Hokkaido Univ. 22:1-97.

Ikeda, T. 1977. The effect of laboratory conditions on the extrapolation of experimental measurements to the ecology of marine zooplankton. IV. Changes in respiration and excretion rates of boreal zooplankton species maintained under fed and starved conditions. Mar. Biol. 41:241-252.

Ivlev, V.S. 1945. The biological productivity of waters. Usp. Sovrem. Biol. 19:98-120.

Jamart, B.M., D.F. Winter, K. Banse, G.C. Anderson, R.K. Lam. 1977. A theoretical study of phytoplankton growth and nutrient distribution in the Pacific Ocean off the northwestern U.S. coast. Deep-Sea Res. 24:753-773. 
Lehman, J.T., D.B. Botkin, and G.E. Likens. 1975. The assumptions and rationales of a computer model of phytoplankton population dynamics. Limnol. Oceanogr. 20:343-364.

Lorenzen, C.J. 1968. Carbon chlorophyll relationships in an upwelling area. Limnol. Oceanogr. 13:202-204.

Lorenzen, C.J. 1972. Extinction of light in the ocean by phytoplankton. J. Cons., Cons. Int. Explor. Mer. 34:262-267.

MacIsaac, J.J. and R.C. Dugdale. 1969. The kinetics of nitrate and ammonium uptake by natural populations of marine phytoplankton. Deep-Sea Res. 16:45,57.

Maclsaac, J.J. and R.C. Dugdale. 1972. Interacliuus of 1 ight and inorganic nitrogen in controlling nitrogen uptake in the sea. Deep-Sea Res. 1y:2Uy-23\%.

Mathisen, O.A., R.E. Thorne, R.J. Trumble, and M. Blackburn. (In press.) Food consumption of pelagic fish in an upwelling area.

McCarthy, J.J. and T.E. Whit ledge. 1972. Nitrogen excretion by anchovy (Engraulis mordax and $\underline{E}$. ringens) and Jack mackerel (Trachurus symmetricas). Fish. Bull. 70:395-401.

McCracken, D.D. and W.S. Dorn. 1964. Numerical Methods and Fortran. Programming, John Wiley and Sons, Inc., New York, Ch. 10 .

McCullough, E.C. and W.P. Porter. 1971. Computing clear day solar radiation spectra for the terrestrial ecological environment. Ecology 52:1008-1015.

Mittelstaedt, E. and K.P. Koltermann. 1973. On the currents over the shelf off Cap Blanc in the northwest African upwelling area. Dt. Hydrogr. Z. 26:193-215.

Mittelstaedt, E., D. Pillsbury, and R.L. Smith. 1975. Flow patterns in the northwest African upwelling are. Dt. Hydrogr. $Z$. $28: 145-167$.

Monod, J. 1942. La Croissance des Cultures Bacteriennes. Herman, Paris, $210 \mathrm{FP}$.

Morishima, D.L., P.B. Bass, and J.J. Walsh. 1974. AUGUR, a three-dimensional simulation program for non-linear analysis of aquatic ecosystems, CUEA Tech. Report No. 7, University of Washington, Dept. of Oceanography.

Mullin, M.M. 1969. Production of zooplankton in the ocean: the present status and problems. Oceanogr. Mar. Biol. Ann. Rev. $7: 293-314$. 
Mullin, M.M., E.F. Stewart, and F.J. Fuglister. 1975. Ingestion by plankton grazers as a function of concentration of food. Limnol. Oceanogr. 10:259-262.

Myers, J. and J. Graham. 1971. The photosynthetic unit in Chlorella measured by repetitive short flashes. Plant Physiol. $4 \overline{8: 282-286}$.

O'Brien, J.J. and J.S. Wrobleski. 1973. On advection in phytoplankton models. J. Theor. Biol. 38:197-202.

Orlob, G.T., Shubinski, R.P., and Feigner, K.D. 1967. Mathematical modelling of water quality in estuarial systems. National Symp. on Estuarine pollution, Stanford University.

Parsons, T.R. and M. Takahashi. 1973. Biological Oceanographic Processes, Pergamon Press. New.York, 186 pp.

Piacsek, S.A. and G.P. Williams. 1970. Conservation properties of convective difference schemes. J. Comp. Phys. 6:392-405.

Platt, T. and A.D. Jassby. 1976. The relationship between photosynthesis and light for natural assemblages of coastal marine phytoplankton. J. Phycol. 12:421-430.

Portman, P.J. and E. Ryznar. 1971. An Investigation of Heat Exchange, East-West Center Press, Honolulu.

Reed, R.K. and D. Halpern. 1974. Radiation measurements off the Oregon Coast (July/August 1973) CUEA Data Report 13. Pacific Marine Environmental Laboratory/NOAA, Univ. of Washington, Seattle, Wash.

Rowe, G.T., C.H. Clifford, and K.L. Smith, Jr. 1977. Nutrient regeneration in sediments off Cap Blanc, Spanish Sahara. Deep-Sea Res. $24: 57-64$.

Ryther, J.H. 1956. Interrelation between photosynthes is and respiration in the marine flagellate, Dunaliella euchlora. Nature (London) 178:861-863.

Ryther, J.H. 1969. Photosynthesis and fish production in the sea. Science 166:72-76.

Ryther, J.H., D.W. Menzel, E.M. Hulburt, C.J. Lorenzen, and N. Corwin 1971. The production and utilization of organic matter in the Peru coastal current. Inv. Pesq. 35:43-59.

Shumann, F.R. and C.J. Lorenzen. 1975. Quantitative degradation of chlorophyll by a marine herbivore. Limnol. Oceanogr. $20: 580-586$. 
Sivkov, S.J. 1971. Computation of solar radiation characteristics. Translated from Russian by the Israel Program for Scientific Translation. Available from U.S. Dept. of Commerce, National Technical Information Service, Springfield, Va. 22151, TT 70-50055.

Smith, S.L. and T.E. Whitledge. 1977. The role of zooplankton in the generation of nitrogen in a coastal upwelling system off northwest Africa. Deep-Sea Res. 24:49-56.

Steele, J.H. and B.W. Frost. 1977. The structure of plankton communities. Phil. Trans. Roy. Soc. Lon. Biol. Sci. 280:485-534.

Steeman-Nielsen, E. and E.G. Jorgensen. 1968. The adaptation of plankton algae. III. With special consideration of the importance in naturo. Phyoiologia P1. 21:647-654.

Strathman, R.R. 1967. Estimating the organic carbon content of phytoplankton from ccll volume or plasma volume, Liumul. Ocuanugr. 12:411-418.

Strickland, J.D.H. 1958. Solar radiation penetrating the ocean. A review of requirements data and methods of measurement, with particular reference to photosynthetic productivity. J. Fish. Res. Bd. Canada, 15:453-493.

Strickland, J.D.H. 1965. Production of organic matter in the primary stages of the marine food chain. In Chemical Oceanography, J. P. Riley and G. Skirrow (eds.), Academic Press, New York.

Syrett, P.J. 1962. Nitrogen assimilation. In Physiology and Biochemistry of Algae, T. Lewin (ed.), Academic Press, New York, pp. 171-188.

Syrett, P.J. and J. Morris. 1963. The inhibition of nitrate assimilation by ammonium in Chlorella. Biochim. Biophys. Acta. 67 :566-575.

Thomann, R.V. 1972. Systems Analysis and Water Quality Management, 286 pp., Environmental Research and Applications, Inc., New York.

Thorne, R.E., O.A. Mathisen, R.J. Trumble, and M. Blackburn. 1977. Dietribution and abundance of pelagic fish off 3 parish 3 alıala during CUEA expedition JOINT-T. Deep-Sea Res. 24:75-82.

University of California Institute of Marine Resources. 1972. Research on the marine food chain - report for the period July 1971-1972. Part 3. Data Record (IMR No. 72-12). Univ. Calif., San Diego, Dec. 10P20-121. 728 p. 
Vollenweider, R.A. 1965. Calculation models of photosynthesis-depth curves and some implications regarding day rate estimates in primary production measurements, p. 425-457. In: C. R. Goldman (ed.), Primary Productivity in Aquatic Environments. Mem. Ist. Ital. Idrobiol 18 (suppl), also Univ. Calif. 1966.

Walsh, J.J. 1972. Implications of a systems approach to oceanography. Science 176:969-975.

Walsh, J.J. 1975a. A spatial simulation model of the Peru upwelling ecosystem. Deep-Sea Res. 22:201-236.

Walsh, J.J. 1976a. A biological sketchbook for an eastern boundary curent. In: The Sea, Vol. 6, E. D. Goldberg, I. N. McCave, J. J. O'Brien, and J. H. Steele, Eds., Wiley-Interscience, pp. 923-968.

Walsh, J.J. 1976b. Model of the sea. In: The Ecology of the Seas, D. H. Cushing and J. J. Walsh, eds., Blackwell, Oxford, pp. 388-407.

Whit ledge, T.E. 1972. Excretion measurements of nekton and the regeneration of nutrients near Punta San Juan in the Peru upwelling system derived from nekton and zooplankton. Ph.D. dissertation, University of Washington, Seattle, $114 \mathrm{pp}$.

Williams, F.M. 1971. Dynamics of microbial poulations. In: Systemns Analysis and Simulation in Ecology, B. C. Patten, ed., Academic Press, New York, pp. 197-267.

Wroblewski, J.S. 1977. A model of phytoplankton plume formation during variable Oregon upwelling. J. Mar. Res. 35:357-394. 
APPENDIX I

\author{
BIOCEAN, A FORTRAN Program for Simulation \\ in a Biological Oceanography
}

The state equations of the models discussed in this study were solved with a FORTRAN program named BIOCEAN. Although BIOCEAN is similar in principal to its predecessor AUGUR (Morishima, et al. 1974), it is different in several operational respects. Like AÜGUR, BIOCLAAN is designed as a program for 3-dimensiulla simulation and analysis in biological oceanography. Both programs use a similar spatial segmentation system and operate on a simulated space divided into $\mathrm{I}, \mathrm{J}, \mathrm{K}$ columns, rows and layers of rectilinear segments, each with a linear subscript or numerical sequence identifier. Unlike AUGUR, BIOCEAN . begins each iteration at the surface; it is not dependent on installation-specific assembly language subroutines and it does not iteratively transfer all computational information to and frum ulass storage. Use-interraction with BIOCEAN is more direct than with AUGUR, because BIOCEAN lacks the lengthy code necessary to interpret a complex set of input fastructious intended to automatically dirert program execution. With a reduced operating overhead, BIOCEAN is mure compact, easier to use and operates at approximately $1 / 30$ the cost of AUGUR for simulations on the scale of the northwest African upwelling study. Smaller scale simulations with fewer equations are run even more efficiently. 


\section{I.A The Numerical Integration Scheme}

The numerical method used in BIOCEAN to integrate model equations over time is the improved Euler predictor-corrector scheme discussed by McCraken and Dorn (1964) and Beckett and Hurt (1967). Most models consist of a set of equations in several variables to be solved simultaneously, but as a simple example to illustrate the solution methodology, consider the equation for a single variable, $y$, where

$$
\frac{d y}{d x}=f(x, y)
$$

Given an initial condition $\left(x_{n}, y_{n}\right)$, Euler's method is used to start the procedure and obtain an initial approximation $y_{n+1}^{\circ}$ to the actual solution at $x_{n+1}$, where $x_{n+1}-x_{n}=h$ as follows:

$$
y_{n+1}^{0}=y_{n}+h f\left(x_{n}, y_{n}\right)
$$

Equation [A.2] is re-evaluated at $x_{n+1}$, using the initial approximation $y_{n+1}^{0}$ to estimate $f\left(x_{n+1}, y+h f(x, y)\right)$. Then with the improved Euler method the second approximation or corrected value $y_{n+1}^{c}$ is given by

$$
y_{n+1}^{c}=y_{n}+(h / 2)\left(f\left(x_{n}, y_{n}\right)+f\left(x_{n}+1, y_{n}+h f\left(x_{n}, y_{n}\right)\right)\right) \cdot[A .3]
$$

The iteration counter is advanced, $y_{n}$ becomes $y_{n-1}$ and $y_{n+1}$ becomes $y_{n}$. New values of $y_{n+1}$ at the new $x_{n+1}$ are approximated by

$$
y_{n+1}^{p}=y_{n-1}+2 h\left(x_{n}, y_{n}\right) \text {. }
$$

This predicted valuc is substituled inco equation [A.1] and $f\left(x_{n+l}\right.$, $y_{n+1}^{p}$ ) determined in order to obtain a corrected value $y_{n+1}^{c}$ in

$$
y_{n+1}^{c}=y_{n}(h / s)\left(f\left(x_{n}, y_{n}\right)+f\left(x_{n+1}, y_{n+1}^{p}\right)\right)
$$

This corrected value can be substituted into equation [A.1], the derivative evaluated, and a presumably better estimate of $y_{n+1}^{c}$ obtained by reiterating equation [A.5]. In a series of tests (to be discussed more fully below) designed to examine the stability characteristics of 
the predictor-corrector scheme, it was found that reiteration of the corrector equation produced less than a $0.2 \%$ difference in an integrated total over 10 days simulation time with a time step of 0.5 hours. Reiteration increases execution time by about $50 \%$, produces a negligible difference in output for the timestep size used in these simulations and was, therefore, judged unnecessary in the present study.

McCracken and Dorn (1964, p. 340) do show, however, that on the basis of an estimate of the truncation error maded possible by the choice of predictor and corrector expression one simple further correction can be made

$$
y_{n+1}^{c^{*}}=\left(4 y_{n+1}^{c}+y_{n+1}^{p}\right) / 5
$$

and this is included in the simulation calculations.

The predictor-corrector scheme is more difficult to program and requires more computer memory and time to execute than a simple predictor method, but it is significantly more accurate. As an example, consider the simple exponential gruwti at a rate, $g$, of $0.08 \mathrm{hr}^{-1}$ at a variable, $p$, whose initial value, $p_{0}$, is 1.0 beginning at time $t_{0}=0$. Then

$$
\frac{d P}{d t}=g P
$$

and

$$
P_{t}=P_{Q} \exp \left[g \cdot\left(t-t_{0}\right)\right]
$$

For such a simple example it is possible to calculate an exact oolution, $P_{t}=54.598$ after $t=50$ hours. With one hour time steps, a simple Euler method predicts 46.902 and the predictor-corrector method used in the model gives a value of 54.586 . The results of the simple 
Euler method are affected by the summation or propagation of successive errors of approximation over time, and the predicted solution tends, as in this example, to diverge further and further from the actual solution. The method used in the model corrects itself and so diminishes the tendency to diverge from the actual solution.

In another model of phytoplankton growth, Jamart, et a1. (1977) experimented with time step length using a different numerical procedure (Crank-Nicholson) and noticed unacceptable errors arising from inaccuracies associated with the photosynthetic production relationship at time steps greater than 0.1 hours over an integration period of 10 days time. Tests were run with the production relationship and integration scheme used in this model to determine whether or not special corrective measures would need to be taken for cases run with time steps of 0.5 hours.

For the tests, solar radiation values were generated as a truncated sine function of time, with $470 \mathrm{~g} \mathrm{cal} \mathrm{cm}^{-2} \mathrm{~d}^{-1}$ as the total incident radiation and a $15 \%$ reflection correction for photosynthetically active radiation applied as assumed by Jamart, et al. The production relationship tested is essentially the same as in the complete model, but $P_{\max }$ is treated as a constant for these single variable test calculations. After 10 days simulation time the chlorophyll in a simulated 50 meter depth region in the 0.1 and 0.5 hour time step tests differed hy $n+y$ y $1.6 \%$ and no corrcctive measures were judged necessary. I.B. The Finite Difference Scheme

The grid in Figure 43 illustrates the scheme used to identify state variable values, current velocities and diffusion coefficients 


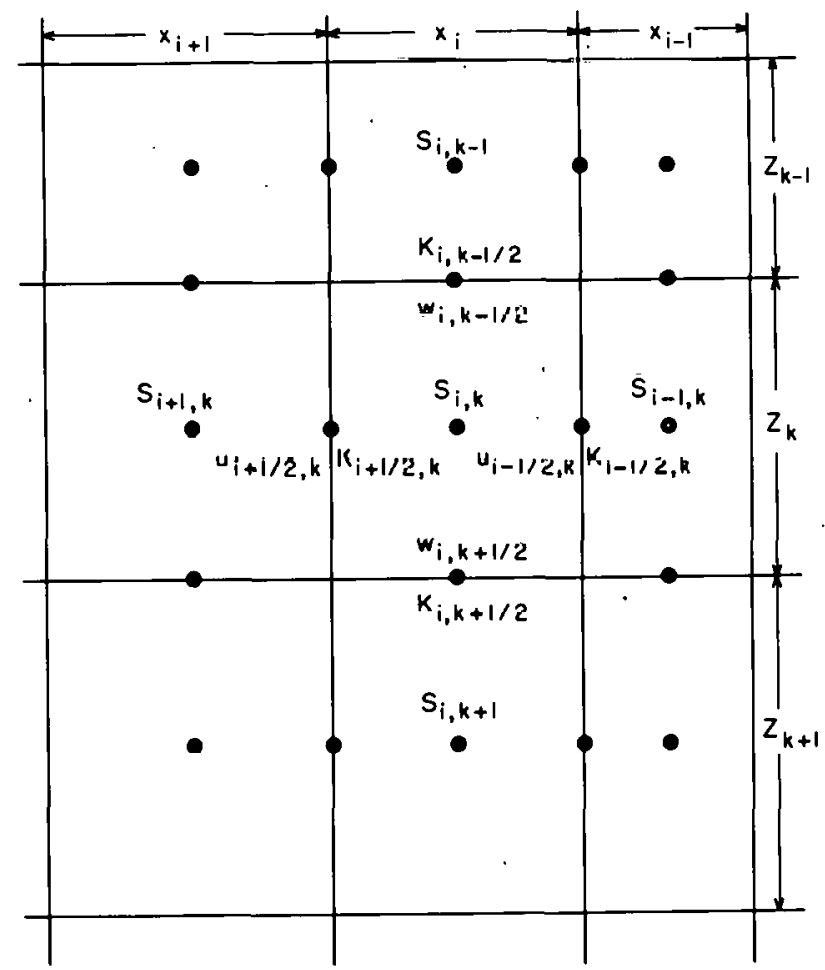

Figuie 43. A schematic diagram showing the convention uocd in the modnl to define the relative and absnlute locations of state variables (S), eddy coefficients (K) and horizontal (u) and vertical (w) current velocities. A segment whose center is at $i, k$ has a dimension $x_{i}$ on the horizontal $i$ axis and a dimension $z_{k}$ on the vertical $k$ axis. Current velocities and eddy cocfficients are defined on the faces between the centers of the rectalinear spatial segments. 
used in the BIOCEAN model of northwest African upwelling. The following finite difference functions for dispersive transport in the vertical and horizontal directions are based on the derivation of Thomann (1972).

$$
\begin{aligned}
& \frac{\partial k_{x} \frac{\partial s}{\partial x}}{\partial x} \simeq\left[\left(k_{i-\frac{1}{2}, k} / x_{i}\right)\left(s_{i-1, k}-s_{i, k}\right) /\left(\left(x_{i}+x_{i-1}\right) / 2\right)\right]+ \\
& {\left[\left(k_{i+\frac{1}{2}, k} / x_{i}\right)\left(s_{i+1, k-s_{i, k}}\right) /\left(\left(x_{i}+x_{i+1}\right) / 2\right)\right]}
\end{aligned}
$$

and in the vertical, or $z$ direction, the function is

$$
\begin{aligned}
& \frac{\partial \mathrm{K}_{z} \frac{\partial s}{\partial z}}{\partial z} \simeq\left[\left(\mathrm{K}_{\mathrm{i}, \mathrm{k}-\frac{1}{2}} / \mathrm{z}_{\mathrm{k}}\right)\left(\mathrm{s}_{\mathrm{i}, \mathrm{k}+1}-\mathrm{s}_{\mathrm{i}, \mathrm{k}}\right) /\left(\left(\mathrm{z}_{\mathrm{k}}+\mathrm{z}_{\mathrm{k}-1}\right) / 2\right)\right]+ \\
& {\left[\left(k_{i, k+\frac{1}{2}} / z_{k}\right)\left(s_{i, k+1}-s_{i, k}\right) /\left(\left(z_{k}+z_{k+1}\right) / 2\right)\right]}
\end{aligned}
$$

The finite difference functions for advection are discussed by Harbaugh and Bonham-Carter (1970) and recommended by Piacsek and Williams (1970). In the horizontal, or $x$ dimension, the approximation is given as

$$
\begin{aligned}
-\frac{\partial(u S)}{\partial x} & =-\frac{\Delta(u S)}{\Delta x} \\
\Delta x \quad & =x_{i} \\
-\Delta(u S) \quad & =(u S)_{i-\frac{1}{2}, k}-(u S)_{i+\frac{1}{2}, k} \\
(u S)_{i-\frac{1}{2}, k} & =u_{i-\frac{1}{2}, k} s_{i, k}, \text { if } u_{i-\frac{1}{2}, k} \leq 0 \\
& =u_{i-\frac{1}{2}, k} s_{i-1, k} \text { if } u_{i-\frac{1}{2}, k>0}
\end{aligned}
$$




$$
\begin{aligned}
(u S)_{i+\frac{1}{2}, k} & =u_{i+\frac{1}{2}, k} S_{i+1, k} \text {, if } u_{i+\frac{1}{2}, k} \leq 0 \\
& =u_{i+\frac{1}{2}, k} S_{i, k} \text {, if } u_{i}=\frac{1}{2}, k>0
\end{aligned}
$$

A functionally similar approximation is used for advection in the vertical direction,

The problem with these and other finite difference methods for advection is the existence of an error arising from the division of the simulated space into finite spatial segments. The nature of the error can be visualized by considering the advection in nne dimension of a concentration peak through a series of initially empty segments. During the first iteration some material is advected from a starting segment into a second adjacent spatial segment. On the assumption that the contents of each spatial segment are completely mixed, some material in the second spatial segment will be advected to the third spatial segment at the next iteration even though the advection velocity may be too slow for a particle to have actually traversed the second segment. This effect results in a spreading of concentration through space in excess of the true advective flux, and has been described as numerical mixing (Orlob, et al. 1967), pseudo-dispersion (Bella and Grenney 1970) or implicit diffusion (Walsh 1975a). The magnitude of the error, expressed as a mixing coefficient, Kpseudo, has been quantified (Bella and Grenney 1970), in the $\mathrm{x}$ dimension for example, as

$$
\mathrm{K}_{\mathrm{pseudo}}=(\mathrm{u} / 2)(\Delta \mathrm{x}-\mathrm{u} \Delta \mathrm{t})
$$


where

$u$ is current velocity $\left(\mathrm{cm}^{\cdot} \mathrm{sec}^{-1}\right)$;

$\Delta x \quad$ is spatial segment length $(\mathrm{cm})$;

$\Delta t$ is iteration time (sec).

For the velocities and spatial segmentation scheme used in mesoscale models of marine systems, the magnitude of the pseudo-mixing coefficient may be of the same order as the specified mixing coefficients, $K_{i, k}$ - Walsh (1975), for example, did not explicitly include expressions for turbulent diffusion in the plane of his model. He assumed that the pseudo-mixing process implicitly associated with the finite difference function for advection adequately expressed turbulent diffusion effects. The problem with this assumption is that the size of the mixing coefficient is directly dependent on the magnitude and direction of advective flow, i.e., in the absence of flow in a given direction, there is no mixing in that direction. Accordingly, there is no vertical mixing, either specified or pseudo, in Walsh's (1975) model at distances greater than $30 \mathrm{~km}$ off shore.

A solution to the pseudo-mixing problem, suggested by Bella and Grenney (1970) and used by Harper (1972), is to estimate the pseudodispersion coefficient and subtract it from the specified coefficient. This solution was used in the northwest African upwelling model. The coefficients, $k_{i, k}$, used in the finite difference expressions are calculated as

$$
\begin{aligned}
& \mathrm{K}_{\mathrm{i}, \mathrm{k}}=\mathrm{K}_{\text {specified }}-\mathrm{K}_{\mathrm{pseudo}} \text {, if } \mathrm{K}_{\text {specified }}>\mathrm{K}_{\mathrm{pseudo}} \\
& =0 \text {, otherwise }
\end{aligned}
$$


where

$$
\begin{aligned}
& \mathrm{K}_{\text {specified }} \text { is the specified diffusion coefficient; } \\
& \mathrm{K}_{\text {pseudo }} \quad \text { is the pseudo-diffusion coefficient. } \\
& \text { Necessary conditions for stability are } \\
& u_{i, k}(\Delta t / \Delta x)<1 \\
& w_{i, k}(\Delta t / \Delta z)<1 \\
& k_{i, k+\frac{1}{2}}\left(\Delta t / \Delta z^{2}\right)<\frac{1}{2} \\
& k_{i+\frac{1}{2}, k}\left(\Delta t / \Delta x^{2}\right)<\frac{1}{2}
\end{aligned}
$$

For $\Delta t=1.8 \times 10^{3} \sec \left(\frac{1}{2}\right.$ hour), $\Delta x=5 \times 10^{5}$ cui, and $\Delta \%=5 \times 10^{2} \mathrm{~cm}$, these conditions are met when $u .278 \mathrm{~cm} \mathrm{sec}^{-1}, w<0.28 \mathrm{~cm} \mathrm{sec}^{-1}$, $\mathrm{K}_{\mathrm{i}, \mathrm{k}+\frac{1}{2}}<69 \mathrm{~cm}^{2} \mathrm{sec}^{-1}, \mathrm{~K}_{\mathrm{i}+\frac{1}{2}, \mathrm{k}}<6.9 \times 10^{6} \mathrm{~cm}^{2} \mathrm{sec}^{-1}$. These stability requirements have been developed from an analysis of the behavior of solutions to equations describing advection only or diffusion only. Although the processes of advection and diffusion ocur simultaneously in a real marine environment, Bella and Dobbins (1968) state that suming the finite-difference effects of diffusion and advection introduces serious errors. They suggest a miltistep procedure, adopted in this model, to eliminate the errors. During the first step, the change in concentration due to advection alone is determined and a new concentration distribution calculated. Next, the changes due to diffusion are evaluated, and the resulting distribution of concentrations is used when the effects of biological interactions are evaluated and a final new distribution colculated. 


\section{APPENDIX II}

\section{Boundary and Initial Conditions}

Boundary conditions for nitrate, ammonium, silicate and chlorophyll are specified at the offshore and lower boundaries only. Alongshore gradients are considered negligible and no flux is permitted through the east or upper boundary. Specified boundary conditions are constant through time and are averages based on data taken throughout the JOINT-I cruise period. Data taken between $18^{\circ} 30^{\prime} \mathrm{W}$ and $18^{\circ} 48^{\prime} \mathrm{W}$ define the offshore boundary conditions $105 \mathrm{~km}$ from the coast and data taken between 100 and $150 \mathrm{~m}$ depth define the lower boundary conditions listed in Table 5. Offshore boundary conditions are used as initial conditions throughout the simulated space.

Values of phytoplankton variables other than chlorophyll are based on the chlorophyll measurements and assumptions concerning the cell size (T. Smayda, pers. comm.) and state of the phytoplankton population. An estimated maximum carbon quota of $7.3 \mathrm{pg}$ at $\mathrm{c} \cdot \mathrm{cell}^{-1}$ is based on the assumptions that phytoplankton are individually $10 \mu \mathrm{m}$ spheres and that the maximum carbon quota is twice the estimate of cell carbon suggerted by 3 Lathman (1967). Other phytoplankton quotas are specified to be values halfway between maximum $\left(c_{i}\right)$ and minimum $\left(d_{i}\right)$ limits. The initial and boundary chlorophyll values divided by the chlorophyl1 quota gives cell numbers, $N$, in units of $10^{6}$ cells $\cdot 1^{-1}$. The product of $\mathrm{N}$ and the quotas of carbon, silica, and nitrogen define the values for the phytoplankton variable values listed in Table 6 . 
Table 4. Initial values for a short term simulation of the mean JOINT-I conditions.

\begin{tabular}{|c|c|c|c|c|}
\hline & & Depth & Range & \\
\hline & $0-30 \mathrm{~m}$ & & & $30-100 \mathrm{~m}$ \\
\hline Nitrate $\left(\mu g\right.$ at $\left.\cdot 1^{-1}\right)$ & 3.43 & & & 7.06 \\
\hline Ammonium $\left(\mu g\right.$ at $\left.\cdot 1^{-1}\right)$ & 0.54 & & & 0.34 \\
\hline Silicate $\left(\mu \mathrm{g}\right.$ at $\left.\cdot 1^{-1}\right)$ & 2.27 & & & 3.02 \\
\hline Chlorophyl1 $\left(\mu g \cdot 1^{-1}\right)$ & 3.74 & & & 1.98 \\
\hline Silica $\left(\mu \mathrm{g}\right.$ at $\left.\cdot 1^{-1}\right)$ & 0.46 & & 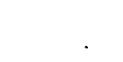 & 0.24 \\
\hline Nillogen $\left(\mu g\right.$ at $\left.\cdot 1^{-1}\right)$ & 1.35 & & & 0.72 \\
\hline Carbon $\left(\mu B\right.$ at $\left.-1^{-1}\right)$ & 13.06 & & & $6 . \dot{9} 1$ \\
\hline Cell Numberc $\left(11^{6}\right.$ r.e.1ls $\left.\cdot 1^{-1}\right)$ & 2.88 & & & 1.32 \\
\hline
\end{tabular}

Table 5. Offshore and lower boundary conditions of nutrients and chlorophyll a based on JOINT-I observations.

\begin{tabular}{|c|c|c|c|c|c|}
\hline \multicolumn{2}{|c|}{$\begin{array}{c}\text { Nitrate } \\
\left(\mu g \text { at } \cdot 1^{-1}\right)\end{array}$} & \multicolumn{2}{|c|}{$\begin{array}{l}\text { Atmnonium } \\
\left(\text { ig at } \cdot 1^{-1}\right)\end{array}$} & \multirow{2}{*}{$\begin{array}{c}\text { Silicate } \\
\left(\mathrm{ig} \mathrm{at} \cdot 1^{-1}\right) \\
0.93\end{array}$} & \multirow{2}{*}{$\begin{array}{l}\left(\begin{array}{c}c h 1 \cdot a^{a} \\
\left(\mu g \cdot 1^{-1}\right)\end{array}\right. \\
1.45\end{array}$} \\
\hline Offshore $(0-30 \mathrm{~m})$ & 1.48 & 2 & 0.24 & & \\
\hline Offohore $(30-1.00 \mathrm{~m})$ & 2.84 & & 0.35 & 1.37 & 0.95 \\
\hline $\begin{array}{l}\text { Lower Boundary } \\
\text { ( } 35-55 \mathrm{~km} \text { of } f \text { shore) }\end{array}$ & 13.59 & & 0.13 & 4.88 & 0.42 \\
\hline $\begin{array}{l}\text { Luwer Rnundary } \\
(55-105 \mathrm{~km} \text { off shore) }\end{array}$ & 9.85 & & $U .24$ & 3,6 & 0.39 \\
\hline
\end{tabular}

Table 6 . Estimates of uffshore and lower boundary pliytoplanklu!! variable concentrations aud cell numbers

\begin{tabular}{|c|c|c|c|c|}
\hline & $\begin{array}{l}\text { Silica } \\
\left(\psi g \text { at } \cdot 1^{-1}\right)\end{array}$ & $\begin{array}{l}\text { Nitrogen } \\
\left(\mu \mathrm{g} \text { at } \mathrm{l}^{-1}\right)\end{array}$ & (ug at. $\left.1^{-1}\right)$ & $\begin{array}{l}\text { Cell Numbers } \\
\left(\times 10^{6} 1^{-1}\right)\end{array}$ \\
\hline Offshore $(0-30 \mathrm{~m})$ & 0.18 & 0.52 & 3.06 & 1.12 \\
\hline offshore $(30-100 \mathrm{~m})$ & 0.12 & 0.34 & 3.32 & 0.73 \\
\hline $\begin{array}{l}\text { Lower Boundary } \\
\text { ( } 35-55 \mathrm{~km} \text { of f shore) }\end{array}$ & 0.05 & 0.15 & 1.47 & 0.32 \\
\hline $\begin{array}{l}\text { Lower Boundary } \\
(55-105 \mathrm{~km} \text { of } f \text { shore })\end{array}$ & 0.05 & 0.14 & 1.36 & 0.30 \\
\hline
\end{tabular}




\section{APPENDIX III \\ Computer Methods for Results Post-Processing}

The computational results of simulation models are often difficult to interpret without some form of processing. In the models discussed in this study, some diagnostic information was listed during execution. In addition to printed maps of variable concentration, items output during execution for each spatial segment (where appropriate) included printed maps of the factor most limiting to phytoplankton growth, the fraction of phytoplankton standing stock consumed per hour, the phytoplankton growth rate, an estimate of zooplankton body-carbon ingestion rate per day, and the process causing the largest absolute changes in nitrate and chlorophyll. Also, in each spatial segment, net photosynthetic carbon production and total herbivore carbon ingestion were integrated over 24 hour periods ending at midnight.

Once generated, simulation results were post-processed in an interactive data base management system developed for this study. Data were selected from the output file to be vertically integrated or prepared as an input file for a general statistics program package. Grid poinls in the ecosystem model are unevenly distributed in space and before statistical calculations were begun, data associated with each point were arithmetically weighted according to the area of the spatial segment from which the data originated.

Model output was also graphically pnst-proceoocd to sliow the changing simulated distributions of variables. A file management system was developed to process the results generated on a CDC 7600 and 
interactively create contour maps on a Tektronix 4014 cathode ray display terminal with a CDC 6600 using DISSPLA, a general plotting package'(Integrated Software"Systems Corp.) and a Brookhaven National Laboratory Central Scientific Computing Facility contouring program, CMRBR, modified to contour unevenly spaced data. Copies of the graphics were recreated on microfilm with an FR-80 (Information International, Inc.) and processed photographically to produce the final illustrations. 


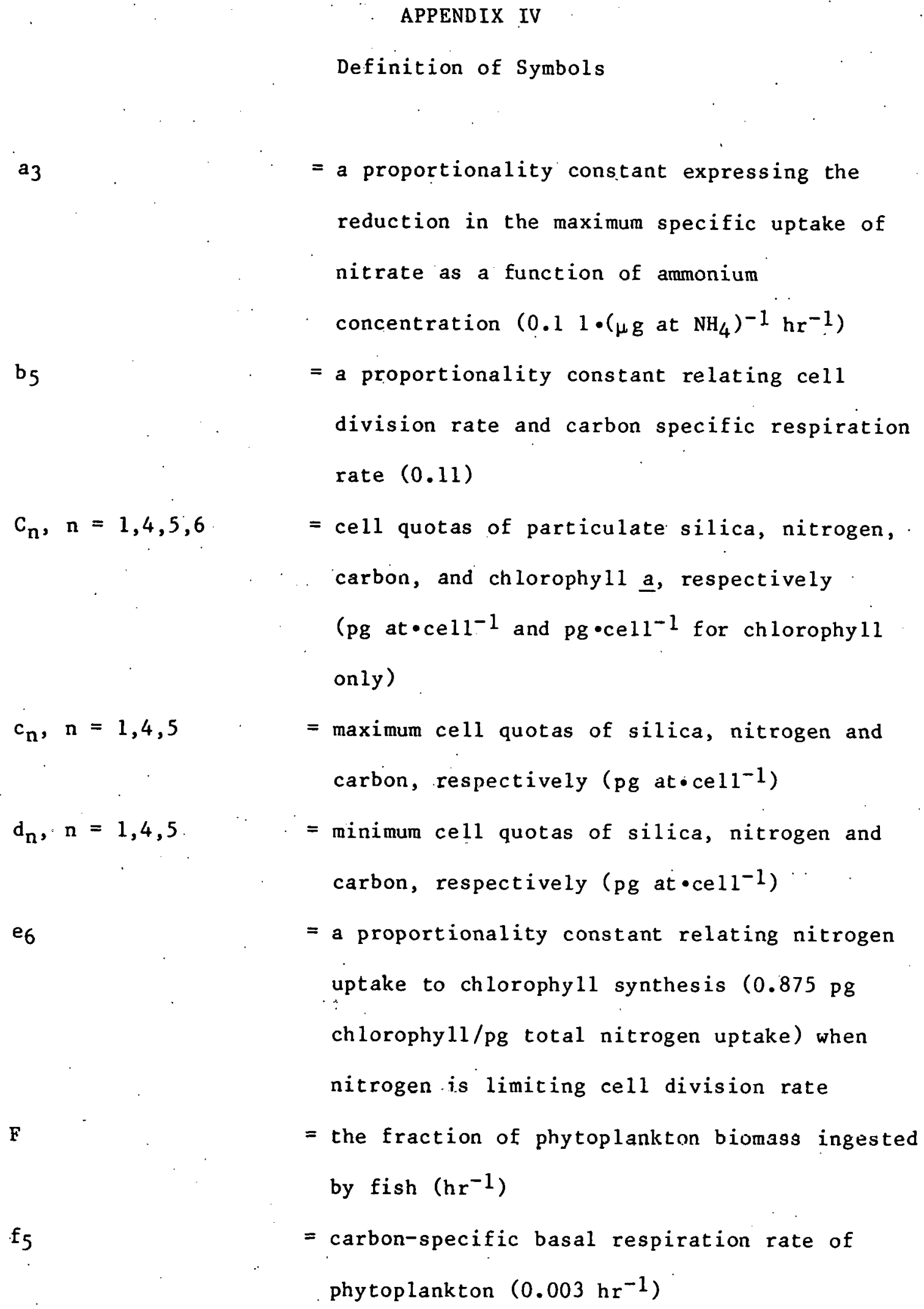


G

g

$I_{0}$

$I_{\max }$

$T_{\boldsymbol{z}}$

j5

$\mathrm{k}_{\mathrm{n}}, \mathrm{n}=1,2,3$

$\mathrm{K}_{\mathrm{c}}$

$\mathrm{K}_{\mathrm{d}} \mathrm{X}$
$=$ cell division rate $\left(\mathrm{hr}^{-1}\right)$

$=$ maximum cell division rate $\left(0.08 \mathrm{hr}^{-1}\right)$

$=$ light intensity at the upper boundary of a segment of thickness $z$ meters (eistein $\cdot m^{-2}$ $\mathrm{hr}^{-1}$ )

= optimal light intensity for photosynthesis. Photosynthes is rate is maximum when light intencity is equal, to $\mathrm{I}_{\max }\left(2.07\right.$ einstein $\mathrm{m}^{-2}$ $h r^{-1}$ )

$=$ light intensity at the lower boundary of a segment of $z$ meters thickness (einstein $\cdot \mathrm{m}^{-2}$ $\mathrm{h}^{-1} \mathrm{r}^{-1}$

= small zooplankton carbon concentration $\left(\mu g\right.$ at $\left.C \cdot 1^{-1}\right)$

= half-saturation constants for uptake of silicate, nitrate and ammonia, respectively $\left(1.0 \mu \mathrm{g}\right.$ at $\left.1^{-1}\right)$

= average spectral extinction coefficient $\left(\mathrm{m}^{2}\left(\mathrm{mg} \cdot \mathrm{Chl} \underline{a}^{-1}\right)\right.$ per unit of phytoplankton concentration, where phytoplankton conceutration is expressed as concentration ( $\mathrm{mg} \cdot \mathrm{m}^{-3}$ ) of chlorophyl1 a $\left(0.016 \mathrm{~m}^{2} \cdot\left(\mathrm{mg} \mathrm{Chl} \underline{a}^{-1}\right)\right.$ = average spectral cxtiustion $\left(\mathrm{m}^{-1}\right)$ for dissolved and suspended substances other than chlorophy 11 


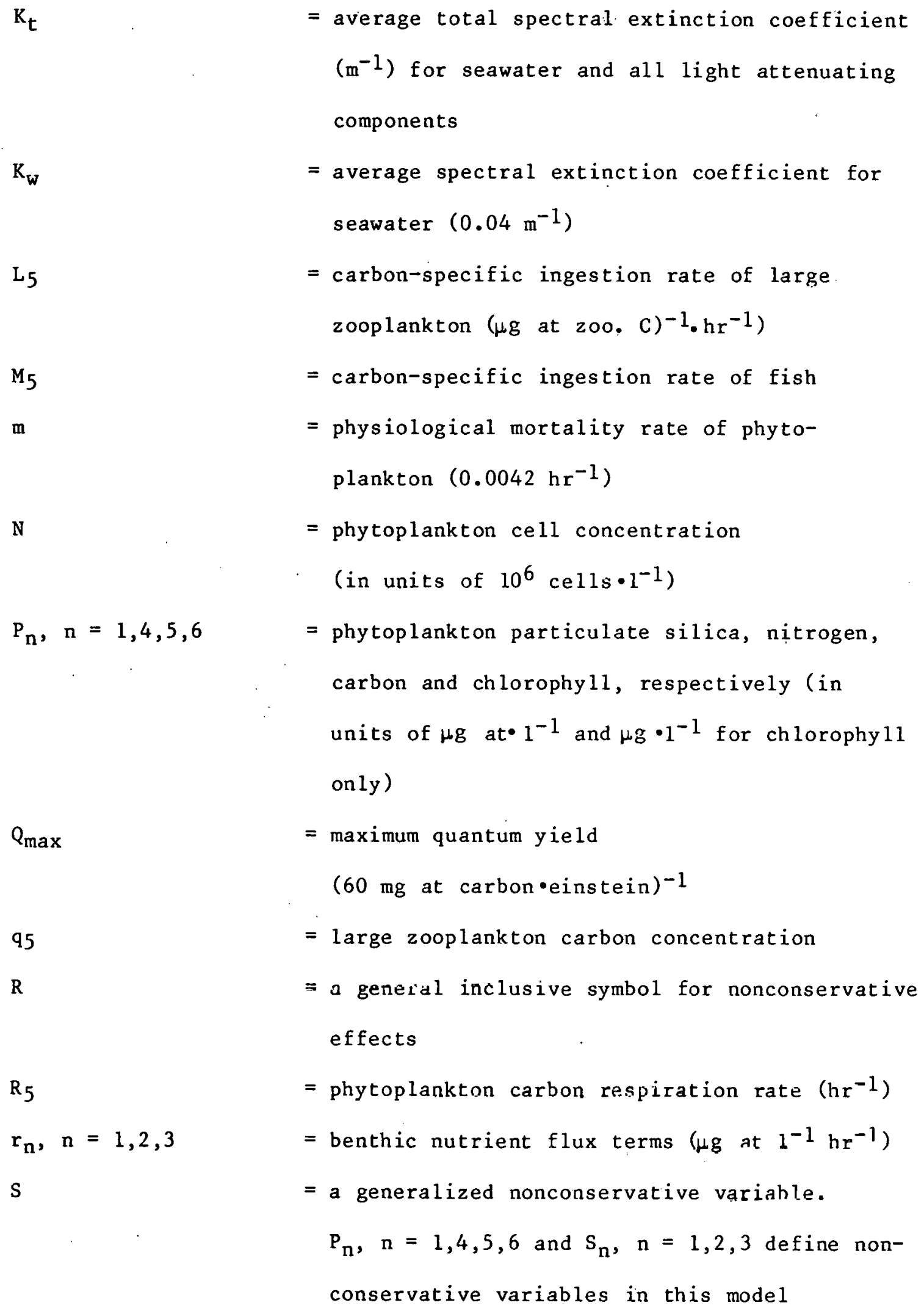

$=$ benthic nutrient flux terms ( $\mu \mathrm{g}$ at $\mathrm{l}^{-1} \mathrm{hr}^{-1}$ )

= a generalized nonconservative variable. $P_{n}, n=1,4,5,6$ and $S_{n}, n=1,2,3$ define nonconservative variables in this model 


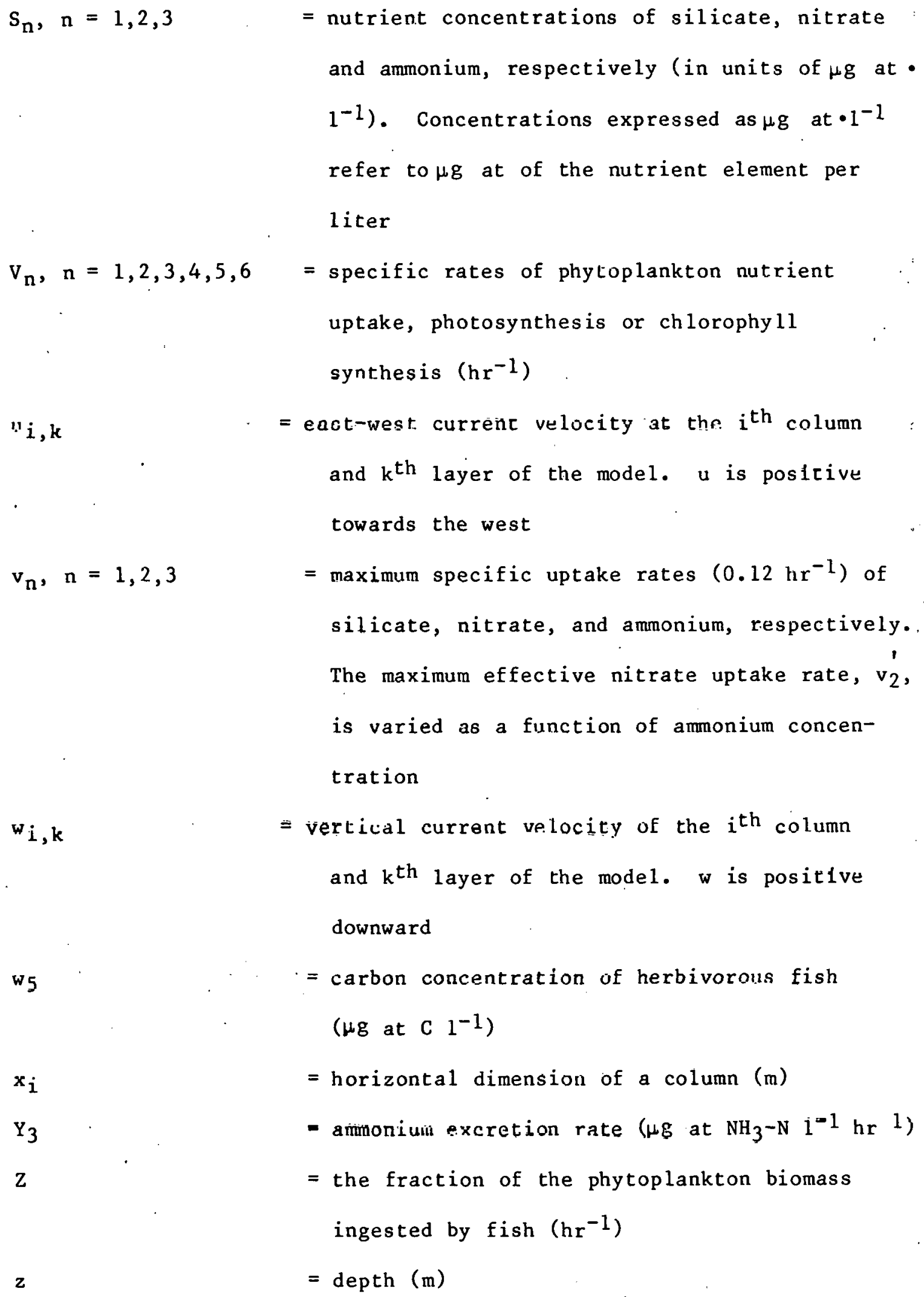

- ammoniun excretion rate ( $\mu \mathrm{g}$ at $\mathrm{NH}_{3}-\mathrm{N} \mathrm{i}^{-1} \mathrm{hr} l$ )

$=$ the fraction of the phytoplankton biomass ingested by fish $\left(\mathrm{hr}^{-1}\right)$

$=\operatorname{depth}(\mathrm{m})$ 
$\alpha_{n}, n=1,2,3$

$B_{3}$

$\gamma_{3}$

$\varepsilon$

$\theta$

$\lambda$

$\tau$

$\psi$

$\Omega$
$=$ the change in nutrient concentration caused by the addition of nutrients to an experimental container. In general, $\alpha_{n}=0$, except at the time when nutrients are added. When $\alpha_{\mathfrak{n}} \neq 0$, the starter sequence of the numerical method (Appendix I.A) is used to continue the simulation

= zooplankton ammonium excretion efficiency $(0.29 \mu \mathrm{g}$ at ammonium excreted $\cdot(\mu \mathrm{g}$ at phytonitrogen ingested) ${ }^{-1}$ )

$=$ fish ammonium excretion efficiency $(0.46 \mu \mathrm{g}$ at ammonium excreted $(\mu \mathrm{g}$ at phytonitrogen ingested) ${ }^{-1}$ )

$=$ zooplankton grazing constant

$=$ fish filtering constant

= small zooplankton size-specific weighting factor (3.22)

= fish grazing constant

$=$ zooplankton filtering constant

$=$ constant vertical scaling factor 


\section{APPENDIX V \\ Equations of the Physical Circulation Submodel}

The equations of continuity, advection and diffusion of density and conservation of momentum, using the Boussinesq approximation and assuming that all longshore gradients may be neglected, are (Hamilton and Rattray 1978), respectively

$\frac{\partial \zeta}{\partial t}+\frac{\partial}{\partial x} \int_{-\zeta}^{h} u d z=0$

$\frac{\partial u}{\partial x}+\frac{\partial w}{\partial z}=0$

$w=\frac{\partial}{\partial x} \int_{z}^{h} u d z$

$\frac{\partial \rho}{\partial t}+u \frac{\partial \rho}{\partial x}+w \frac{\partial \rho}{\partial z}-\frac{\partial}{\partial x}\left(K_{x} \frac{\partial \rho}{\partial x}\right)-\frac{\partial}{\partial z}\left(K_{z} \frac{\partial \rho}{\partial z}\right)=0$

$\frac{\partial u}{\partial t}+u \frac{\partial u}{\partial x}+w \frac{\partial u}{\partial z}-t v=-\frac{q}{\rho_{0}} \frac{\overline{\partial \rho}^{z}}{\partial x}-g \frac{\partial \zeta}{\partial x}+\frac{\partial}{\partial z}\left(N \frac{\partial u}{z z}\right)$

$\frac{\partial v}{\partial t}+u \frac{\partial v}{\partial x}+w \frac{\partial v}{\partial z}+f u=-g \frac{\partial \tau}{\partial y}+\frac{\partial}{\partial z}\left(N_{z} \frac{\partial v}{\partial z}\right)$ 
The symbols in the above equations are defined as follows

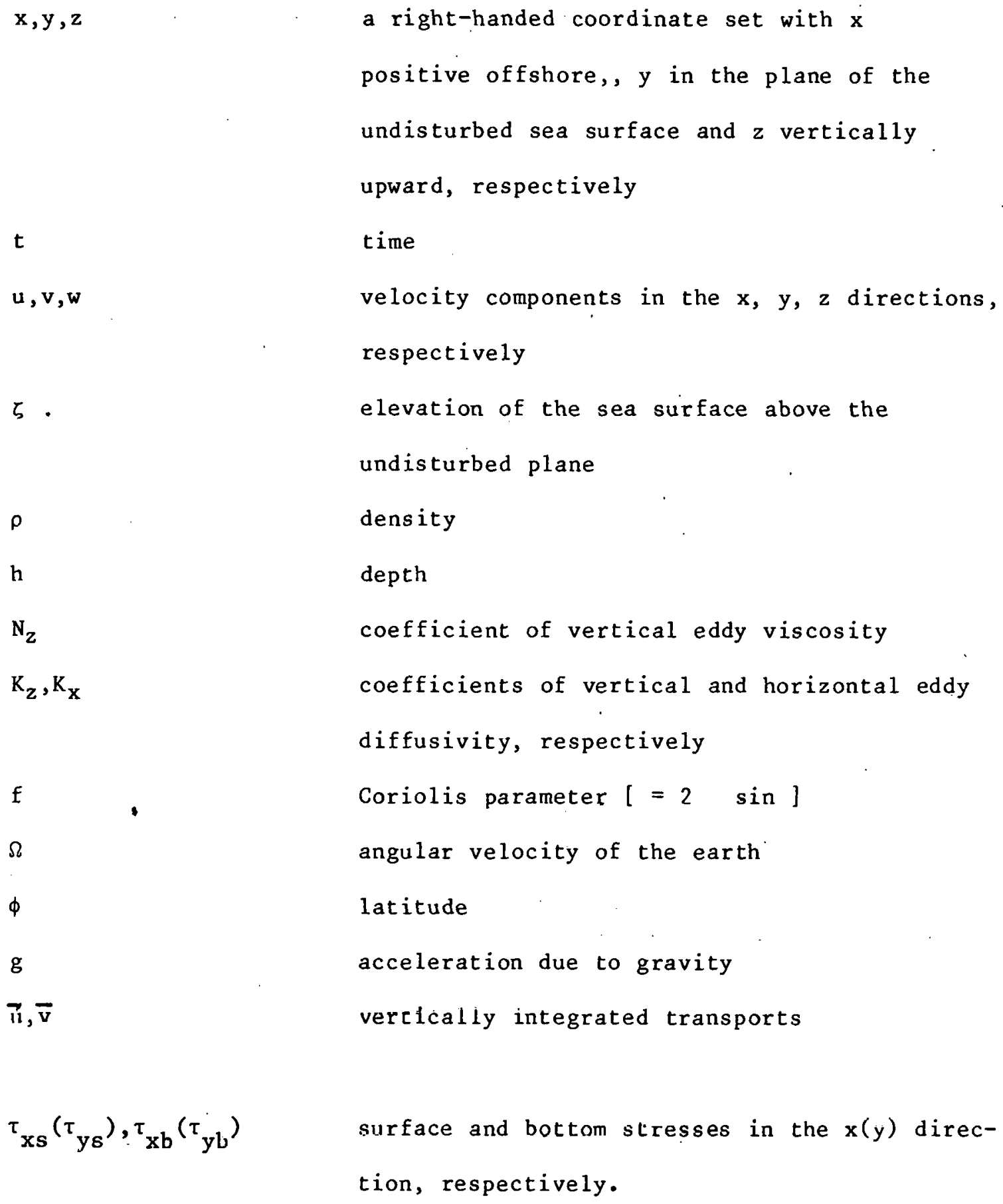

